\section{OM1}

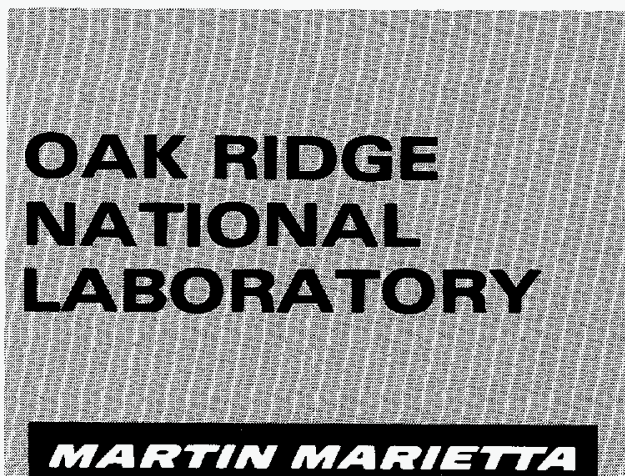

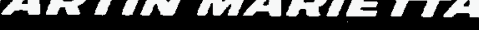

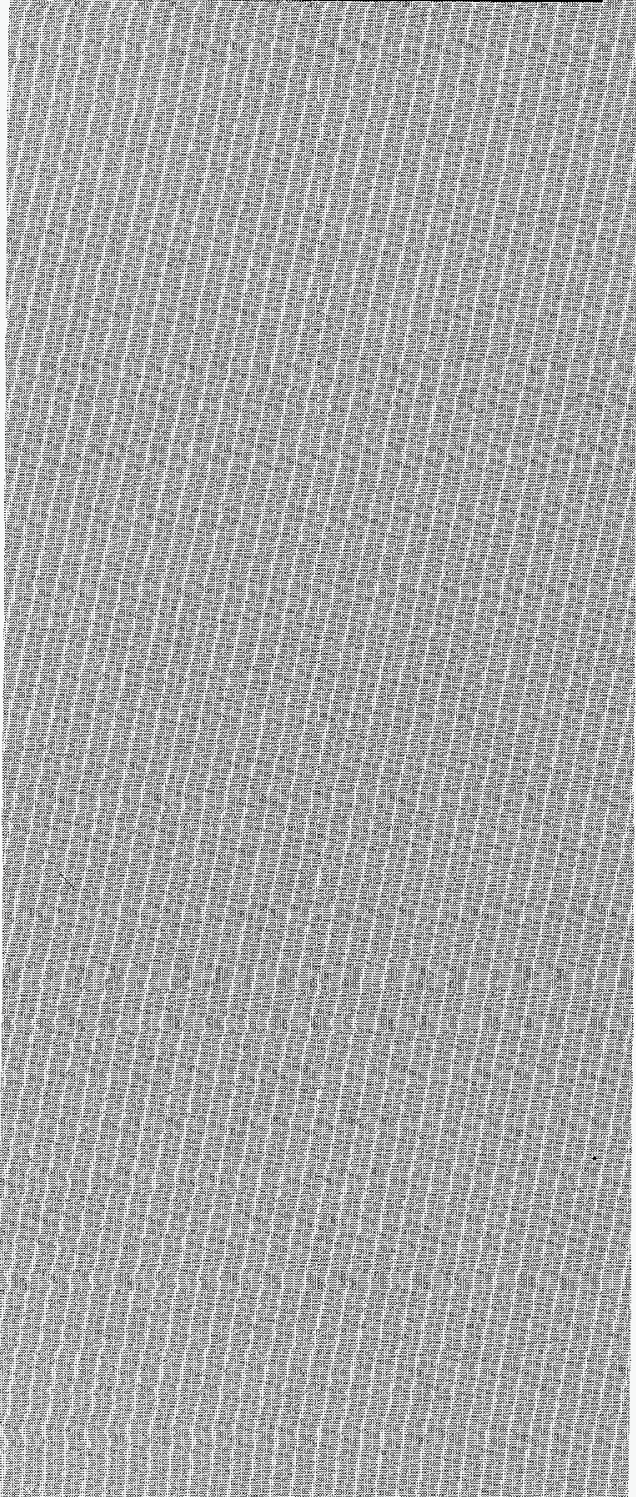

\section{MANAGED BY}

MARTIN MARIETTA ENERGY SYSTEMS, INC.

FOR THE UNITED STATES

OEPARTMENT OF ENERGY

\author{
RECEIVED \\ MAR 041996
OSTI \\ Advanced Neutron Source \\ Probabilistic Flow Blockage \\ Assessment \\ C. T. Ramsey
}

August 1995

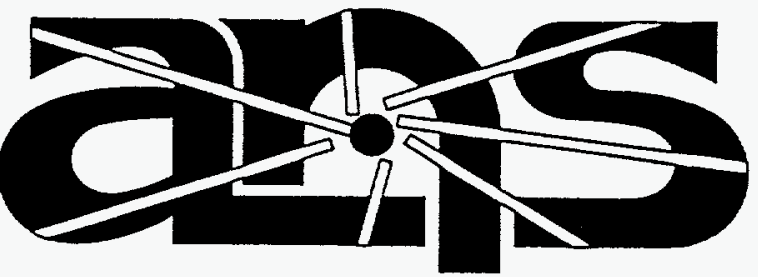

Advanced Nautron Source 
This report has been reproduced directly from the best available copy.

Available to DOE and DOE contractors from the Office of Scientific and Technical Information, P.O. Box 62, Oak Ridge. TN 37831; prices available from (615) 576-8401, FTS 626-8401.

Available to the public from the National Technical Information Service, U.S. Department of Commerce, 5285 Port Royal Rd., Springfield, VA 22161.

This report was prepared as an account of work sponsored by an agency of the United States Government. Neither the United States Government nor any agency thereof, nor any of their employees, makes any warranty, express or implied, or assumes any legal llability or responsibility for the accuracy, completeness, or usefulness of any information, apparatus, product, or process disclosed, or represents that its use would not infringe privately owned rights. Reference herein to any specific commerclal product, process, or service by trade name, trademark, manufacturer, or otherwise, does not necessarily constitute or imply its endorsement, recommendation, or favoring by the United States Government or any agency thereof. The views and opinions of authors expressed herein do not necessarily state or reflect those of the United States Government or any agency therect. 


\title{
ADVANCED NEUTRON SOURCE REACTOR PROBABILISTIC FLOW BLOCKAGE ASSESSMENT
}

\author{
C. T. Ramsey
}

Date published: August 1995

\author{
Prepared by \\ OAK RIDGE NATIONAL LABORATORY \\ Oak Ridge, Tennessee 37831-8218 \\ managed by \\ LOCKHEED MARTIN ENERGY SYSTEMS, INC. \\ for the \\ U.S. DEPARTMENT OF ENERGY \\ under contract DE-AC05-84OR21400
}


• 


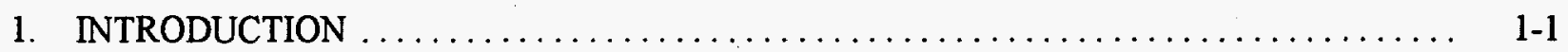

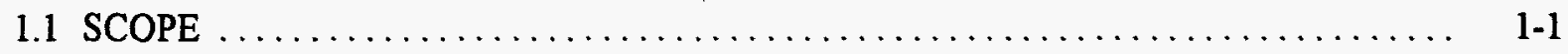

1.2 METHODOLOGY $\ldots \ldots \ldots \ldots \ldots \ldots \ldots \ldots \ldots \ldots \ldots \ldots \ldots \ldots \ldots \ldots \ldots \ldots \ldots, 1-2$

1.3 COMPUTER SOFTWARE $\ldots \ldots \ldots \ldots \ldots \ldots \ldots \ldots \ldots \ldots \ldots \ldots \ldots \ldots \ldots \ldots \ldots \ldots, 1-3$

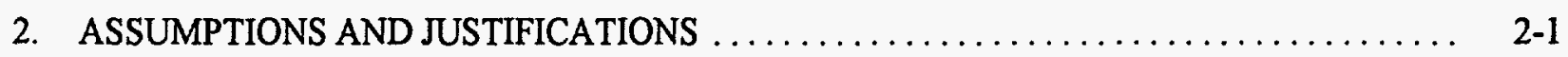

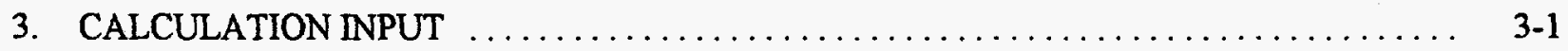

3.1 THERMAL-HYDRAULIC FLOW BLOCKAGE ANALYSIS $\ldots \ldots \ldots \ldots \ldots \ldots \ldots$ 3-1

3.2 FLOW BLOCKAGE DATABASE AND ELICITATION OF
EXPERT JUDGMENT

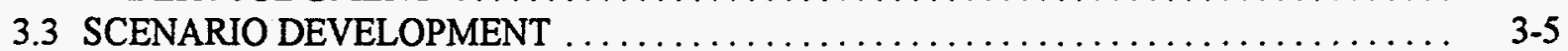

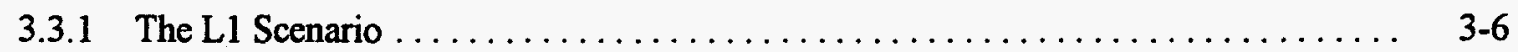

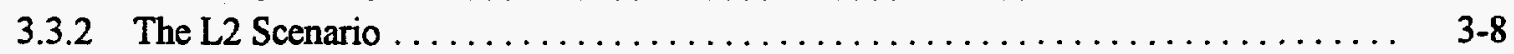

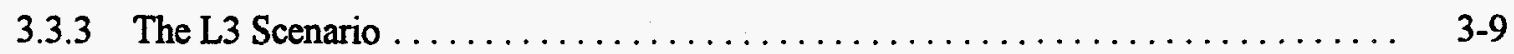

3.4 SYSTEM DESIGN FEATURES TO PREVENT DEBRIS-INDUCED

FLOW BLOCKAGE $\ldots \ldots \ldots \ldots \ldots \ldots \ldots \ldots \ldots \ldots \ldots \ldots \ldots \ldots \ldots \ldots \ldots \ldots, 3-11$

3.4.1 Pressure and Inventory Control System $\ldots \ldots \ldots \ldots \ldots \ldots \ldots \ldots \ldots \ldots \ldots, 3-11$

3.4.2 Reflector Vessel Cooling System $\ldots \ldots \ldots \ldots \ldots \ldots \ldots \ldots \ldots \ldots \ldots \ldots \ldots \ldots \ldots \ldots, \quad 3-11$

3.4.3 Primary Cooling System $\ldots \ldots \ldots \ldots \ldots \ldots \ldots \ldots \ldots \ldots \ldots \ldots \ldots \ldots \ldots \ldots \ldots, \quad 3-12$

4. EVENT TREE QUANTIFICATION RESULTS AND ANALYSIS $\ldots \ldots \ldots \ldots \ldots \ldots \ldots .4 .1$

4.1 CALCULATION OF THE LI SEQUENCES $\ldots \ldots \ldots \ldots \ldots \ldots \ldots \ldots \ldots \ldots \ldots, 4,1$

4.2 CALCULATION OF THE L2 SEQUENCES $\ldots \ldots \ldots \ldots \ldots \ldots \ldots \ldots \ldots \ldots, 4,2$

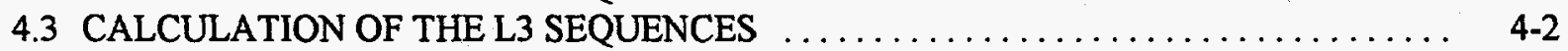

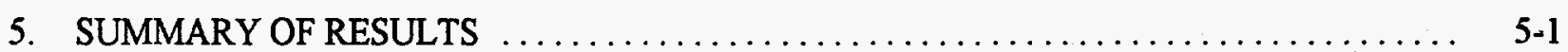

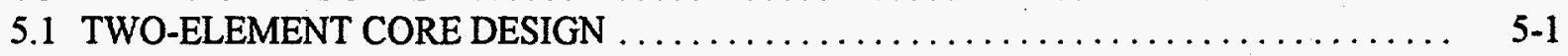

5.2 THREE-ELEMENT CORE DESIGN $\ldots \ldots \ldots \ldots \ldots \ldots \ldots \ldots \ldots \ldots \ldots \ldots \ldots \ldots \ldots \ldots \ldots \ldots, 5,2$

6. CONCLUSIONS ............................................... 6-1

6.1 POST SCRIPT_EVOLVING CHANGES AT ANALYSIS COMPLETION $\ldots \ldots \ldots \ldots$ 6-1

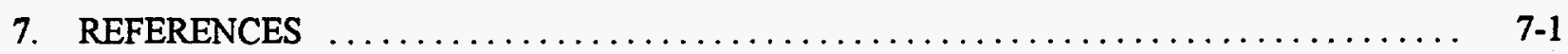

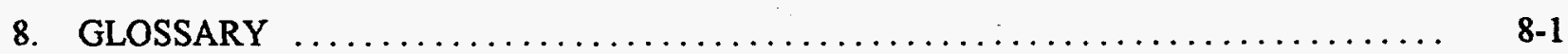

Appendix A. FLOW BLOCKAGE DATA BASE $\ldots \ldots \ldots \ldots \ldots \ldots \ldots \ldots \ldots \ldots \ldots \ldots \ldots \ldots \ldots$

Appendix B. QUANTIFICATION USING RISKMAN AND UNCERTAINTY

TREATMENT EVALUATION $\ldots \ldots \ldots \ldots \ldots \ldots \ldots \ldots \ldots \ldots \ldots \ldots, \quad$ B- 1 
Appendix C. BOOLEAN OPERATOR PROBABILITY CALCULATION AND RISKMAN SOFRWARE

C-1

Appendix D. LETTER TO DOMAIN EXPERTS, JUNE 8, 1994

D-1

Appendix E. DOMAIN EXPERT QUERY RESPONSES

E-1

Appendix F. EXCEL SPREADSHEET MODEL CONTAINING EXPERT

INPUT, EVENT TREES, AND RESULTS

F-1

Appendix G. CRYSTAL BALL SIMULATION OUTPUT REPORT -TWO-

ELEMENT CORE

G-1

Appendix H. CRYSTAL BALL SIMULATION OUTPUT REPORT -THREE

ELEMENT CORE

H-1

iv 


\section{LIST OF FIGURES}

$\underline{\text { Figure }}$

Page

1.1 Simplified piping and instrumentation diagram of the ANS

primary coolant system and flow blockage model $\ldots \ldots \ldots \ldots \ldots \ldots \ldots \ldots \ldots, 1-2$

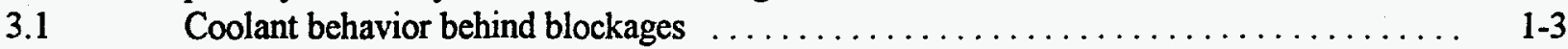

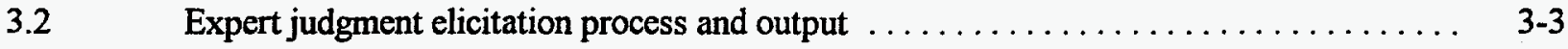

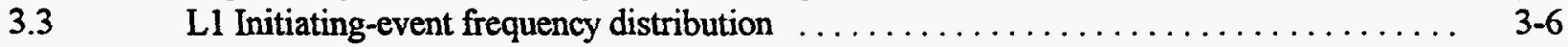

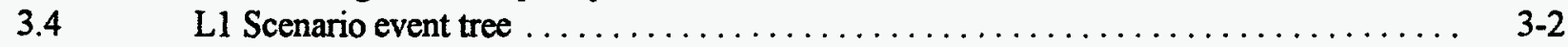

$3.5 \quad$ L2 Initiating-event frequency distribution $\ldots \ldots \ldots \ldots \ldots \ldots \ldots \ldots \ldots \ldots \ldots \ldots$

$3.6 \quad$ L3 Initiating-event frequency distribution $\ldots \ldots \ldots \ldots \ldots \ldots \ldots \ldots \ldots \ldots \ldots \ldots$

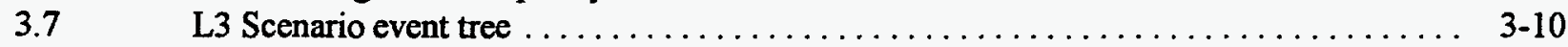

$4.1 \quad$ Ll flow blockage frequency leading to fuel damage $\ldots \ldots \ldots \ldots \ldots \ldots \ldots \ldots \ldots$ 4-1

$4.2 \quad$ L2 flow blockage frequency leading to damage $\ldots \ldots \ldots \ldots \ldots \ldots \ldots \ldots \ldots \ldots, 4.2$

$4.3 \quad$ L3 flow blockage frequency leading to fuel damage $\ldots \ldots \ldots \ldots \ldots \ldots \ldots \ldots \ldots$

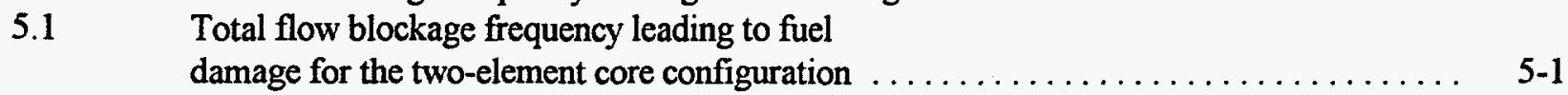

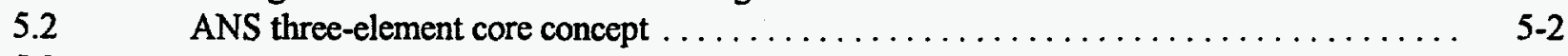

5.3 Expected flow blockage frequency Leading to fuel

damage for the three-element core configuration $\ldots \ldots \ldots \ldots \ldots \ldots \ldots \ldots \ldots \ldots \ldots \ldots$ 
. 


\section{LIST OF TABLES}

$\underline{\text { Table }}$

Page

3.1 Domain expert failure rate and debris size input

3-4

4.1

Top event SC evaluation ...

4-4

5.1

Summary of two-element core results

$5-1$

5.2

Summary of three-element core results

$5-2$ 



\section{ACRONYMS}

$\begin{array}{ll}\text { ANS } & \text { Advanced Neutron Source } \\ \text { CB } & \text { Crystal Ball } \\ \text { CDF } & \text { care damage frequency } \\ \text { CPBT } & \text { core pressure boundary tube } \\ \text { DPD } & \text { discrete probability distribution } \\ \text { FI } & \text { final inspection } \\ \text { HFIR } & \text { High Flux Isotope Reactor } \\ \text { I\&C } & \text { instrumentation and control } \\ \text { IE } & \text { initiating event } \\ \text { LCSS } & \text { lower core support structure } \\ \text { LDV } & \text { Laser Doppler Velocimeter } \\ \text { PRA } & \text { probabilistic risk assessment } \\ \text { RCP } & \text { reactor coolant pump } \\ \text { RM } & \text { RISKMAN } \\ \text { RPC(S) } & \text { reactor primary coolant (system) } \\ \text { RPIC(S) } & \text { reactor pressure and inventory control (system) } \\ \text { RR } & \text { recognition and removal } \\ \text { RVC(S) } & \text { reflector vessel coolant (system) } \\ \text { SC } & \text { scenario classification } \\ \text { TLC } & \text { thermoluminescent crystal } \\ \text { T/M/I } & \text { testing/maintenance/inspection } \\ \text { TRU } & \text { transuranic assembly }\end{array}$





\section{INTRODUCTION}

The Phase 1 Level 1 Probabilistic Risk Assessment (PRA) ${ }^{1}$ of the conceptual design of the Advanced Neutron Source (ANS) Reactor identified core flow blockage as the most likely internal event leading to fuel damage. The flow blockage event frequency used in the original ANS PRA was based primarily on the flow blockage work done for the High Flux Isotope Reactor (HFIR) PRA. ${ }^{2}$ This report examines potential flow blockage scenarios and calculates an estimate of the likelihood of debris-induced fuel damage. The bulk of the report is based specifically on the conceptual design of ANS with a 93\%-enriched, two-element core; insights to the impact of the proposed three-element core" are examined in Sect. 5. In addition to providing a probability (uncertainty) distribution for the likelihood of core flow blockage, this ongoing effort will serve to indicate potential areas of concern to be focused on in the preliminary design for elimination or mitigation. It will also serve as a loose-parts management tool.

\subsection{SCOPE}

The scope of this analysis is to study the likelihood of flow blockage resulting from debris that in some way reaches the core inlet and blocks a sufficient portion of one or more fuel channels to cause at least local exceeding of safety parameters, primarily those of critical heat flux and the wall temperature's $\left(\mathrm{T}_{\text {wall }}\right)$ exceeding the fluid saturation temperature. Thermal-hydraulic analyses indicate that these parameters can be exceeded by very small blockages on the order of a few millimeters (see Sect. 3.1). Emphasis is placed on the primary coolant system and those systems that have a direct interface with the primary coolant system as shown in Fig. 1.1.

To facilitate the evaluation of flow blockage events resulting from loose debris, three scenarios, based on the debris' point of entry into the primary system, were defined: scenario Ll includes debris originating between the core outlet and the loop strainers, scenario L2 includes debris originating from the loop strainers to the core inlet, and scenario L3 includes debris entering from outside the system boundary. These are also noted in Fig. 1.1. Once the debris enters the primary system, event trees model its path to the fuel using various top events (e.g., strainer availability, debris size, debris detection and removal) specific to the scenario being analyzed. As an aid in understanding this report, Sect. 8 provides a glossary of frequently used terms.

Another category of flow blockage scenario, designated L4 in the ANS PRA, addresses the possibility of loading a fuel element having undetected manufacturing defects into the reactor. It is postulated that these defects (e.g., nonbonds, surface defects, inhomogeneities, or cracks) would manifest themselves during operation in such a way that, through blistering or plate deformation for example, flow would become obstructed between two plates, causing local melting that could then propagate. This issue will be evaluated in a separate calculation when details of the fuel element properties, design, fabrication, and inspection are better characterized.

"In December 1994, the ANS Change Control Board, with the approval of the Department of Energy, approved a change to the three-element core as the authorized core configuration of ANS. 


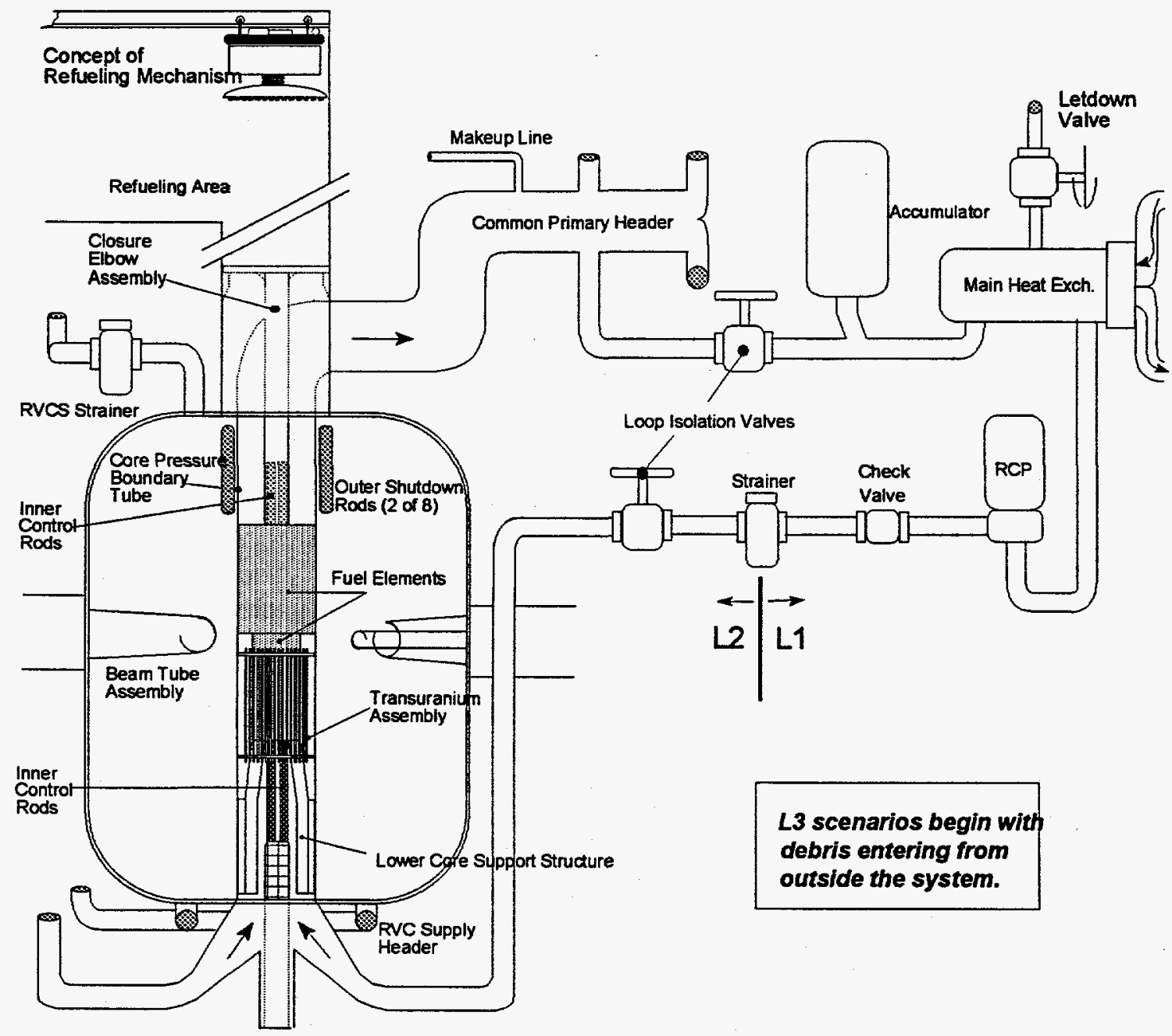

Fig. 1.1. Simplified piping and instrumentation diagram of the ANS primary coolant system and flow blockage model.

This document describes methodology (Sect. 1.2), assumptions and their justifications (Sect. 2), calculation input (Sect. 3), computations and analyses (Sect. 4), results (Sect. 5), and conclusions (Sect. 6). Other applicable information, including data base files associated with this assessment, are incorporated as appendixes.

\subsection{METHODOLOGY}

A probabilistic risk assessment such as this seeks to answer quantifiably three fundamental questions: (1) what can go wrong, (2) how likely this event is to occur, and, given that things go wrong at the determined frequency, (3) how often they result in undesirable (risky) conditions. Simplistically put, these questions are answered through scenario analysis (classifying what can go wrong into typical accidents based on their 
outcome), data analysis (analyzing the frequency of individual failures that may initiate or contribute to the continuation of an event), and event sequence analysis (using event trees to model the wide range of possible sequences that lead to one or more damage states).

A critical part of evaluating the risk of damage to ANS from flow blockage was the collection of data regarding the frequency of events that could result in core flow blockage. One difficulty in analyzing the frequency of flow blockage is that ANS is a facility in concept only. There is no directly applicable flow blockage experience base to draw data from. While flow blockage incidents have occurred at other reactors in the past, in most instances there are differences in materials used and, more importantly, in the fuel element design and vulnerability to flow blockages. There have also been incidents in which items have been retrieved from a strainer: during annual inspection of the HFIR primary strainer, such items as bearing shaft retaining pins, control rod bearings, and screw heads from the control plate brackets were found. The HFIR events were not used directly as experience data because of the design differences between the systems, structures, and components of ANS and HFIR. They are, however, indicative of the types of failures that could occur. Future events at either ANS or other facilities should be considered for applicability and possibly be incorporated into the ANS model to update the expert estimates.

The methodology behind the ANS flow blockage analysis involved five basic tasks as illustrated by the flow chart in Fig. 1.2. As a first step, the system designers helped to produce a debris data base (see Appendix A) that documented potential debris in the systems that most directly interfaced with the reactor primary coolant system [reactor pressure and inventory control system (RPICS), refueling, instrumentation and control (I\&C), and transuranics]. In task A, many of these engineers were asked to take part in an

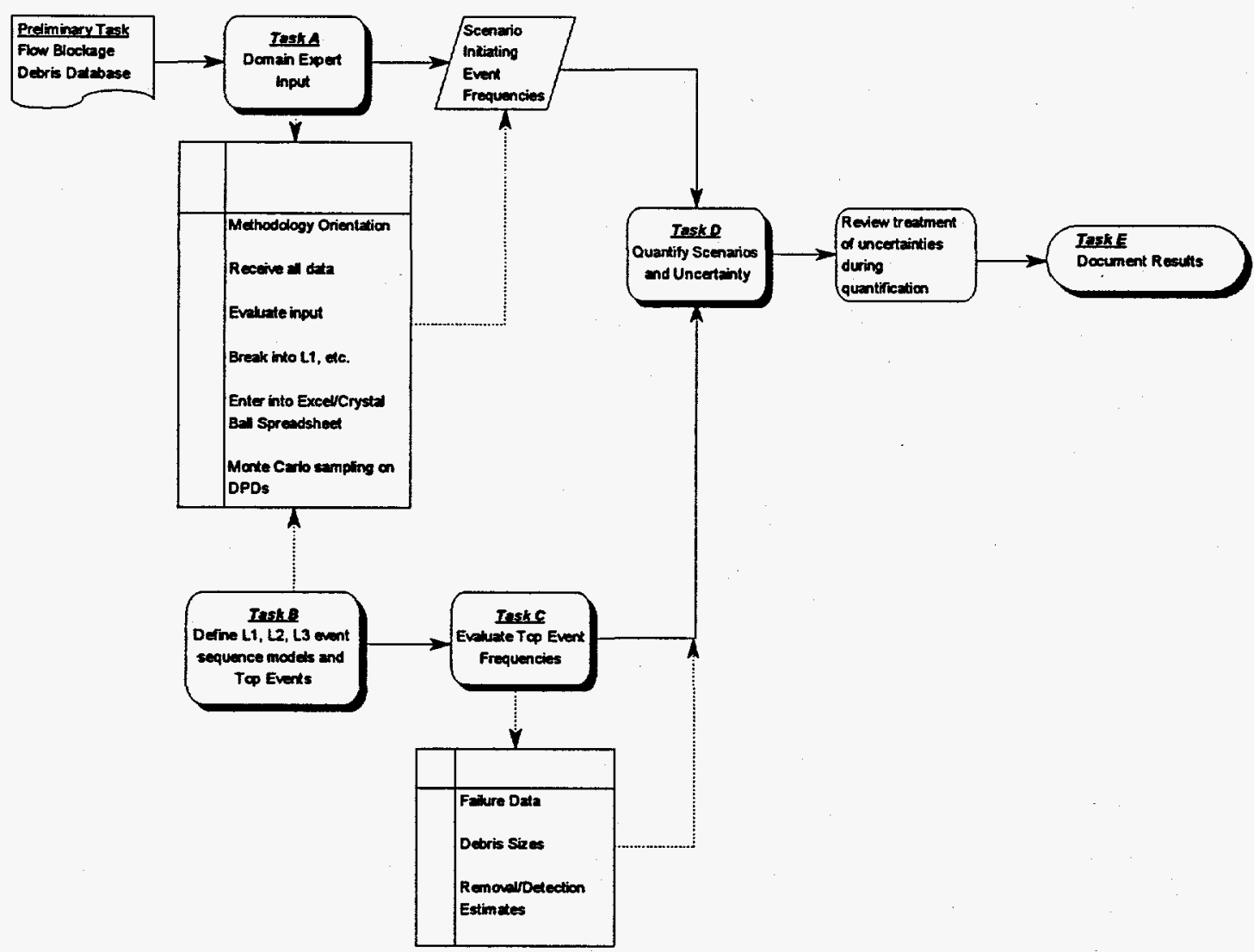

Fig. 1.2. Process logic diagram. 
exercise in expert judgment elicitation, using the debris data base, to estimate the likelihood of failures that produce debris (see Sect. 3.2). The point estimate (expected) mean for each expert is calculated by multiplying the confidence times the associated bin frequency for all bins and then summing. The experts also estimated the likelihood of discrete ranges, or bins, of debris sizes that could occur. This expert judgment input now forms the prior (what is already known or expected about the frequency of occurrences or failures) that will be updated in the future with applicable plant-specific data, as it becomes available. Tasks B and C were performed by the analyst concurrently with task $A$ to define the event sequences and specific occurrences leading to the flow blockage end states (fuel damage, no damage, no flow blockage). Tasks $A$ and $\mathrm{B}$ combine in assigning the expert's input to the appropriate flow blockage scenario so that initiatingevent frequency distributions can be calculated for each scenario (see Sect. 3.3). Task $C$ then involves the definition and failure frequency evaluation of each "event" along a scenario path that must fail in order to reach the undesired end state, flow blockage. Task D (documented in Section 4) brings tasks A, B, and C together during quantification when Monte Carlo sampling operations are performed on the initiating-event as well as the top-event frequency distributions. This step is done to incorporate uncertainty into the results, rather than just to have a point estimate. This report represents task $E$, the documentation and explanation of the ANS flow blockage analysis, including summaries of tasks A through D.

\subsection{COMPUTER SOFTWARE}

The flow blockage assessment relied on the following computer programs:

1. Excel $\left(\right.$, Version $4.0,{ }^{3}$ the spreadsheet software used to compile the expert data and the event tree equations, as well as to draw the event trees.

2. Crystal Ball@, Version $3.0,{ }^{4}$ an add-on package designed to be used with Excel. Crystal Ball allows the user to specify distribution types (lognormal, normal, wiebull, etc.) and to estimate uncertainties for input data. Then, using the formulas written into the Excel spreadsheet, Crystal Ball runs a prespecified number of Monte Carlo simulations to calculate a resulting probability distribution.

3. RISKMAN®, Version $5.1,{ }^{5}$ a PC-based PRA software package used in the analysis portion of many commercial and laboratory risk analyses, including the HFIR and ANS. In this analysis, RISKMAN was used as a check to verify that the input distributions were being properly combined during quantification. Input data, including the elicited expert data, was entered into the DATAMAN module, and a large fault tree was constructed to simulate the event trees in the Excel file. Additional information about the capabilities and limitations of this software is in Appendixes B and C. 


\section{ASSUMPTIONS AND JUSTIFICATIONS}

This section lists important analysis assumptions and their corresponding justifications. These assumptions, along with the thermal-hydraulic analysis information in Sect. 3.1, form the analytical basis for the data manipulation and calculations that follow.

1. Assumption-Based on the current core fuel grading and the use of a 50-mm unheated length at the fuel plate inlet, there is a potential for fuel damage from any blockage that covers more than $10 \mathrm{~mm}$ of the width of a fuel coolant channel. To account conservatively for the uncertainty of this damage limit, a debris size of $5 \mathrm{~mm}$ is used to represent the blockage size that could lead to fuel damage.

Justification-Assumption 1 is based on thermal-hydraulic analyses discussed in Sect. 4. A fully probabilistic analysis would assign a distribution of the likelihood of fuel damage versus blockage size. However, the analytical support has not yet progressed to allow such a distribution to be developed. This step will be done as work progresses.

2. Assumption-Any fuel damage because of flow blockage is unacceptable, whether it be local or widespread (large enough to cause propagation of damage around the element).

Justification-The blockage size or number of affected plates that represents the threshold of propagating damage is not currently known. Future plans are for this to be investigated under the severe accident analysis task in coordination with the thermal-hydraulic safety analysis task. At this point in the reactor design, it prudent to treat any fuel damage as severe.

3. Assumption-Propagation of fuel damage, were it to occur, is not assumed to transfer from one fuel element to another. In light of assumption 2, this assessment does not attempt to define (probabilistically or otherwise) the blockage size leading to damage that propagates within a fuel element.

Justification-Obviously, if the upper fuel element were to incur damage, the lower element would be unaffected due to its position upstream in the coolant flow. The limiting case, therefore, is complete damage to the lower fuel element. If total damage propagation were to occur around the lower fuel element, the pressure drop across the lower fuel element could eventually decrease (due to the sweeping away of melted fuel plate material) to the point where it robbed flow from the upper element. Melted material passing the radiation detectors in the primary loop combined hot leg would cause a scram.

4. Assumption-Any debris identified in the flow blockage debris evaluation data base (see Sect. 4.1) requiring failure of more than two filters or strainers prior to entering the core region is assumed to have a flow blockage frequency of less than $10^{-6}$ per year. This debris includes the introduction of resins as well as solids. Heat exchangers are not included as strainers in this assumption.

Justification-This assumption is based on the frequency of two filters or strainers failing without notice or at the same time in such a way as to allow passage of the debris into the core region. Resins and colloids are included in this assumption because of the mixing and dilution that will

have taken place (because of the filters or strainers, pumps, and heat exchangers through which they must pass) in the time and distance between their introduction and the core region.

5. Assumption-A single loop is used to model the passage of debris from its point of entry to the core, rather than attempting to model all three operating loops. Contribution from the idle and valved-out primary loop is considered to be negligible during operation because of the relative absence of flow. This 
is not to say that the components of all primary loops do not contribute to the scenario initiating event frequencies; they do.

Justification-The ANS is a four-loop plant with three loops normally in operation and one loop isolated (idle). All primary loops are identical in design and components. Given that debris has been introduced between the core outlet and the primary loop strainers, there is a likelihood of nearly 1.0 that it will pass into at least one of three operating coolant loops. Once the debris passes into one of the three loops, only the availability of that loop's strainer needs to be considered. If debris were to enter more than one loop, the likelihood of dual-independent or common-cause strainer failures is much less than that of a single failure. Therefore, only one primary loop is modeled following introduction of debris.

With the low (almost zero) flow in the idle loop during normal operation, it is very unlikely that any substantial debris would exit the main flow stream to reside in that portion preceeding the hot leg or following the cold leg isolation valves. If the debris is a group of material, it is conceivable that debris could enter more than one loop. However, with the periodic rotation of the idle loop (for maintenance and inspection or repair purposes), the contribution from all loops is taken into consideration both for active failure during operation and for intrusion of debris left behind by maintenance activities.

6. Assumption-Clothing-, tool-, and part-inventory practices equivalent to those used at HFIR for refueling and primary system maintenance are assumed for $\mathrm{L} 3$ scenarios.

Justification-This is a logical assumption for this facility because of the lessons learned from the initial HFIR flow blockage analysis and the benefits (reduced risk to fuel damage) as a result of better controls on who and what is allowed in vulnerable areas.

7. Assumption—Failure estimates are assumed to adhere to a lognormal distribution.

Justification-Lognormal distributions are widely used in situations where values are positively skewed (where most of the values occur near the minimum value) as in financial analysis for security valuation or in real estate for property valuation and in probabilistic analyses for frequency evaluation where factors or percentages can characterize the variation. The three conditions underlying lognormal distributions are as follows:

1. The unknown variable can increase without bound but is confined to a finite value at the lower limit.

2. The unknown variable exhibits a positively skewed distribution.

3. The natural logarithm of the unknown variable will yield a normal curve. ${ }^{6}$

According to McCormick, one of the reasons that the lognormal distribution is frequently suitable for describing failures in reliability and risk analysis is that data for rarely occurring events may not be extensive. In these situations, component failure rates can vary by factors or orders of magnitude, as in the estimates here. 


\section{CALCULATION INPUT}

The input required to begin the task of analyzing the likelihood of flow blockage at ANS consisted of three basic components. The first was to define blockage in the context of fuel damage: how large a blockage can be sustained without even local damage? Section 3.1 presents work of thermal-hydraulic analysts in evaluating the flow reattachment lengths behind various blockage sizes, which in turn points to the blockage size sustainable without incurring damage. The second component is the input of domain experts regarding the frequency of events through which debris of certain sizes could be introduced into the primary system (task A in Fig. 1.2), and this process is described in Sect. 3.2. The final input component is the delineation of blockage event scenarios based on their point of origin (where debris came from and its path to the fuel), because this is the stepping-off point for the rest of the analysis. This is task B from Fig. 1.2 and is detailed in Sect. 3.3. The information gleaned from the following subsections, then, contains (1) the blockage size that can cause damage, (2) the estimated likelihood of events where debris is introduced into the primary system, and (3) how that debris reaches the core.

\subsection{THERMAL-HYDRAULIC FLOW BLOCKAGE ANALYSIS}

This section contains information reported in the 1994 ANS progress report contribution from Yoder et. al. ${ }^{8}$ on analytical and experimental efforts to define the maximum core inlet flow blockage that can be tolerated without incurring fuel damage. This information is presented here, rather than with the assumptions above, because of its significance in associating deterministic analysis and experimentation with a probabilistic analysis. To ensure that consistency is maintained, the subject work is quoted verbatim:

Core inlet flow blockage caused by debris within the primary coolant loop is a significant safety issue. A local reduction of heat transfer within the fueled region of the core caused by the flow recirculation downstream of the blockage may cause some fuel melting. Efforts have focused on defining the maximum flow blockage at the core inlet that will not result in fuel damage. An initial estimate of $10 \mathrm{~mm}$ for this limiting blockage size (assuming an unfueled entrance length of $50 \mathrm{~mm}$ ) was based on an extrapolation of Sparrow and Cur's (1983) experimental work in a partially blocked rectangular channel. (The experiment used mass transfer measurements at a Reynolds number of 30,000 .) The extrapolation showed that the recovery to reasonable flow rates would occur at a downstream location in the channel about five times the width of the blockage. Because of the large amount of uncertainty associated with the extrapolation, an extensive effort using both analytical and experimental tools has been made to understand the flow recovery region more fully.

Both the experimental and analytical results show that the disturbance behind a blockage located on the edge of the channel persists longer than the disturbance behind a centrally located blockage. The edge blockage, therefore, represents the worst, or most conservative, case. An LDV [Laser Doppler Velocimeter] was used to measure hydraulic parameters within a channel designed to match the ANS core cooling channels (for further description of this experimentation, see Sect. [3.4]). The results for a $21-\mathrm{mm}$ ( $25 \%$ of the $84 \mathrm{~mm}$ span) blockage placed at one side of the span show that the flow reattaches (or changes from back- to forward-flow) between 58 and $90 \mathrm{~mm}$. The Fluent computational fluid dynamics analysis predicts such reattachment at $65 \mathrm{~mm}$, or about three times the blockage width. The LDV results show that the flow surpasses $50 \%$ of its undisturbed velocity between 90 and $121 \mathrm{~mm}$. The Fluent analysis predicts that this point will be reached at $105 \mathrm{~mm}$, or about five times the blockage width. An 8.4-mm ( $10 \%$ of the span) blockage was also tested in an edge position. TLCs [thermoluminescent crystals] were used to measure the wall heat transfer characteristics in the region behind the blockage. 
These results have limited accuracy near the side walls but show a region of reduced heat transfer extending at least 36-mm downstream from the blockage, or four times the blockage width. The Fluent results for the $10 \%$ case show reattachment occurring at $44 \mathrm{~mm}$ (or five times the blockage width) and the $50 \%$ velocity recovery occurring at $90 \mathrm{~mm}$ (or 10 times the blockage width). This $10 \%$ edge blockage will be investigated using the LDV system in the near future to provide more information about the extended length of the recovery region for this smaller blockage.

One major question must still be addressed. The hydraulic behavior within the channel has been well. characterized by the work to date. The next step in the analysis will address the temperature fields within the channel (for various wall heat flux patterns) to determine whether or not our preliminary definitions of acceptable flow recovery are valid."

The information quoted above is taken to be the most current source regarding the critical blockage size. Figure 3.1 is a graphical representation of the numerical information presented there. For the $21-\mathrm{mm}$ blockage, flow does not even reattach until $8 \mathrm{~mm}$ into the fuel meat, resulting in definite damage in the entrance region. With the 8-mm inlet blockage, while the flow has reattached prior to the fueled region, an estimated $40 \mathrm{~mm}$ into the fueled region is under $<50 \%$ flow conditions with the potential for exceeding safety margins. Until the temperature fields within the channels are better defined along with the associated behavior of the fuel plates in $<50 \%$ flow regimes, uncertainty will remain about the sustainable blockage size. This uncertainty is the primary reason that $5 \mathrm{~mm}$ is used in this analysis as the limiting size for fuel damage. With the current information, there is a confidence that fuel damage will not occur for a blockage this small.
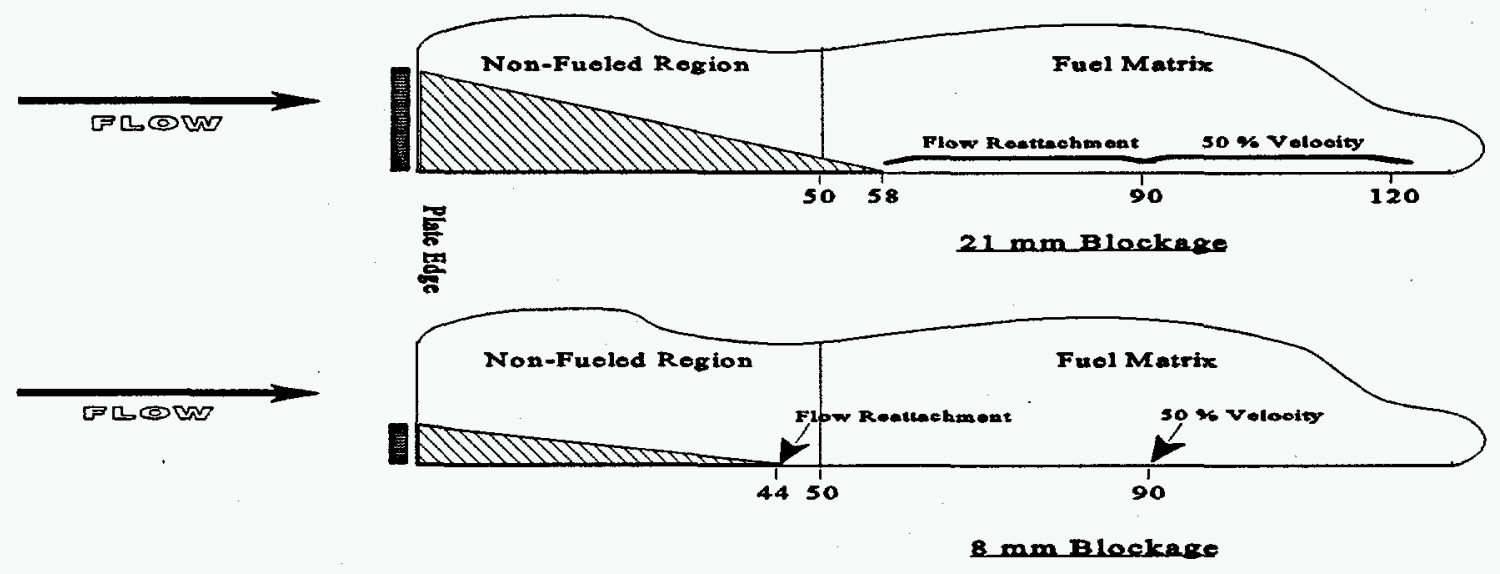

Fig. 3.1. Coolant behavior behind blockages.

\subsection{FLOW BLOCKAGE DATABASE AND ELICITATION OF EXPERT JUDGMENT}

The basis for using expert judgment to estimate likely event frequencies was presented in Sect. 1.2. This process involves a panel of "domain experts" in the area of interest, focusing their knowledge and experience to formulate, in this case, estimates of the probability of discrete frequencies being the true frequency (see references in Appendix D). Figure 3.2 shows the processes involved. As a part of the preparation for this calculation, the ANS system designers were asked to evaluate their systems for potential debris or loose parts that, given the proper failure mechanisms, could find their way into the primary coolant system. Systems 


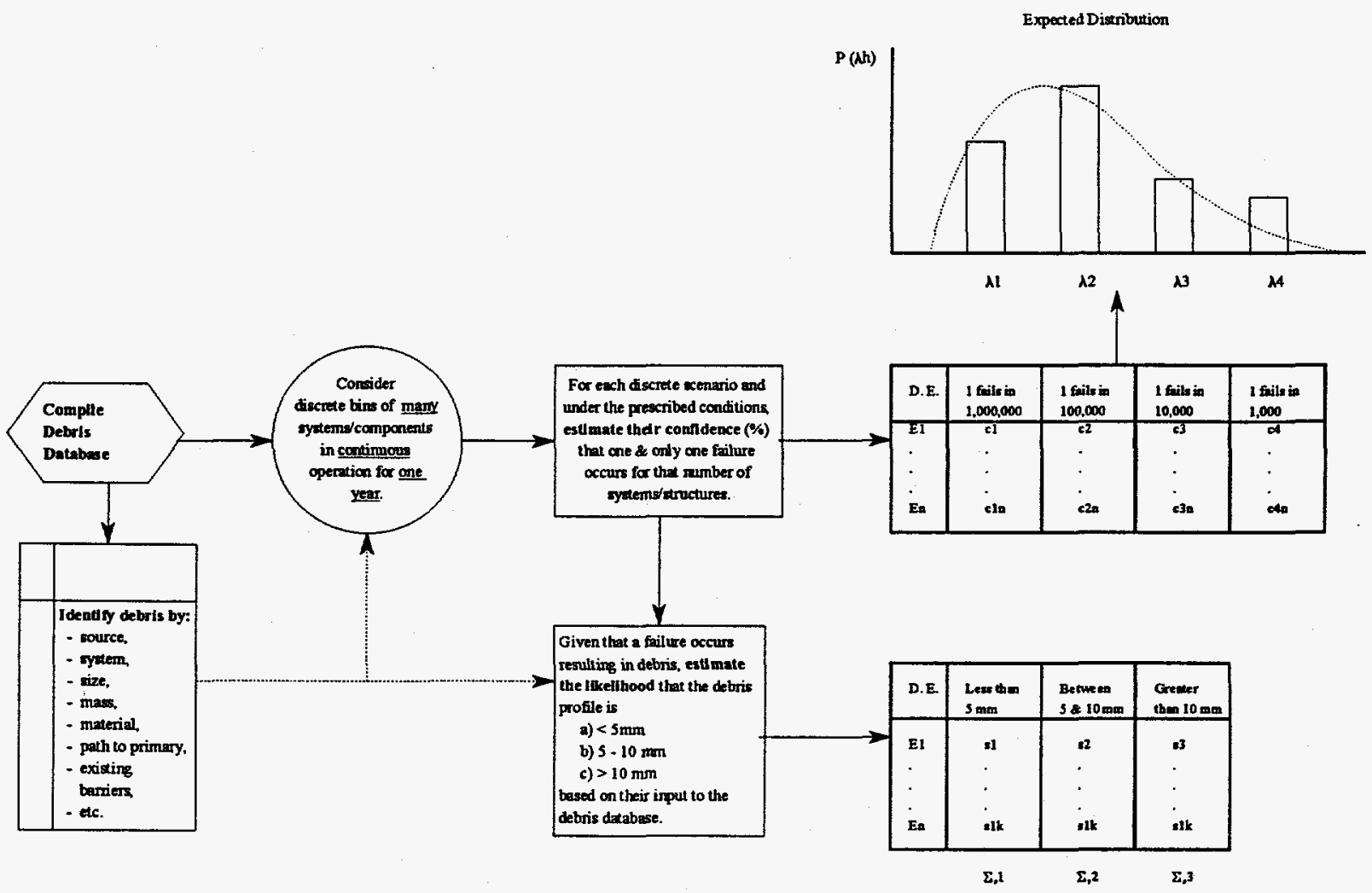

Fig. 3.2. Expert judgment elicitation process and output.

considered were the primary coolant, secondary coolant, reflector vessel coolant, experiments and materials irradiation, pressure and inventory control, detritiation and upgrade, reactor assembly, instrumentation and control, and refueling systems. ${ }^{9}$ All designers responded to the survey questions, though not all were able to identify specific sources of debris at this time primarily because of the conceptual nature of the current design. The outcome of this exercise is the flow blockage debris data base found in Appendix A. The debris data base became the basis for evaluation of the probability of the frequency of debris being released in to the primary system by a failure.

Information regarding the value and use of expert judgment in technical analyses and the methodology to be used was sent to the domain experts prior to any data gathering (see Appendix D). Following an informal training session on estimating probability of frequencies using discrete probability distributions (DPDs), the experts were presented with the information that they had previously provided for the debris data base. The DPD format simplifies the estimation process by allowing the experts to express their confidence in each member of a set of discrete frequencies. The experts were requested to estimate the most likely frequency of failures that create debris if a given number of their systems operated side-by-side continuously for one year, 
based on (1) their state of knowledge about their system, component, or assembly; (2) the debris information that they provided; and (3) the level of system design.

A lower bound of $1 \times 10^{-6}$ was placed on the estimates because of the difficulty in perceiving estimates below this frequency as valid. The upper bound of $1 \times 10^{-3}$ is a reflection of the plant design and assumed maintenance practices and may later prove to be nonconservative when applicable experience and experimental data are incorporated into updates of this analysis.

The raw input from the experts is in Table 3.1 and was taken directly from their responses in Appendix $\mathrm{E}$, which also contains additional information pertaining to the thought processes and reasons behind the experts' estimates. For each discrete frequency, or bin, in Table 3.1, the expert input should be read as the confidence (percentage of surety) that that bin represents the true mean frequency, with $100 \%$ confidence that the expected mean frequency lies in the range between $1 \times 10^{-6}$ and $1 \times 10^{-3}$ per year." Thus, the first table entry means that the primary cooling system expert is $60 \%$ confident that, if one million of his systems operated side-by-side for a year, one failure would occur that resulted in loose debris in the coolant. The expected mean for each expert is calculated by multiplying the confidence level by the associated bin frequency for all bins and then summing.

Also included in Table 3.1 is the experts' estimate of the most probable size of debris, given that a failure resulting in loose debris had occurred in their system. For this exercise, size estimates were limited to $<5 \mathrm{~mm}$ width or effective diameter, $5-10 \mathrm{~mm}$, and $>10 \mathrm{~mm}$. Depending on the changes in core design and their

Table 3.1. Domain expert failure rate and debris size input

\begin{tabular}{|c|c|c|c|c|c|c|c|c|}
\hline \multirow[b]{2}{*}{$\begin{array}{l}\text { System or } \\
\text { component }\end{array}$} & \multicolumn{5}{|c|}{ Failure rate likelihood distribution } & \multicolumn{3}{|c|}{ Debris size likelihood distribution } \\
\hline & $1 \times 10^{-6}$ & $1 \times 10^{-5}$ & $1 \times 10^{-4}$ & $1 \times 10^{-3}$ & $\begin{array}{l}\text { Expected } \\
\text { annual } \\
\text { frequency }\end{array}$ & $\begin{array}{c}<5 \mathrm{~mm} \\
\text { width or } \\
\text { diam }\end{array}$ & $\begin{array}{c}5-10 \mathrm{~mm} \\
\text { width or } \\
\text { diam }\end{array}$ & $\begin{array}{c}>10 \mathrm{~mm} \\
\text { width or } \\
\text { diam }\end{array}$ \\
\hline $\begin{array}{l}\text { Reactor primary } \\
\text { cooling }\end{array}$ & 0.60 & 0.25 & 0.10 & 0.05 & $6.4 \times 10^{-5}$ & 0.2 & 0.3 & 0.5 \\
\hline $\begin{array}{l}\text { I\&C-thermowells } \\
\text { (Scenario L1) }\end{array}$ & 0.00 & 0.00 & 0.10 & 0.90 & $9.2 \times 10^{-4}$ & 0.1 & 0 & 0.9 \\
\hline $\begin{array}{l}\text { I\&C-capillary } \\
\text { debris }\end{array}$ & 0.00 & 0.00 & 0.90 & 0.10 & $1.9 \times 10^{-4}$ & 0.9 & 0.1 & 0 \\
\hline $\begin{array}{l}\text { Inner control rods } \\
\text { and internals }\end{array}$ & 0.83 & 0.10 & 0.05 & 0.02 & $2.7 \times 10^{-5}$ & 0.3 & 0.1 & 0.6 \\
\hline Transuranics & 0.20 & 0.55 & 0.15 & 0.10 & $1.2 \times 10^{-4}$ & 0.4 & 0.5 & 0.1 \\
\hline Refueling & 0.70 & 0.20 & 0.09 & 0.01 & $2.2 \times 10^{-5}$ & 0.6 & 0.3 & 0.1 \\
\hline $\begin{array}{l}\text { Pressure and } \\
\text { inventory control }\end{array}$ & 0.40 & 0.30 & 0.20 & 0.10 & $1.2 \times 10^{-4}$ & 0.4 & 0.2 & 0.4 \\
\hline
\end{tabular}

"When the probability distribution is created, higher and lower frequencies will appear on the curve because of continuity. 
associated vulnerability to flow blockage, future revisions may require further breakdown of the likely debris sizes whose width or diameter is greater than $10 \mathrm{~mm}$ (e.g., $10-15 \mathrm{~mm}, 15-20 \mathrm{~mm}$, etc.).

The estimates of these two parameters (failure frequency and size distribution) are combined in calculating the likelihood of an event producing debris that could cause flow blockage if it reached the fuel.

Following a review of the expert input and associated documentation, the elicited data were categorized into the event scenarios (L1, L2, L3), and in some cases, the elicited data were discussed further with the experts for clarification. Section 3.3 discusses the calculation of scenario initiating-event frequency from these estimates.

In analyzing all scenarios, some global modeling parameters were set regarding the type of distribution used to represent each variable. First, all debris event bin frequencies $\left(1 \times 10^{-6}, 1 \times 10^{-5}, 1 \times 10^{-4}\right.$, and $1 \times$ $10^{-3}$ ) were assigned to a lognormal distribution in Crystal Ball. The degree of uncertainty is expressed by the standard deviation quantity. The software arbitrarily assigns a $10 \%$ standard deviation to these assumed distributions, resulting in a relatively narrow distribution about the expected mean, usually within the same order of magnitude (a factor of 10). In an effort to include more of the range of failure probabilities and uncertainty from the expert judgment analyses, the standard deviation was increased to $100 \%$ of the expected mean. This action produces a wider uncertainty range, allowing for a wider range to sample from during quantification. As a result, the assumed distribution covers a range of frequencies more closely reflecting the estimates.

\subsection{SCENARIO DEVELOPMENT}

The entry point of a foreign object has a significant impact on the likelihood of a scenario's ending in flow blockage. Breaking down the possible debris entry paths by scenario encourages focus on high-risk areas for risk management, risk reduction, and possibly loose-parts monitoring. Three flow blockage scenarios were defined as L1, L2, and L3 (see Fig. 1.1):

- Scenario L1 includes debris originating between the core outlet and the loop strainers, exclusive of the strainers themselves. The closure elbow, the combined hot leg, and the three operating coolant loops are included as potential sources of debris that could reach the loop strainers.

- Scenario L2 includes debris originating between the three operating loop strainers and the core inlet, including the strainers and the transuranic element support assembly, situated around the lower fuel element and below the upper fuel element.

- Scenario L3 includes debris that is introduced to the primary system from outside the primary system pressure boundary. Contributors are refueling, maintenance, and connected systems such as the pressure and inventory control system and the reflector vessel cooling system.

By categorizing the blockage scenarios in this manner, the relative importance of each area is made clear through the results. Appendix F contains the Excel spreadsheet used to model the anticipated ANS debris flow blockage scenarios, including data, event trees, and results, and should be studied to gain a more complete understanding of the model. Prior to the scenario calculation of initiating-event frequencies, the expert input in Table 3.1 had to be separated to conform to these definitions, based on the point or method of entry into the primary coolant flow.

In performing their estimates, the experts were to consider a large number of their systems operating side-by-side continuously for one year. This condition does not apply to the ANS directly because shutdown time will be required for maintenance and refueling. Current plans are for the ANS to have 14 neutron- 
producing fuel cycles per year, at $17 \mathrm{~d}$ per cycle for a total of $238 \mathrm{~d} /$ year. Therefore, frequencies for those systems that are in continuous use during a fuel cycle but are not required during refueling or maintenance were adjusted accordingly during quantification. For the refueling system, which operates between cycles and during periods of major maintenance on reactor and reflector vessel components, yearly usage was estimated at $127 \mathrm{~d}$ (365 less 238 ), or $34 \%$ of a year, and initiator frequencies were changed to compensate for this modification. The final categorized, cycle-adjusted estimates were then placed in an Excel spreadsheet. Crystal Ball, an add-on program for generating frequency distributions using Monte Carlo sampling techniques, was used to produce a lognormal representation of each scenario estimate. Further discussion of event sequence quantification is contained in Sect. 4.

\subsubsection{The L1 Scenario}

The $\mathrm{L} 1$ scenario is concerned with debris that enters the primary system between the core outlet and the loop strainers. Potential sources of such debris or loose parts are bolts, tools from maintenance, weld beads (unlikely), fragments, pins, check valve disks, etc. Many of these were identified in the flow blockage debris data base in Appendix A. The important quantity being sought is the likelihood of failures that produce debris large enough $(>5 \mathrm{~mm}$ ) to result in fuel damage if it reaches the fuel. If debris (single or conglomerate) that has bypassed a failed strainer covers $<5 \mathrm{~mm}$ of the fuel channels, no damage is expected to result. If the debris is $<1.27 \mathrm{~mm}$, it can pass through the fuel without any impact.

Estimates by the domain experts for failures and likely debris sizes were presented in Sect. 3.2. As stated above, the desired quantity is the likelihood of failures that produce debris large enough ( $>5 \mathrm{~mm}$ ) to result in fuel damage if the fuel is reached. An estimate of this frequency can be found for each domain by multiplying the expert's estimate of failure frequency with his corresponding estimate for the likelihood that the debris size is $<5 \mathrm{~mm}$. The domain frequencies are summed within each scenario to approximate the scenario frequency, which is then used in the scenario event tree. The likelihood of an L1type event, calculated from the domain expert input with Crystal Ball, is shown in Fig. 3.3. This probability distribution displays the range over which the estimated frequency lies, with the expected mean identified by a solid line. The breadth of the distribution represents the uncertainty associated with the estimate. More statistical information about this

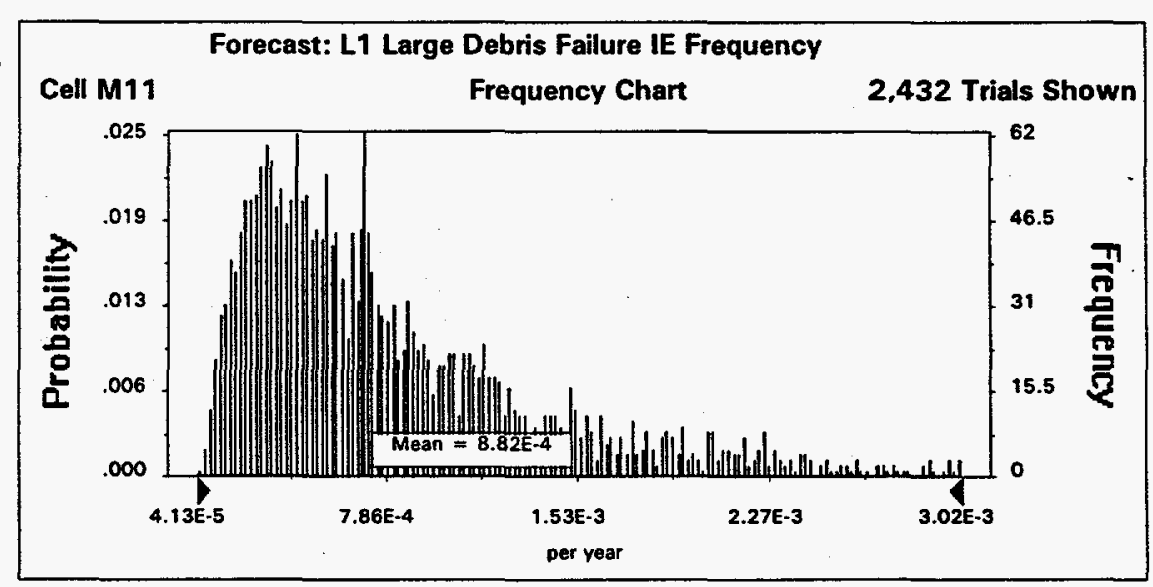

Fig. 3.3. L1 Initiating-event frequency distribution. forecasted frequency may be found in Appendix G.

The $\mathrm{Ll}$ event tree, shown in Fig. 3.4, depicts the event sequences modeled for the $\mathrm{L} 1$ scenarios. Each sequence begins with debris introduction on the left side of the event tree and proceeds to the right, "asking" whether a top event is successful (right) or failed (down) before proceeding to the next event. Top events are used to account for the success or failure (availability or unavailability) of a system or function. If a top event 


\begin{tabular}{|c|c|c|c|}
\hline $\begin{array}{c}\text { Initiating L1 } \\
\text { event }\end{array}$ & $\begin{array}{c}\text { Top event } \\
\text { LS }\end{array}$ & $\begin{array}{c}\text { Damage } \\
\text { state }\end{array}$ & $\begin{array}{c}\text { Sequence } \\
\text { ID }\end{array}$ \\
\hline
\end{tabular}

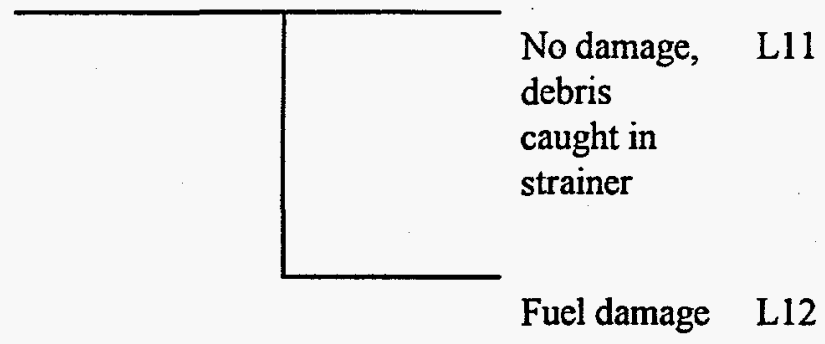

Fig. 3.4. L1 Scenario event tree.

is successful, the sequence path continues to the right; if failed, the path goes down then right to the next top event until the sequence terminates. The status of previous top events determines whether subsequent ones are considered in the event sequence or bypassed.

As the $\mathrm{Ll}$ initiating-event frequency has already screened out the frequency of failures with debris smaller than those thought to result in fuel damage, only the availability of strainer integrity (top event LS) remains to be questioned. The basket strainers proposed for ANS are constructed of heavy-gauge stainless steel with $0.5 \mathrm{~mm}\left(1 / 50 \mathrm{in}\right.$.) perforations, far less than the size that would lead to fuel damage. ${ }^{8}$ With an intact strainer, Ll debris is stopped by the strainer before reaching the core (scenario L11). It is considered highly unlikely that the strainer could fail independently or be caused to fail in such a way that basket material could become entrained in the primary flow. More information about the loop strainers and their design and operation is discussed in Sect. 3.4.3.

A thorough search of numerous failure data sources produced only one entry for strainer rupture ${ }^{10}$ at $5 \times$ $10^{-7} / \mathrm{h}$ with an error factor of 10 . Treating this mean value as a point estimate, this figure translates to an annual probability of rupture of $2.8 \times 10^{-3}$ based on the scheduled operating time of ANS, 14 fuel cycles at 17 days each. Appendix B of the HFIR PRA, ${ }^{2}$ estimates the unavailability of the strainer basket (i.e., likelihood that the debris encounters a failed basket) as $3.62 \times 10^{-4} /$ year, or a 1 in 2800 chance. Using these . two values as the 20th and 80th percentiles, a single-stage bayesian update was performed (using the DATAMAN module in RISKMAN), yielding a mean strainer failure likelihood of $2.1 \times 10^{-3} /$ year of scheduled ANS operation.

Several data entries related to strainer plugging were found, especially for component cooling water system strainers or essential (raw) cooling water strainers. The plugging phenomenon is believed not to apply to ANS because of the use of separate strainers in each operating loop. If one strainer is plugged, two other loops are available to cool the fuel. Although it is likely that plugging of a strainer would lead to shutdown, flow blockage is not likely because plugging of multiple strainers within a short period of time is extremely unlikely.

The primary coolant flow rate of $20 \mathrm{~m} / \mathrm{s}(\approx 40 \mathrm{mph})$ is not so fast that any of the identified Ll debris would cause a strainer failure on impact, even though the strainer itself will be hot due to the rapid flow through very small $(0.5-\mathrm{mm})$ perforations. The danger is from the debris encountering a strainer that has a local failure (e.g., rupture or fatigue failure) too small to indicate a great drop in strainer differential pressure but large enough to allow a fairly sizeable piece of material to pass into the L2 region and then on to the fuel.

"The error factor is equal to the median divided by the 95 th percentile. 


\subsubsection{The L2 Scenario}

L2 scenario events can begin with a debris-producing failure of a loop strainer, of an isolation valve, of small parts of the transuranic support assembly, or of other such material between the core inlet and the loop strainers. From the domain expert's input comes the expected frequency distribution of L2 events in Fig. 3.5. Because the likelihood of large debris is already included, this initiating-event frequency also represents probability of fuel damage from L2 scenario events

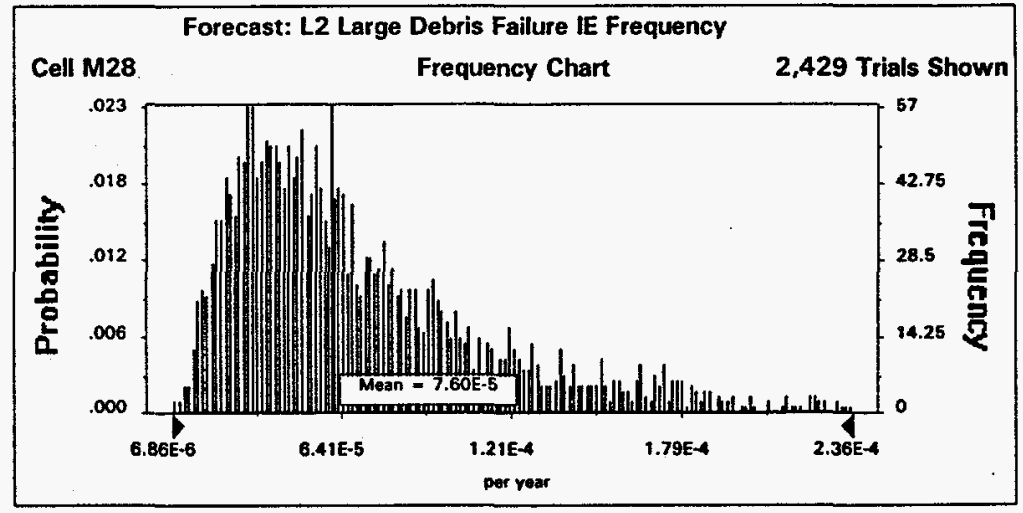

Fig. 3.5. L2 Initiating-event frequency distribution. (i.e., no event tree is necessary to quantify the frequency of fuel damage). The highest expected contributor in the conceptual design is the transuranic support assembly, which is discussed separately below. Because of the unobstructed path to the fuel elements, the risk of fuel damage from material originating in this region is much greater than that in scenario L1. Material introduced to the coolant flow in this region is virtually certain to contact the fuel elements without obstruction. The openings in the lower core support structure are sized such that most debris $<40 \mathrm{~mm}$ would readily pass through.

\subsubsection{Consideration of Debris Causing Transuranic Element Failure Leading to Flow Blockage}

The ANS transuranium production facility is an assembly of identical target rods that encircle the lower fuel element in the two-element core design. The conceptual design of the transuranic assembly ${ }^{11}$ is a series of 30 target rods restrained vertically and horizontally by retaining rings at the ends of the rods with a horizontal retaining ring in the center section of the rods to provide added stability in a high-flow regime. This design is quite different from the HFIR target rod assembly, which is contained in a basket located in the center of the fuel elements. (HFIR is a flux trap reactor, meaning that the center region is the region of highest neutron flux, whereas the high flux region of the ANS is radially outward from the core.)

Based on a careful review of the current ANS target rod assembly design, it is very likely that debris large enough to cause damage to the target rods from flow blockage would also cause concurrent damage to the fuel elements. However, based on the debris identified in Appendix A and system review, this is considered to be a very infrequent event. A more likely event would be sudden failure of a target rod in place, which would release fission products and debris up onto the upper fuel element, potentially causing damage there. If sudden target failure were to occur, early fission-product releases from the affected target rods prior to their structural failure would probably be detected by the primary coolant high-level gamma-ray detectors, prompting a reactor trip."

\footnotetext{
*A probabilistic fracture mechanics evaluation of the transuranic production assembly, both rods and support assembly, is currently planned. Financial constraints will dictate the schedule and completion date of this important task.
} 


\subsubsection{The L3 Scenario}

An L3 event may originate through a failure in another system that directly interfaces with the primary coolant system or as the result of human error. Such an event could occur during refueling operations, core pressure boundary tube (CPBT) change-out, work on components within the reflector vessel, or periods when the primary system is open for valve, pump, or strainer maintenance and inspection. The expected L3 initiating-event frequency (Fig. 3.6) includes the estimated frequency of failures and the likelihood that any debris resulting from those failures or left behind after

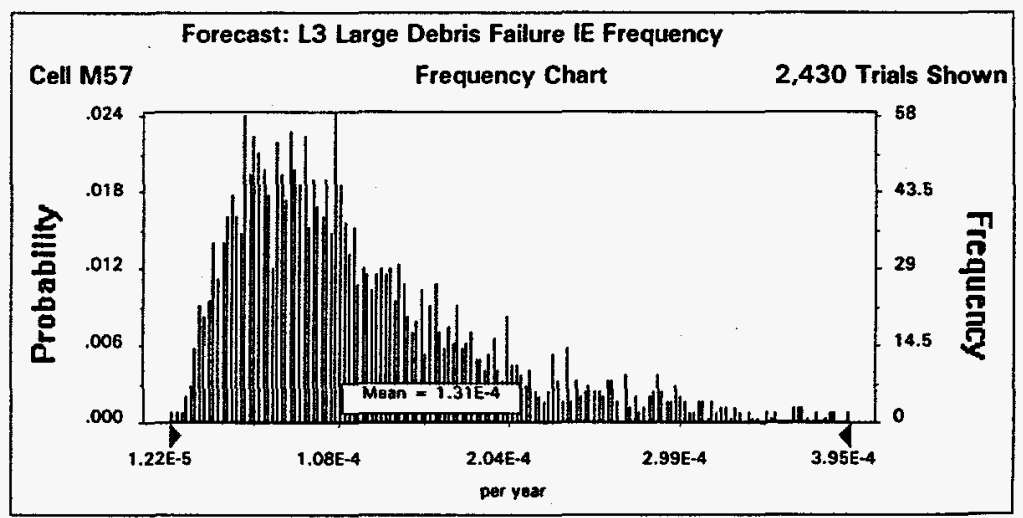

Fig. 3.6. L3 Initiating-event frequency distribution. maintenance or inspection exceeds $5 \mathrm{~mm}$.

The L3 event tree in Fig. 3.7 shows the top events and event sequences modeled for potential flow blockage scenarios stemming from introduction of loose parts from outside the primary system boundary. The L3 scenarios are further divided into two subscenarios, $\mathrm{L} 3 / 1$ and $\mathrm{L} 3 / 2$. The $\mathrm{L} 3 / 1$ scenario refers to instances when debris from outside the primary system is introduced to the primary flow and follows the same path of sequences as an L 1 scenario, based on its point of entry. Included in the L3/1 scenarios is debris injected from the RPICS via the makeup line, material introduced during times when the primary system boundary is opened for maintenance, and items dropped during refueling after the fresh fuel elements are in place. Maintenance items could include a glove, badge, piece of tape, small wrench, or small piece of wire, to mention a few. As stated in assumption 7 (Sect. 2), strict inventory practices similar to those used at HFIR are assumed to be followed at ANS. This means that operations personnel performing maintenance in the primary loop area will be required to maintain stringent control on items brought into the maintenance area. Before the loop is closed after a maintenance action, it is current HFIR procedure to have a separate, independent inspection by a different crew to make sure that no tools, parts, rags, etc. are left in the loop. This procedure increases the likelihood that large objects such as these, if left behind, will be recognized and removed prior to system closure. However, objects $\leq 1 \mathrm{~cm}$ will have a greater likelihood of escaping detection. It is therefore estimated that the likelihood of introducing debris to the primary system as a result of testing, maintenance, or inspection activities is equal to the total estimated contribution from primary system failures $\left(\phi=5.6 \times 10^{-5} / y e a r\right)$. This estimate may later prove to be low because of the types and frequency of activity that must be performed and the nature of human factors.

The limited access to the vessel head region during operation and refueling and maintenance (the vessel head is isolated from the environment in the refueling stack-and-tunnel and hot cell) all but excludes such debris as wrappers, office materials, badges, etc. Animals and insects should not be a factor either because of the ANS containment, which, unlike HFIR's confinement, has no direct access to the environment. The most likely debris, according to Appendix A, are loose parts from the refueling machine but could also be material

"Prior to primary-loop maintenance, the loop must first be drained and dried to minimize the spread of tritium contamination. This procedure improves the chances of visually identifying articles or debris prior to system closure. 


\begin{tabular}{|c|c|c|c|c|c|c|}
\hline $\begin{array}{c}\text { Initiating } \\
\text { event L3 }\end{array}$ & $\begin{array}{c}\text { Top event } \\
\text { RR }\end{array}$ & $\begin{array}{c}\text { Top event } \\
\text { SC }\end{array}$ & $\begin{array}{c}\text { Top } \\
\text { event } \\
\text { FI }\end{array}$ & $\begin{array}{c}\text { Top event } \\
\text { LS }\end{array}$ & Damage state & $\begin{array}{c}\text { Sequence } \\
\text { ID }\end{array}$ \\
\hline
\end{tabular}

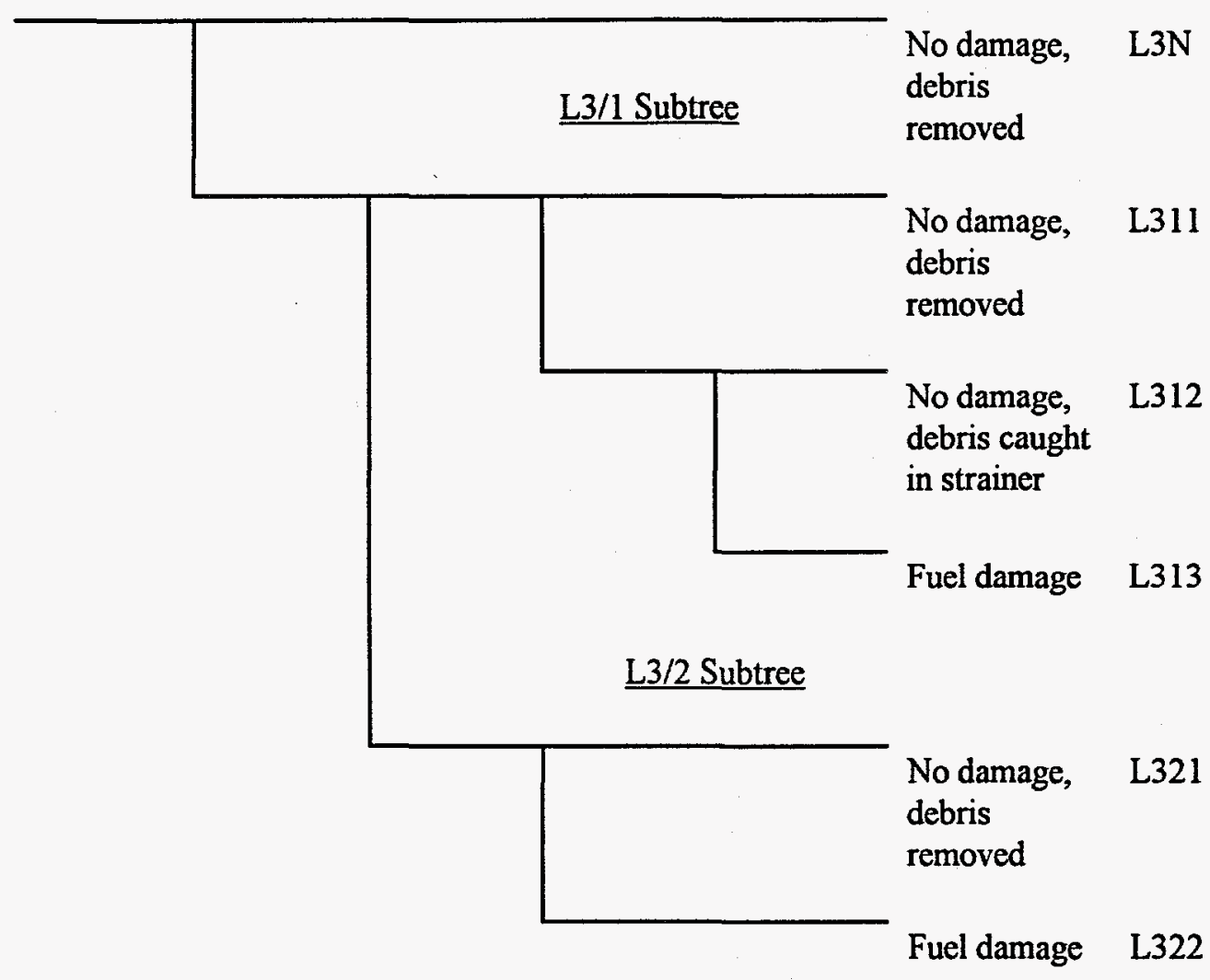

Fig. 3.7. L3 Scenario event tree.

from a failure in the inner control rod assembly or transuranic support assembly, which are also removed during refueling. ${ }^{12}$ With the fuel removed, any loose debris could land in either (1) one of three active loops, where it would either scenario L2; (2) the single inactive loop, where only a small flow exists to warm the loop; or (3) the "dead" region around the lower control rod assembly, where it could become entrained in the primary flow after loop startup because of the swirling action of the three active primary loops in this region. A prerefueling camera observation of the lower regions of the core region would increase the probability that any debris located in these areas be identified and removed.

It is also conceivable that some debris could be dropped following installation of fresh fuel elements. The space limitations of the CPBT (i.e., no dead spaces) are such that, once the upper core support structure is installed, any item dropped would likely be visible to inspection cameras and easily removed. In the event that the debris went unnoticed, it would become $\mathrm{Ll}$ material upon system startup and be analyzed under the rules of the $\mathrm{Ll}$ event tree. Because of the order in which parts are placed back into the reactor, there is a small chance that debris could sink down to the $\mathrm{L} 2$ area through the control rod region between the time the fuel is installed and the installation of the stack weldment.

During the refueling process, the facts that the CPBT is not open to the reactor pool and that there is no hands-on activity by the operators, as there is at HFIR, are a deterrent to the introduction of debris (badges, 
tape, plastic, etc). Items dropped after the fresh fuel elements have been installed in the reactor could be recognized and removed because they would most likely rest on top of a fuel element. Those on top of the outer element would be more readily seen than those on the lower element. Upon detection, a magnetic pickup or vacuum device could be used to effect removal. Top events $R R$ (recognition and removal), SC (scenario classification), and FI (final inspection) deal with these issues, and are discussed in detail in Sect. 4.3.

\subsection{SYSTEM DESIGN FEATURES TO PREVENT DEBRIS-INDUCED FLOW BLOCKAGE}

This section describes features in the ANS conceptual design that either are designed to or may reduce the likelihood of a flow blockage event. The primary loop strainers are the only one of these directly included in the model. Their contribution to reducing the flow blockage frequency is reflected in the experts' estimates. The unheated fuel element entrance region is credited in establishing the tolerable blockage size but is not modeled as a specific design feature. Figure 1.1 contains examples of each of these components.

\subsubsection{Pressure and Inventory Control System}

As modeled in Chap. 6 of the ANS PRA, ${ }^{11}$ the RPICS begins at the letdown control valves (PCV-XX$18 \mathrm{~A}, \mathrm{~B}, \mathrm{C}, \mathrm{D})$ and continues until the last check valve in the makeup line (V-0-006). Primary water passing through the letdown valves empties into the letdown tank, which also receives letdown from the reflector vessel cooling system (RVCS). A portion of the letdown tank inventory is cycled through a 4-in. line into the RPICS purification circuit for filtration, ion exchange, and chemical addition. The purification circuit ${ }^{13}$ depicts a series of strainers, pumps, filters, ion exchange tanks, and more filters prior to re-entering the letdown tank. Additionally, there are prestrainers to the makeup pumps to remove any debris and/or resin that might find its way into the letdown tank. The outlet side of these strainers is instrumented with pressure transmitters to indicate low pressure in the event of strainer blockage. The makeup pump prestrainer perforations should be sized to remove resin beads that could flow into the letdown tank because of failures in the purification system. It is assumed that procedural controls on the frequency and extent of strainer inspection, maintenance, and cleaning will be developed and used effectively.

\subsubsection{Reflector Vessel Cooling System}

This section is presented for information only. A strainer currently in the RVCS in the outlet line coming from the reflector vessel is scheduled to be removed after initial startup of ANS. Because of the potential to introduce foreign material during CPBT change-out and maintenance in the heavy water reflector vessel region, it may be beneficial for this strainer to remain as a permanent component of the RVCS and possibly to be instrumented similarly to the makeup pump prestrainers. A similar strainer might also be employed in the reflector vessel cooling inlet line.

\subsubsection{Primary Cooling System}

\subsubsection{Main Heat Exchangers}

Because of the close spacing $(\approx 12.7 \mathrm{~mm})$ of the cooling tubes in the primary heat exchangers, they could be considered as strainers for large objects. However, because of the potential for debris to re-enter the primary flow and the fact that debris that could cause problems is smaller than the tube spacing, the main heat exchangers are not considered as strainer-type devices. 


\subsubsection{Loop Strainers}

As discussed above in Sect. 3.3.1, the primary loop strainers are robustly constructed basket strainers with perforations of only $0.5 \mathrm{~mm}$ that strain out all particles (originating between the core outlet and the strainer itself) except those that could pass easily through the flow channels of a fuel element. Each loop is equipped with its own strainer to preclude the likelihood of flow starvation because of strainer blockage as a precursor to fuel damage. Currently, strainer blockage or plugging is indicated to the operators through the plant control and data acquisition system by high differential pressure across the strainer, but a small blockage would likely go undetected on pressure measurement alone. This is not a safety-related measurement, and the associated reactor coolant pump would continue to run. The alarm setpoint is not currently specified in project documentation, but, according to the primary cooling system designer, a $50 \%$ deviation from normal is generally accepted.

The ANS primary coolant system loop strainers have not yet been designed. However, it is known that they will likely be basket-type strainers with perforations of approximately $0.5 \mathrm{~mm}(0.02 \mathrm{in} .)^{14}$ or 625 holes per square inch of perforated metal ( $20 \%$ open area). In the ANS RPCS conceptual design calculations performed by Atomic Energy of Canada Limited, a strainer pressure drop of $28 \mathrm{kPa}$ (4.1 psi) was estimated using a wye-type strainer. Using this estimated pressure drop and the proposed allowable core damage frequency, the strainers can be designed such that the stress level is low enough that fatigue failure will not occur from the pressure oscillations caused by flow through the perforations. However, there will always be some likelihood for strainer failure, albeit very low. Therefore, to provide a quantifiable estimate of flow blockage and to introduce some conservatism into the analysis, the above mean failure frequency of $2.1 \times 10^{-3} / y e a r$ will be used as an unavailability of strainer function at any given time during the operating year.

Having a pump trip on high strainer differential pressure if the pressure reached $50 \%$ of the tested strainer burst pressure would protect both the pump and the strainer. A low differential pressure signal would also be useful in indicating a breach of strainer integrity or improper installation following repair or maintenance. Neither feature is currently incorporated in the design.

\subsubsection{Lower Core Support Structure}

The lower core support structure (LCSS) may be considered analogous to the flow distributor in HFIR in that it serves to give direction to flow entering the core region, but the similarities end at this point. The LCSS, shown in Fig. 1.1, can be thought of as three concentric cylinders with radial ribs between the inner and center cylinders and an evenly spaced sunburst pattern of ribs between the center and outer cylinders. The openings in these spaces are fairly large (the smallest being $\approx 1300 \mathrm{~mm}^{2}$ ), and thus no filtering action is given to this component for debris sizes smaller than $40 \mathrm{~mm}$ in effective diameter.

\subsubsection{Fuel Element Unheated Length at Core Inlet}

There is currently a 50-mm unfueled region at the inlet of each fuel element that allows for re-establishment of coolant flow behind debris. Current testing shows that coolant flow can be re-established within this region for blockages that cover up to $8 \mathrm{~mm}$ in effective diameter (see Sect. 3.1). 


\section{EVENT TREE QUANTIFICATION RESULTS AND ANALYSIS}

Once the preceding information is assembled, the following question remains to be answered in a quantifiable manner: Given the likelihood of debris being introduced into the primary system and the estimated ranges of debris sizes obtained through expert judgment, what is the likelihood that the loose material actually gets to the fuel to cause damage? The event trees (Figs. 3.4 and 3.7) are read from left to right, beginning with the initiating event. When coming to a top event, the success path continues to the right, while the failure path drops down. The success and failure frequencies are provided under each top event. For example, top event LS, the primary loop strainer, is available (succeeds) 0.998 of the time and is unavailable (fails) 0.002 of the time. The event sequence quantifications are a mathematical representation of the likelihood of each particular sequence's occurring. The sum of all event sequence probabilities for each event tree is equal to the scenario initiating-event frequency.

\subsection{CALCULATION OF THE L1 SEQUENCES}

The $\mathrm{Ll}$ scenario is analyzed using the event tree in Fig. 3.4. Following the initiating event (IE), with the frequency $\left(\phi=1.2 \times 10^{-3} /\right.$ year $)$, the top event used to define the potential L1 scenarios is top event LS, the probability of the loop strainer's physical integrity being unavailable at the time of the event. The most likely cause of this failure is a material flaw in the strainer itself that is aggravated into failure by the force of the primary flow. As stated previously, the unavailability of the strainer is estimated to be 0.002 .

There are only two sequences in the $\mathrm{Ll}$ event tree, one of which may lead to fuel damage. Sequence $\mathrm{L} 11$ involves a fully functional and available loop strainer. This blockage sequence does not lead to fuel damage, even in the unlikely event of complete strainer blockage (for up to two loops), because the remaining loop(s) are expected to provide adequate flow following a power reduction or scram.

As stated earlier, the initiating-event frequency for $\mathrm{Ll}$ includes the likelihood of debris being large enough to cause fuel damage. For illustrative purposes, suppose that the loop strainer has failed in such a manner as to allow debris to pass but that the debris is too small to cause any damage to the fuel (i.e., flow recovery behind the blockage is adequate to prevent critical heat flux) or that the debris passes on through. In this case, the differential pressure alarm for the failed strainer should notify the operators of the adverse strainer condition so that they can take appropriate action. The one $\mathrm{Ll}$ sequence resulting in fuel damage



Fig. 4.1. L1 flow blockage frequency leading to fuel damage. involves a strainer breach that has allowed more sizeable debris to pass on to the fuel.

As shown above in Fig. 4.1, the calculated mean core damage frequency (CDF) for $\mathrm{L} 1$ debris scenarios is $10^{-6}$ per year. The $95 \%$ confidence level is $3.4 \times 10^{-6}$ year, and the $5 \%$ confidence level is $2.5 \times 10^{-7}$ for the lognormal distribution. Additional statistical information is contained in Appendix G. 


\subsection{CALCULATION OF THE L2 SEQUENCES}

The initiating event L2IE represents the estimated frequency of debris originating from failures in the region between the respective operating loop strainers (inclusive) and the core inlet $\left(\phi=5.0 \times 10^{-5} / \mathrm{year}\right.$ ). This frequency also includes the likelihood of debris $>5 \mathrm{~mm}$. Any debris present in the idle primary loop is unlikely to be swept into active flow during normal operation and thus is not considered in the estimated frequency. The primary sources of debris in this region are (1) the loop strainer(s), (2) the loop isolation gate valve(s), and (3) the transuranic assembly. Because there is no "last-chance" barrier before the core inlet, L2 debris has a direct path to the fuel elements. The exception to this rule is debris with a profile $>40 \mathrm{~mm}$ perpendicular to the direction of flow; such debris could be restrained by the lower core support assembly. Of the three scenarios modeled in this analysis, L2 is by far the most crucial because there are very limited means to recognize and remove the debris before it causes damage. In this case, the best hope is to detect early fuel damage or precursors to it (possibly by using cladding failure detection) and scram the reactor as soon as possible to prevent or minimize fuel melting. The mean CDF for L2 scenarios is calculated to be $5.0 \times 10^{-5} /$ year.

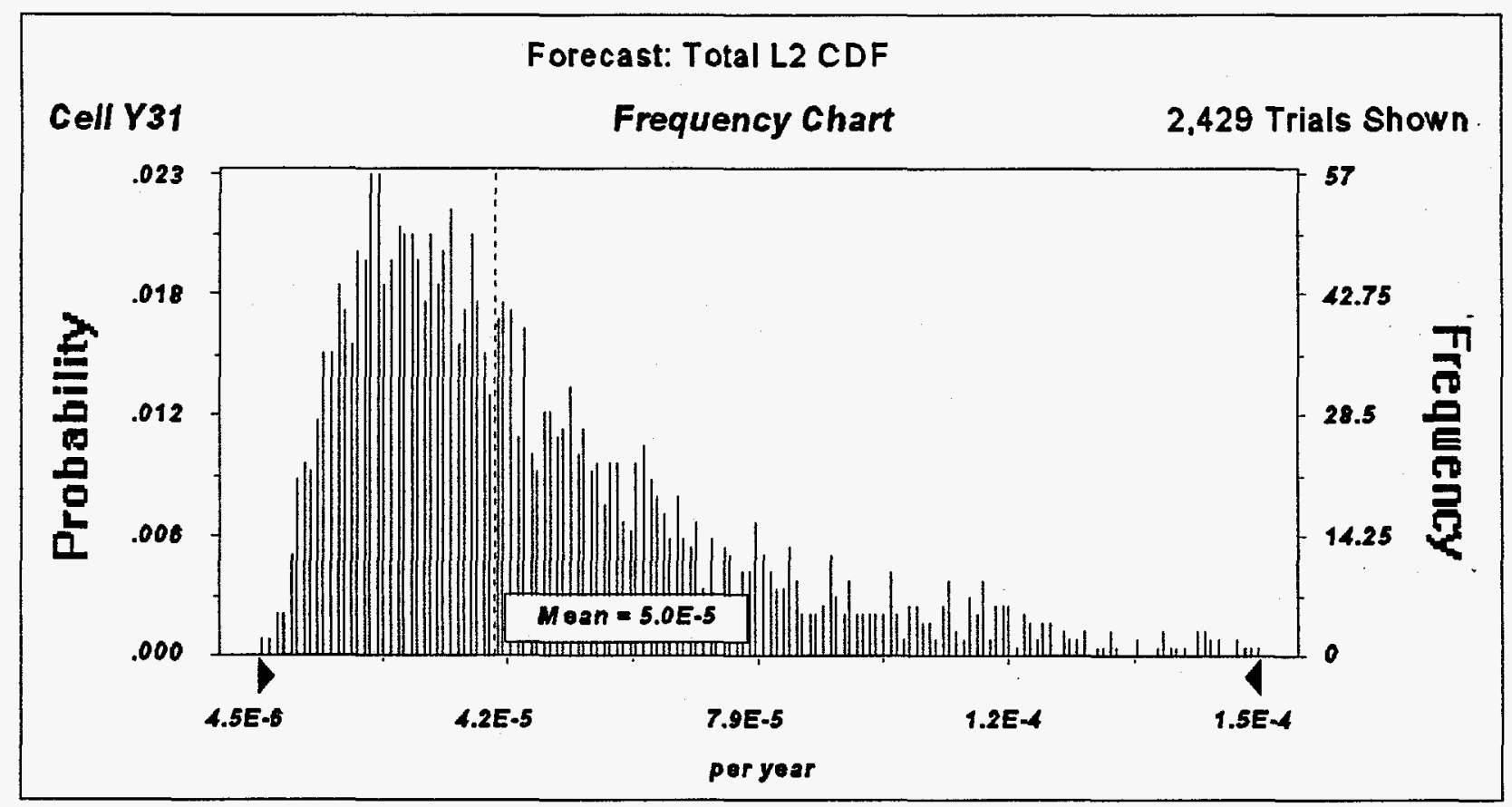

Fig. 4.2. L2 flow blockage frequency leading to damage.

The $95 \%$ confidence level is $1.2 \times 10^{-4} /$ year, and the $5 \%$ confidence level is $1.4 \times 10^{-5} /$ year. Additional statistical information is contained in Appendix G. Figure 4.2 shows the resulting distribution.

\subsection{CALCULATION OF THE L3 SEQUENCES}

The L3 scenario event tree combines the introduction of external debris ( $\phi=1.3 \times 10^{-4} /$ year) with the possibility for detection and removal. Three new top events appear at the beginning of each $\mathrm{L} 3$ sequence in addition to the top events already defined for $\mathrm{Ll}$ and $\mathrm{L} 2$ scenarios. The first of these new top events, RR, represents the likelihood that the introduction of the object or particle is recognized and that actions are taken to remove the material. The second new top event, SC, estimates the likelihood that the material would follow the L1 path through the hot leg or, depending on its point of introduction, sink to the lower portion of the 
primary system into the $\mathrm{L} 2$ scenario region. There is also the possibility that, after activity is completed and the system is closed, debris left in the system will manifest itself after loop circulation startup but prior to criticality. This third new top event is designated FI.

Three parameters were considered in estimating the likelihood to recognize and remove foreign debris (top event RR): (1) identified sources of debris and the potential for others, (2) limited number of paths of entry, and (3) anticipated scrutiny that activities will likely undergo because of the known consequences of flow blockage. In light of these conditions, top event RR was estimated by the author to be unsuccessful $10 \%$ of the time with a standard deviation of 0.05 .

Potential contributors to L3 events in the RPCS include component maintenance and inspection and injection with the makeup water from the letdown tank. The testing/maintenance/inspection (T/M/I) frequency for components in the primary system has yet to be established. As shown in Fig. 1.1, there are numerous components in the primary system that may will be subject to periodic $\mathrm{T} / \mathrm{M} / \mathrm{I}$; however, unless a complete replacement is being performed, the strainers are the only components likely to require opening the system for these procedures. Therefore, the frequency of $L 3$ initiators resulting from $T / M / I$ activity specific to the primary system is assumed to be at least equal to that estimated by the domain expert for failures that produce debris within the system $\left(6.5 \times 10^{-5} / \mathrm{year}\right)$. As $\mathrm{T} / \mathrm{M} / \mathrm{I}$ activities become better defined, this frequency will need to be reassessed.

The most likely operation whereby foreign debris could enter the primary system is during refueling (14 times per year) or during CPBT change-out (once per 2.5 years). Due to the essentially two phases (defueling and refueling) and the associated core internal activities that take place, it is estimated that any debris introduced during refueling operations has an equal chance (50/50) to become either an L1 or L2 event.

Debris present in the reflector vessel during CPBT change-out has potential to fall to the primary cooling core inlet supply area. This possibility is particularly strong for any debris near the base of the CPBT in the reflector region. Any perturbations in the heavy water behind the CPBT as it is removed would tend to draw particulates inward over the core region. No attempt is made to estimate the likelihood of debris in the reflector vessel or its being drawn into the core inlet region of the primary cooling system. Rather, the point is raised to illustrate another conceivable scenario. Operational and administrative countermeasures should be adopted to prevent such postulated scenarios from actually causing flow blockage.

Top event SC actually represents the frequency that external debris entering the primary system follows. the L1 path (SC is successful) or the L2 path (SC fails). All debris injected with the primary makeup will follow the $\mathrm{L} 1$ path, so it is excluded from the SC estimate. Because the injection of material from the RPICS would most likely take place during operation, the likelihood of recognition and removal is not credited. Consequently, makeup debris events are moved forward in the event tree to bypass top events SC and RR. The frequency of success of SC (debris following the $\mathrm{Ll}$ path) is estimated as follows.

Using the data in Table 4.1, the likelihood of top event SC succeeding and precipitating subscenario L3/1 can be calculated as $76 \%$. This path presupposes that the debris is not recognized and removed upon its initial introduction to the system ( $R R$ fails).

As stated previously, top event FI assesses the likelihood of debris manifesting itself after loop closure and circulation startup but prior to criticality (except as discussed for makeup). The manifestation could be acoustical noise, increase in strainer differential pressure because of the presence of debris, low strainer differential pressure if the strainer has failed, primary coolant pump trip if damage to the impeller has occurred, or realization by plant personnel that something was seen but mistakenly left in the system. In any case, a decision would be made as to whether or not the pumps should be stopped and the system reopened to try to retrieve the item(s). While not a certainty, it can be assumed that debris remaining in the system after closure is likely small in size. This is also true of any material introduced by RPICS during operation, except in the case of check valve internal failures or makeup pump prestrainers. Accordingly, the likelihood that the presence of significant debris is recognized at this time in the startup sequence is estimated at only $50 \%$, 
Table 4.1. Top event SC evaluation

\begin{tabular}{lccc}
\hline \multicolumn{1}{c}{ L3 Initiating event } & $\begin{array}{c}\text { Domain expert L3 } \\
\text { estimate }\end{array}$ & $\begin{array}{c}\text { Estimated fraction } \\
\text { becoming L1 }\end{array}$ & $\begin{array}{c}\text { Resulting L3/1 } \\
\text { frequency }\end{array}$ \\
\hline $\begin{array}{l}\text { Refueling and } \\
\text { maintenance activities }\end{array}$ & $2.2 \times 10^{-5}$ & 0.5 & $1.1 \times 10^{-5}$ \\
$\begin{array}{l}\text { Primary cooling system } \\
\text { from T/M/I) }\end{array}$ & $6.5 \times 10^{-5}$ & 0.85 & $5.5 \times 10^{-5}$ \\
$\begin{array}{l}\text { Total nonmakeup L3 } \\
\text { frequency }\end{array}$ & $8.7 \times 10^{-5}$ & & $6.6 \times 10^{-5}$ \\
\hline
\end{tabular}

regardless of its location, because of the realistic limits on what is detectable at full system flow. From this point in the L3 event tree, the sequences proceed as described earlier for the L1 or L2 scenarios, depending on top vent $\mathrm{SC}$.

The expected mean flow blockage frequency leading to fuel damage from L3 scenarios is $3.5 \times 10^{-7} /$ year. The $95 \%$ confidence level is $9.6 \times 10^{-7} /$ year, and the $5 \%$ confidence level is $6.1 \times 10^{-8} /$ year. Additional statistical information is contained in Appendix G. Figure 4.3 contains the resulting frequency distribution.

The $L 3 / 1$ sequences resulting in fuel damage are those involving a damaged strainer and debris $>5 \mathrm{~mm}$; the L3/2 fuel damage sequences depend on debris size alone. Any L3 sequences leading to damage must also escape recognition and removal.

To verify the results and the treatment of uncertainties from quantifying with Excel/Crystal Ball, additional simulations were run using RISKMAN. These exercises are presented in Appendix B. The conclusion drawn from the extra simulation results is that the Excel/Crystal Ball results are valid, if somewhat conservative, and that they properly treat uncertainty in combining the distributions.

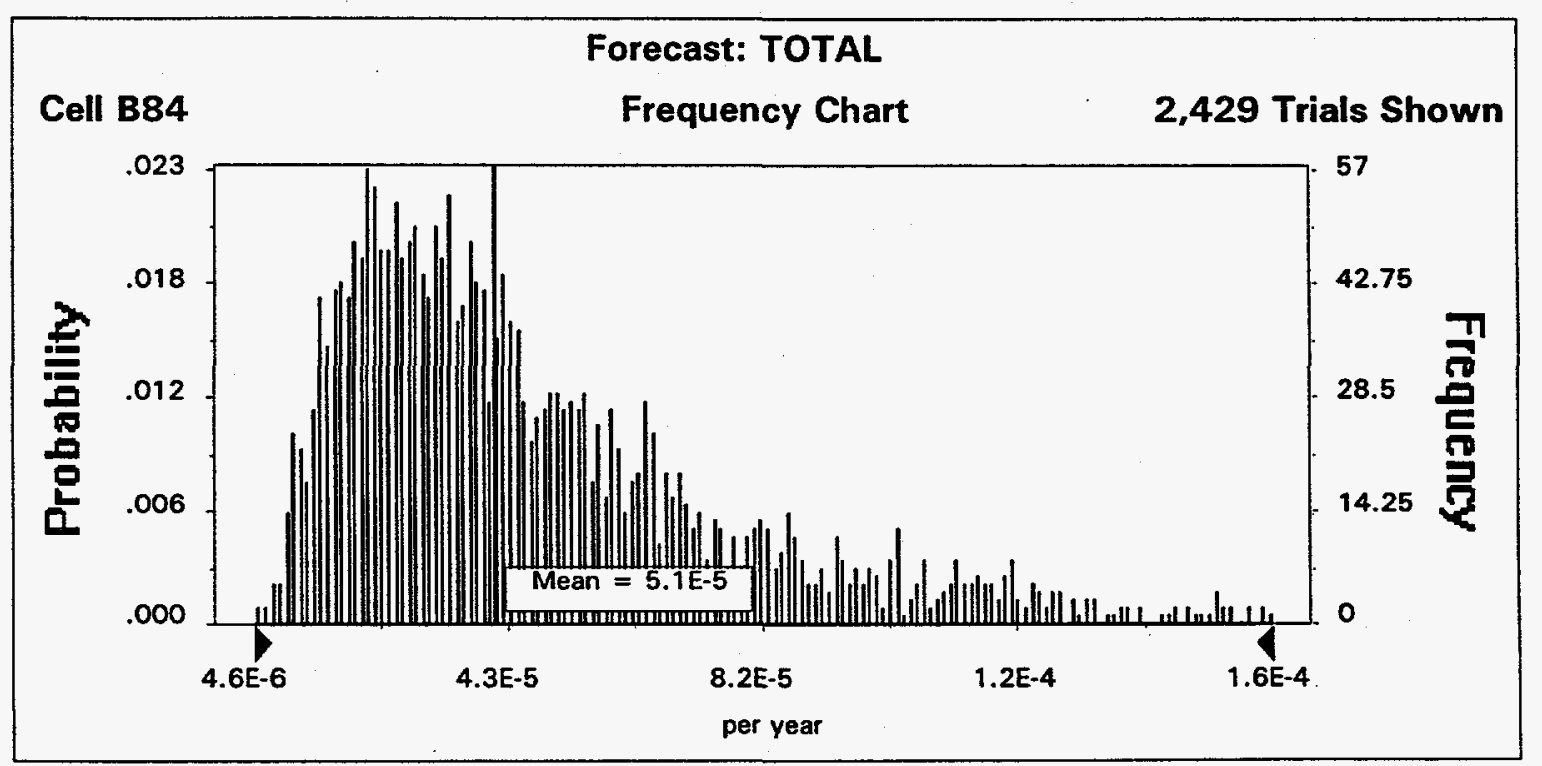

Fig. 4.3. L3 flow blockage frequency leading to fuel damage. 


\section{SUMMARY OF RESULTS}

\subsection{TWO-ELEMENT CORE DESIGN}

An analysis has been performed on the likelihood of core damage frequencies resulting from flow blockage to the two-element ANS core. The basis of this analysis rests on the elicitation of initiating event data from domain experts intimately involved with systems that could introduce foreign material into the primary coolant system. The experts estimated the frequency of failures resulting in debris and the possible size of such debris. These estimates then became the input for three event-sequence diagrams representing three different flow blockage scenarios called L1, L2, and L3, as described above. Available statistical data was used to for the failure probability distribution of the primary loop strainers. The sequence quantification results for the two-element core design are summarized in Table 5.1. Figure 5.1 shows the total distribution. including all scenarios.

Table 5.1. Summary of two-element core results

\begin{tabular}{lcc}
\hline Scenario & $\begin{array}{c}\text { Fuel damage } \\
\text { frequency }\end{array}$ & $\begin{array}{c}\text { Share of Total } \\
(\%)\end{array}$ \\
\hline L1 & $1.2 \times 10^{-6} /$ year & 2 \\
L2 & $5.0 \times 10^{-5} /$ year & 97 \\
L3 & $3.5 \times 10^{-7} /$ year & 1 \\
Total & $5.1 \times 10^{-5} /$ year & 100 \\
\hline
\end{tabular}

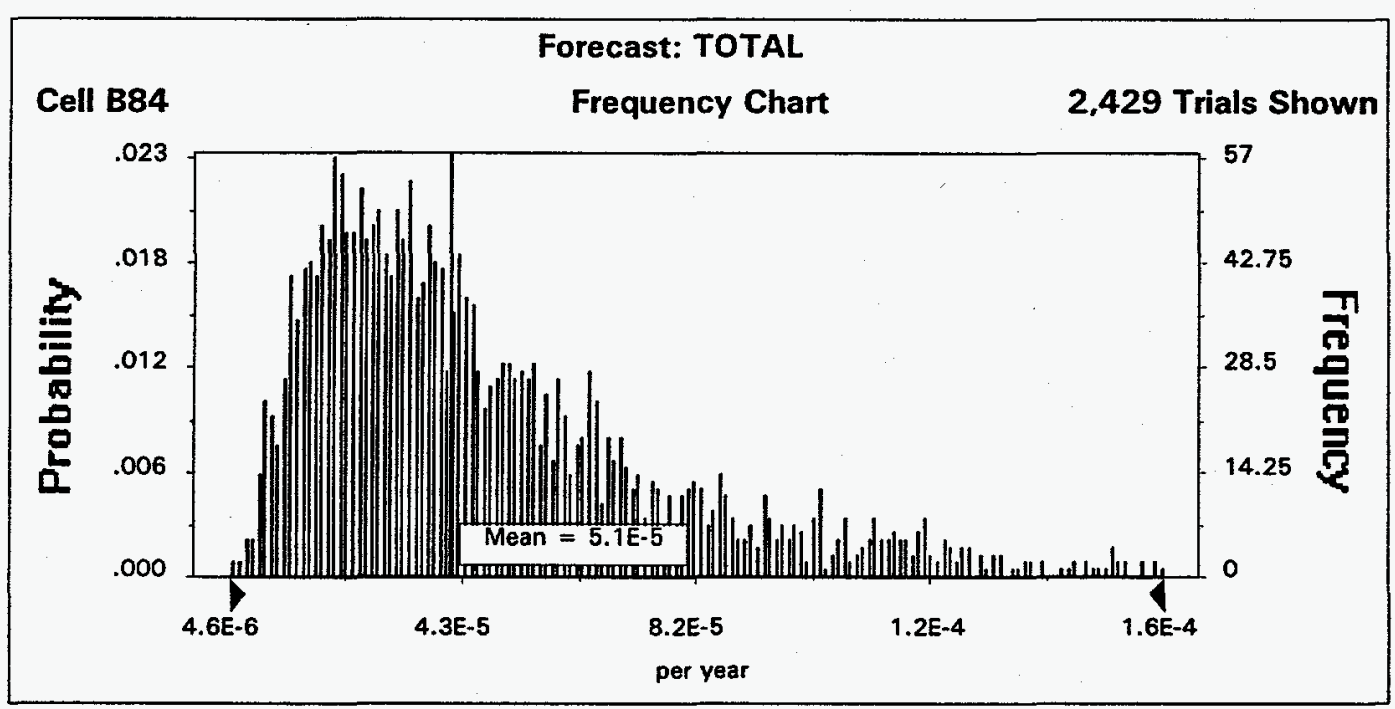

Fig. 5.1.Total flow blockage frequency leading to fuel damage for the twoelement core configuration. 


\subsection{THREE-ELEMENT CORE DESIGN}

All of the previous analysis pertained to the base case two-element, $93 \%$-enriched core configuration shown in Fig. 1.1. It was necessary to determine the core damage frequency due to flow blockage of the twoelement core, among other reasons, to gauge the risk-reduction worth of the three-element core (Fig. 5.2). The three-element core has a greater volume $(83 \mathrm{~L}$ rather than $67.3 \mathrm{~L}$ ), a lower power density, and likely lower enrichment than the two-element core. The safety margins are therefore expected to be larger, possibly allowing larger flow blockages before fuel damage occurs. To provide consistency and conservatism, the assumptions made previously for the two-element core were maintained in this estimation of the likelihood of core damage due to flow blockage to the three-element core. The same uncertainties apply as well.

As Fig. 5.2 shows, the transuranic assembly (TRU) has been relocated downstream of the core, eliminating the largest contributor in the L2 scenario as well as in the overall results of the two-element design. This assembly will likely be combined with the materials irradiation experiments to form a single large assembly with 30 transuranic target rods and 5 materials facilities. In the absence of a specific design concept for this combined assembly and knowledge of how it will be held together, the previous estimated distribution for the likelihood of debris-producing failures was used. Since the TRU is now in the $\mathrm{L} 1$ scenario region, there is no longer a direct path to the core for potential debris resulting from the presence of loop strainers.

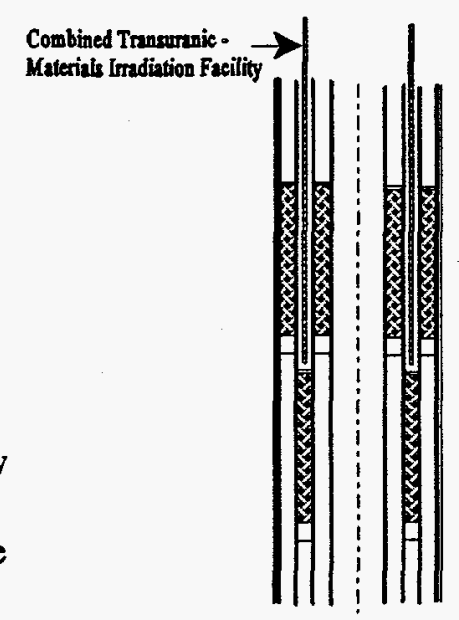

Fig. 5.2. ANS three-element core concept.

Table 5.2. Summary of three-element core results

\begin{tabular}{lcc}
\hline Scenario & $\begin{array}{c}\text { Fuel damage } \\
\text { frequency }\end{array}$ & $\begin{array}{c}\text { Share of total } \\
(\%)\end{array}$ \\
\hline L1 & $1.2 \times 10^{-6} /$ year & 26 \\
L2 & $2.9 \times 10^{-6} /$ year & 63 \\
L3 & $4.7 \times 10^{-7} /$ year & 11 \\
Total & $4.6 \times 10^{-6} /$ year & 100 \\
\hline
\end{tabular}

In the quantification run, the frequency of TRU failures was combined with the existing $\mathrm{Ll}$ contributors (primary cooling system, I\&C, inner control rod assembly), leaving only the after-strainer portion of the RPCS to contribute to the L2 scenario. The results are shown below in Table 5.2 and Fig. 5.3. A Crystal Ball simulation report containing more thorough statistical information is in Appendix $H$. With the TRU moved to the core outlet, the estimated mean likelihood of core damage is lowered by a factor of 10 to $4.6 \times 10^{-6} /$ year. This represents a $92 \%$ decrease in the mean CDF compared to that of the two-element design $\left(5.8 \times 10^{-5} /\right.$ year $)$. 
$5-3$

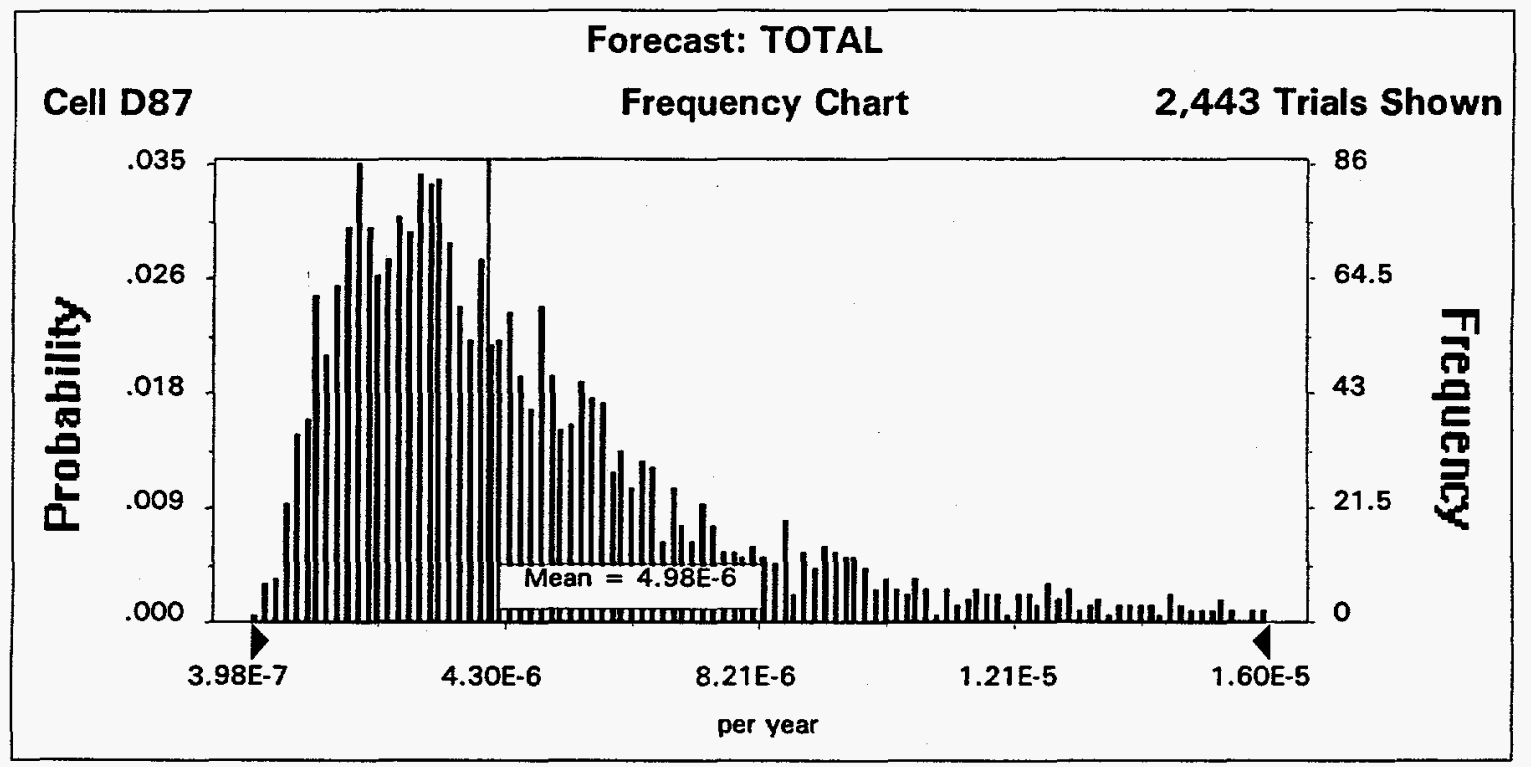

Fig. 5.3. Expected flow blockage frequency leading to fuel damage for the three-element core configuration. 



\section{CONCLUSIONS}

Regardless of the final design, this investigation shows that flow blockage is a possible event, albeit one of low probability but likely greater than $10^{-6}$ per year. The low frequency of occurrence is a result of a plant design that considers lessons learned from other reactors and attention to detail. Some relatively simple actions can be taken to help ensure that the frequency of fuel damage due to flow blockage remains low, such as a robust primary-loop strainer design, leaving in the RVCS strainer, sizing the makeup pump prestrainer perforations the same as those in the primary-loop strainers, debris inspection in the reflector vessel prior to CPBT removal, and adequate procedures restricting and tracking material allowed in areas where the primary system is open. These factors are not reflected in the analysis results but would demonstrate good practice in addressing the potential for debris and loose parts to cause flow blockage.

The results presented in Sect. 5 indicate an substantial advantage in using the three-element core design as opposed to the base case two-element configuration. Relocating the TRU downstream of the core provides a definite risk reduction. The primary advantages of using the three-element core are (1) the relocation of the transuranic targets to the core outlet rather than at the core inlet and (2) its lower power density because of the larger volume with either the original highly enriched fuel or a lower enrichment. These features make the three-element core able to tolerate larger blockages without damage than the two-element core can. If the twoelement core design is kept, attention should be devoted to equipment in the region between the loop strainers and the core inlet to reduce the likelihood of flow blockage and core damage. As stated in Sect. 3, the strainer can be designed such that its fatigue failure frequency is as low as deemed necessary. This strategy would leave the cold leg isolation gate valves, the weld beads, and the transuranic support assembly as the most likely contributors to flow blockage, assuming that the practices described in the preceding paragraph are implemented.

\subsection{POST SCRIPT-EVOLVING CHANGES AT ANALYSIS COMPLETION}

As this report was being completed, some new information was obtained from the ANS thermalhydraulic analysts related to the onset of fuel damage from flow blockages. In Sect. 3.1, fuel damage was related to the reattachment and reestablishment of a certain percentage of flow at some distance downstream from the blockage. Rationale for limiting blockages to $5 \mathrm{~mm}$ before assuming fuel damage was also given. Whereas the boundary of fuel damage was previously defined as $50 \%$ recovery length, the current conservative definition of the onset of fuel damage is when the surface temperature of the plate $\left(T_{\text {surf }}\right)$ is greater than the fluid saturation temperature $\left(T_{\text {sat }}\right)$ for the pressure at the same location. This definition is conservative because it assumes that any wall temperature greater than $T_{\text {sat }}$ will lead to bubble formation and thence to void formation. This is also conservative because the Fluent code used to predict surface temperatures has been benchmarked to underpredict heat transfer coefficients (and therefore overpredict surface temperatures) in the regions of separated flow. Preliminary results indicate that, with an outlet pressure of $1.7 \mathrm{Mpa}$ and a 50-mm unheated entrance length, no fuel damage $\left(T_{\text {surf }} \ngtr T_{\text {sat }}\right)$ occurs for inlet blockage sizes of $10 \mathrm{~mm}$. The onset of fuel damage occurs for blockages $10-21 \mathrm{~mm}$. This redefinition could

result in a 10 to $40 \%$ reduction in the mean frequency of fuel damage, which still lies within the first standard deviation of all scenarios (see Appendixes $G$ and $H$ ). 



\section{REFERENCES}

1. C. T. Ramsey, Phase I Probabilistic Risk Analysis of the Advanced Neutron Source Conceptual Design, ORNL/ANS/INT-50, Martin Marietta Energy Systems, Inc., Oak Ridge Natl. Lab., February 1995.

2. D. H. Johnson et al., High Flux Isotope Reactor Probabilistic Risk Assessment, ORNL/RRD/INT-36/R1, Martin Marietta Energy Systems, Inc., Oak Ridge Natl. Lab., August 1991.

3. Excel, Version 4 [computer program], Microsoft Corporation, Redmond, Wash., 1993.

4. Crystal Ball, Version 3.0 [computer program], Decisioneering, Inc., Denver, 1993.

5. RISKMAN-PRA Workstation Software [computer program], PLG, Inc., Newport Beach, California, 1993.

6. Crystal Ball, Version 3.0, Decisioneering, Inc., Denver, 1993.

7. N. J. McCormick, Reliability and Risk Analysis, Academic Press, Inc., Orlando, Fla., 1981.

8. D. L. Selby et al., Advanced Neutron Source (ANS) Project Progress Report: FY 1994, ORNL 6821, Martin Marietta Energy Systems, Inc., Oak Ridge Natl. Lab., January 1995.

9. ANS System Design Descriptions, ORNL/ANS/INT-26/S31-S34, S36, S44, S61 (Sects. 611-13), S64 (Sect. 641)/R0, Martin Marietta Energy Systems, Inc., Oak Ridge Natl. Lab., 1992.

10. C. H. Blanton and S. A. Eide, SRP Generic Data Base Development (U), WSRC-TR-93-262, Westinghouse Savannah River Co., Aiken, S.C., June 1993.

11. A. Rittenhouse, Advanced Neutron Source Transuranic Production Support Assembly, Machine Kinetics Corp., Knoxville, Tenn., November 1993.

12. Ref. 9, S32.

13. Drawing J3E017026A002, Rev. A, Sheet 1 in Ref. 9, S612.

14. Sect. 2.2.2.3 or Ref. 9, S61. 



\section{GLOSSARY}

The terms and expressions in this appendix are used frequently in the flow blockage analysis for the ANS. They are included here to provide better understanding of their intended meaning in the text of the report.

discrete-probability distribution-a set or range of discrete probability bins that are believed to bound the actual statistical properties of a given frequency. When coupled with probability of frequency estimates, a histogram of the frequency can be obtained.

end State - the plant condition (e.g., core damage) following a specific event sequence.

event Sequence - one of possibly many combinations (paths) of top event successes and failures, beginning with the initiating event and progressing through an event tree to a specific end state.

event Tree-a graphical representation of the possible event sequences following an initiating event. An event tree is usually scenario-specific unless the plant response to several initiating events is approximately the same.

expert judgment-a frequently used method of estimating the rate of occurrence of a rare event based on the state of knowledge of a panel of experts or specialists in the area of concern. In this study, the experts used the probability-of-frequency concept in a discrete probability distribution.

initiating event-an occurrence that sets into motion one or more event sequences based on inherent system characteristics or capabilities, as modeled in top events.

probability of frequency - the likelihood that the subject frequency, as estimated by the experts, is indeed the actual frequency. Similar to a confidence level.

scenario-Here, a set of event sequences characterized by a particular initiating event and of unique responses associated with that event.

top event - the availability or likelihood of failure of a system component or function in an event tree. 

Appendix A

FLOW BLOCKAGE DEBRIS DATA BASE 

The information in the attached spreadsheet was provided by the responsible ANS system design engineers. The compilation of this data (i.e., identification of possible debris for flow blockage considerations) was the first step taken in beginning the ANS design-specific flow blockage analysis. Items are listed by system. The primary goal of this exercise was to identify potential debris in the existing design, its likely path to the primary system, and any barriers (filters, strainers, etc.) between the point of failure and the primary system or fuel. Debris material, estimated size, and estimated mass are also included where design information was available. Generally, sizes ranged from $<1 \mathrm{~mm}$ to several centimeters, with the majority being $>1 \mathrm{~cm}$. From a material standpoint, all identified debris except for charcoal and resin in the detritiation system is metallic. The detritiation system is not expected to contribute to the risk of flow blockage because of the number of barriers between it and the primary system. Also listed is the most likely method that the debris would manifest its presence or would be detected. Those objects $>5 \mathrm{~mm}$, few if any barriers, and low detectability (e.g., screws and fasteners from the refueling system) are considered higher risks than those that must pass through two or more barriers to enter the primary system (e.g., debris from the detritiation system). This information was provided, without any mention of risk or likelihood, to the domain experts as a reminder of the potential debris that could originate from their system(s). 


\begin{tabular}{|c|c|c|c|c|c|c|c|c|c|}
\hline 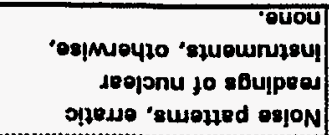 & 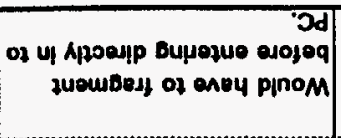 & 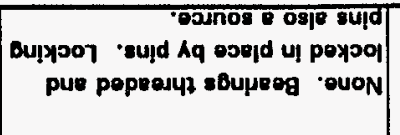 & mb & wotxol & ग्यापवल्गण & हारा & Poy |वरणOS douU| & 081 & 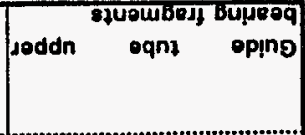 \\
\hline 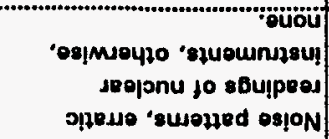 & פem mo|l כd oxul & 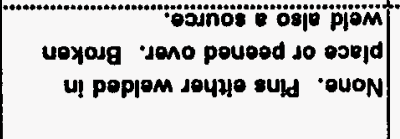 & "ü & تïzXs ó & "jöüosuij & हi) & 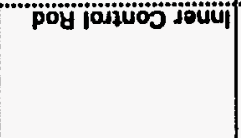 & 081 & 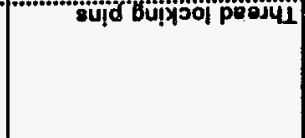 \\
\hline 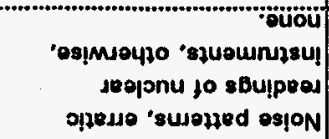 & 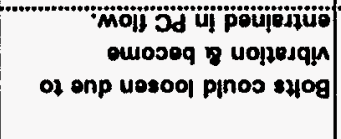 & 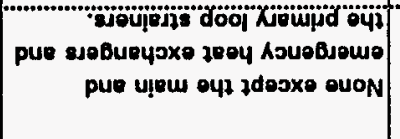 & 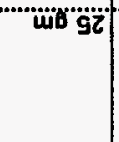 & "iijo $\varepsilon \times i \times i$ & | & (7) & pö iojiüoj joüüi & 081 & $\begin{array}{l}\text { pus syoq jusuyjorne } \\
\text { Ouyds Hoddns leddn }\end{array}$ \\
\hline 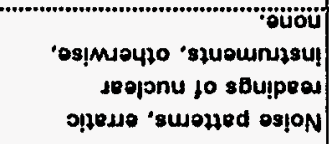 & 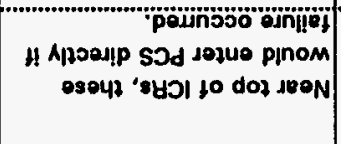 & 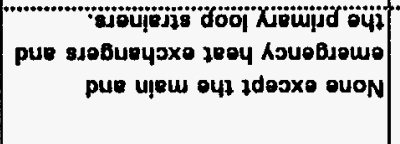 & "iibosit & $\begin{array}{r}136 \\
\times 9.1 \times 9.1\end{array}$ & "äuัöวัüi & हो & 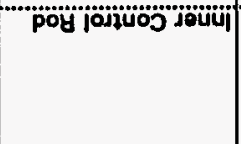 & 081 & 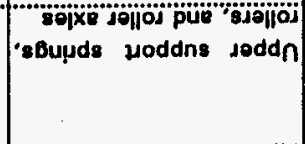 \\
\hline 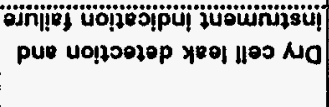 & aooj & dool pue uB!sep to ssoujsnqoy & & $\mid \begin{array}{r}\text { ww osz-0oz } \\
x \text { p!p wwitio }\end{array}$ & s9ojụpus & ziิ & 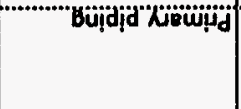 & Sdy & 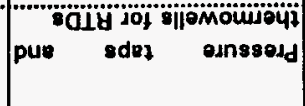 \\
\hline 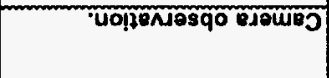 & 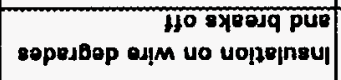 & outon & oz & & 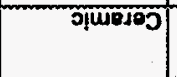 & 17 & peo4 1002 Bu!pontoy & penjoy & पọpo|nsu| \\
\hline 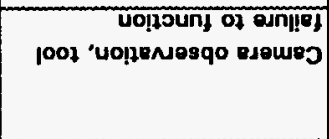 & 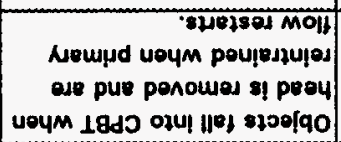 & OUON & og & & POMIN| & 17 & opmateopent & jonjoy & 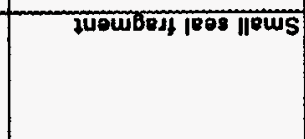 \\
\hline 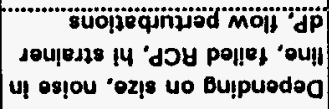 & soüij üмöpioj & 'sdund 'sse8ueyjxo zeeY SJdY & & & 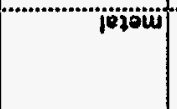 & Z̈iิ & $\begin{array}{l}\text { "e obseyos!p } \\
\text { wost SJIdy }\end{array}$ & sody & 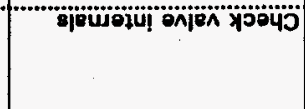 \\
\hline $\begin{array}{l}\text { dp jouịeits "Moij } \\
\text { dool mol 'os!ou ९q!pn }\end{array}$ & 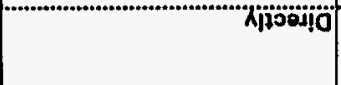 & 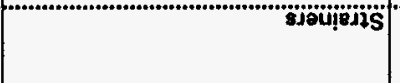 & & & | & zii & $\begin{array}{l}\text { objeyosip } \\
\text { dund SOdY }\end{array}$ & sody & 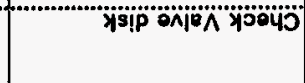 \\
\hline oúon & 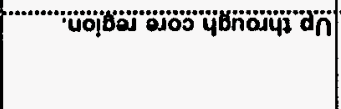 & 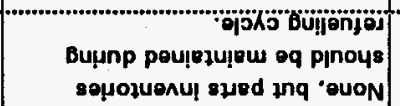 & & & 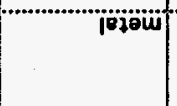 & เi7) & 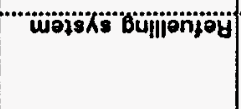 & SOdY & 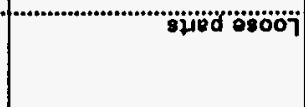 \\
\hline 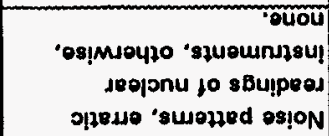 & & ouा! 9!47 20 oUON| & & & 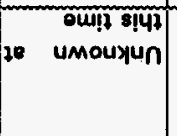 & 17 & spoi 10 s|001 & 081 & 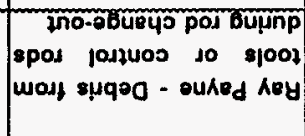 \\
\hline 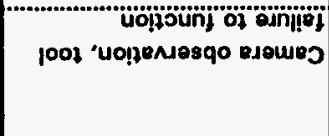 & 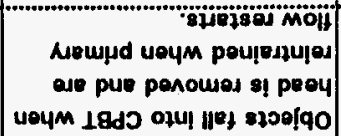 & oq plnom No\}uөлu! sนed 'ouon & $60 i$ & & ssopulpis & "iii & peou & jenjoy & 'sbup Bu!n!pjos 'Modos \\
\hline roppoppr sogea & 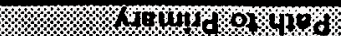 & 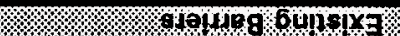 & sesens & axis: & To1910W & ondupos: & oomos: & 140184 & พผ1 \\
\hline
\end{tabular}




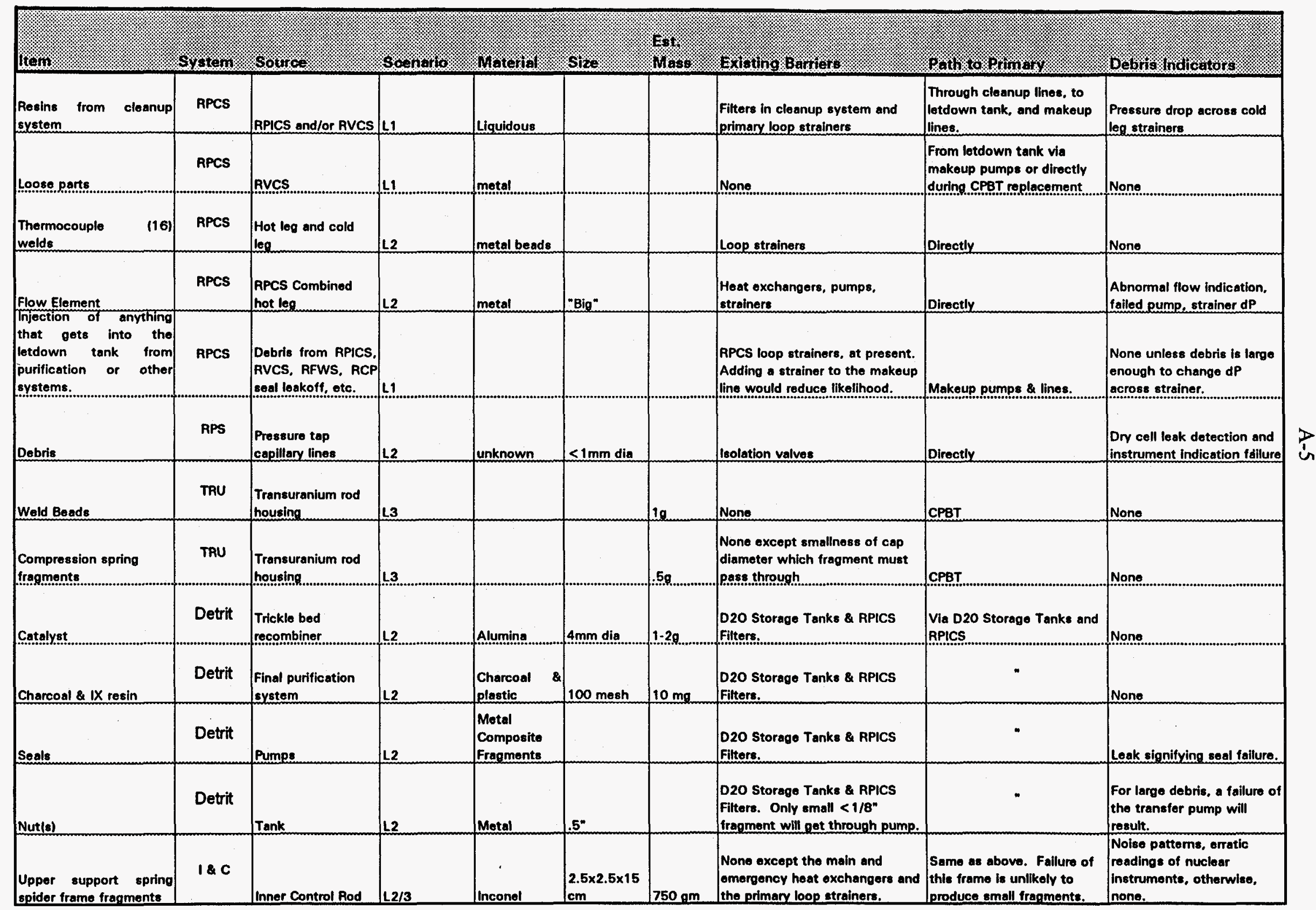




\begin{tabular}{|c|c|c|c|c|c|c|c|c|c|}
\hline iten & systent & sotroo & $80018 r 10$ & Wateria & sizo & Nass & Existing Barrat & Poth to primots & Debrts naloworor \\
\hline $\begin{array}{l}\text { ICR drive shaft } \\
\text { disconnect bolts and } \\
\text { springs }\end{array}$ & $1 \& \mathrm{C}$ & Inner Control Rod & $L 2 / 3$ & $\begin{array}{l}\text { Inconel \& } \\
\text { steol }\end{array}$ & $\begin{array}{l}2 \mathrm{~cm} \text { dia } x \\
20 \mathrm{~cm} \text { long }\end{array}$ & $500 \mathrm{gm}$ & $\begin{array}{l}\text { None. Bolts locked into place. } \\
\text { Springs can't enter flow unless } \\
\text { bolt fails. }\end{array}$ & $\begin{array}{l}\text { Directly into PC flow. } \\
\text { Failure of these locking } \\
\text { balts is unlikely. }\end{array}$ & $\begin{array}{l}\text { Nolse patterns, erratic } \\
\text { readings of nuclear } \\
\text { instruments, otherwise, } \\
\text { none. }\end{array}$ \\
\hline $\begin{array}{l}\text { Acceleration and } \\
\text { deceleration spring } \\
\text { fragments }\end{array}$ & $1 \& C$ & Inner Control Rod & L2 & $\begin{array}{l}\text { Stainless } \\
\text { Steel }\end{array}$ & $\begin{array}{l}1 \mathrm{~cm} \text { dia } x \\
10 \mathrm{~cm} \text { long }\end{array}$ & $50 \mathrm{gm}$ & $\begin{array}{l}\text { Bocause springs normally break } \\
\text { into only two pieces, } \\
\text { fragmentation unlikely. Would } \\
\text { be captured by other hardware. }\end{array}$ & $\begin{array}{l}\text { Would have to escape other } \\
\text { hardware before ontering } \\
\text { PCS. }\end{array}$ & $\begin{array}{l}\text { Noise pattems, erratic } \\
\text { readings of nuclear } \\
\text { instruments, otherwise. } \\
\text { none. }\end{array}$ \\
\hline 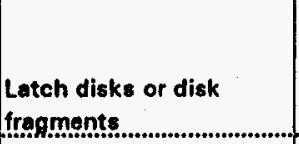 & $18 \mathrm{C}$ & Inner Control Rod & 1.2 & $\begin{array}{l}\text { Stellite } \\
\text { ceramic. }\end{array}$ & or $1.4 \mathrm{~cm}$ dia $x$ & $5 \mathrm{gm}$ & $\begin{array}{l}\text { Captured by control rods. } \\
\text { Unless control rod id ejected. } \\
\text { disk will stay. in place. }\end{array}$ & $\begin{array}{l}\text { Virtually Impossible due to } \\
\text { location and surrouding } \\
\text { hardware. }\end{array}$ & $\begin{array}{l}\text { Noise pattems, erratic } \\
\text { readings of nuclear } \\
\text { instruments, otherwise. } \\
\text { none. }\end{array}$ \\
\hline Strainer. Bagkets & RPCS & Each loop & L.3. & metal. & & & None. & Directly. & Low strainer dp \\
\hline $\begin{array}{l}\text { Gate valve (4 per loop) } \\
\text { internals }\end{array}$ & RPCS & $\begin{array}{l}\text { Pump suction and } \\
\text { discharge }\end{array}$ & 12 & metal & & & $\begin{array}{l}\text { None for discharge valves: } \\
\text { Pumps, hx \& strainers for } \\
\text { suction valves. }\end{array}$ & $\begin{array}{l}\text { Directly, but more likely to } \\
\text { bo ejected from valvo body } \\
\text { than to entor system. }\end{array}$ & Strainer dP \\
\hline Gate valve (4) Internals & RPCS & RPICS.. & 1.2 & metal. & & & $\begin{array}{l}\text { Makeup pumps, APCS strainers, } \\
\text { heat exchangers }\end{array}$ & letdown lines. & $\begin{array}{l}\text { Failed pump thot leg } \\
\text { valves), high strainer dP. } \\
\text { logp.flow. }\end{array}$ \\
\hline Pump (2) impellers & RPCS & RPICS. & & metal. & & & $\begin{array}{l}\text { Makeup pumps, RPCS strainers. } \\
\text { heat exchangers }\end{array}$ & letdown lines. & Failed makeup pump.... \\
\hline Flow element fragment & RPCS & APICS & 12 & metal & & & $\begin{array}{l}\text { RPCS heat exchangers. pumps, } \\
\text { strainers. }\end{array}$ & Letdown line: & $\begin{array}{l}\text { Nono unless large onough } \\
\text { to raise strainer dP. }\end{array}$ \\
\hline $3 / 4^{\prime \prime}$ valves (3) & RPCS & RPICS & $L 2$ & metal & & & $\begin{array}{l}\text { RPCS heat exchangers, pumps, } \\
\text { strainers. }\end{array}$ & Letdown lines & $\begin{array}{l}\text { None unless large enough } \\
\text { to raise strainer dP. }\end{array}$ \\
\hline Upper retaining ring: & TRU & $\begin{array}{l}\text { Transuranium rod } \\
\text { housing................... }\end{array}$ & L.3. & & & & Welded to oach tranguranic rod. & CPBT & None \\
\hline Single transuranic rod. & TRU & $\begin{array}{l}\text { Transuranium rod } \\
\text { housing }\end{array}$ & 13 & & & & $\begin{array}{l}\text { Each rod is circumironcially } \\
\text { welded to the upper as well as } \\
\text { the lower retaining rings. }\end{array}$ & CPBT & Nono \\
\hline
\end{tabular}


Appendix B

QUANTIFICATION USING RISKMAN AND UNCERTAINTY TREATMENT EVALUATION 



\section{Appendix B. QUANTIFICATION USING RISKMAN AND UNCERTAINTY TREATMENT EVALUATION}

In observing the final Crystal Ball quantification results (Fig. B.1) there was some question as to the method used to combine uncertainty distributions in the equations: Were the distributions actually merged or were the Monte Carlo samples from each iteration simply added? Specifically, the total core damage distribution does not seem to reflect the lower portion of the L1 and L3 core damage distributions. The DATAMAN and system analysis modules of RISKMAN (RM) were employed to answer this question. Initially, the spreadsheet results for each scenario (L1, L2, L3) from Crystal Ball (CB) were input (using the 5\% and 95\% values) to DATAMAN to generate individual lognormal distributions. These three distributions (L1CDF, L2CDF, L3CDF) were then merged* into a single distribution, CPFBT, to approximate the total frequency. Figure B.2 displays the probability density curve of each scenario as well as the merged total. Note the bimodal distribution that occurs for the total flow blockage frequency and the coverage of over four orders of magnitude in uncertainty. This is a result of merging two distributions where the mean values are separated by two orders of magnitude and have approximately the same frequency of occurrence within the sampling process. Additionally, the combination of lognormals results not in a subsequent lognormal but in an approximate distribution that has statistical properties similar to those of a lognormal.

In addition to using the Monte Carlo data merge, the event tree models were translated into a single large fault tree model in the RM system analysis module (see Fig. B.3). To do so, all data used in the spreadsheet were used to create distributions in the DATAMAN module. Figure B.4 shows the two-element core fault tree Monte Carlo quantification results (2500 iterations) in the same manner that Fig. B. 2 displays the $C B$ merged data. The total fault tree core damage distribution is similar in mean value to the original spreadsheet results $\left(\approx 5 \times 10^{-5}\right)$ and similar in uncertainty to the merged distribution $\left(1 \times 10^{-7}\right.$ to $\left.1 \times 10^{-4}\right)$ as shown in Table B.1. It also appears that the minimal impact of lower frequency scenarios in the total distribution is similar between CB and the fault tree results, as the final distribution most resembles the most frequent values, L2. Figure B.5 shows the three-element fault tree results compared to the two-element fault tree results. Note the marked absence of the peak in the three-element results when the transuranic support assembly is moved downstream of the core.

Table B.1. Statistical properties for flow blockage frequencies (two-element core)

\begin{tabular}{lccc}
\hline \multicolumn{1}{c}{ Method } & $\begin{array}{c}\text { Mean annual } \\
\text { frequency }\end{array}$ & 5th Percentile & 95th Percentile \\
\hline Spreadsheet results & $5.8 \times 10^{-5}$ & $1.6 \times 10^{-5}$ & $1.5 \times 10^{-4}$ \\
Merge of scenario data & $2.0 \times 10^{-5}$ & $1.7 \times 10^{-7}$ & $9.7 \times 10^{-5}$ \\
Fault tree quantification & $5.6 \times 10^{-5}$ & $5.6 \times 10^{-7}$ & $4.2 \times 10^{-4}$ \\
\hline
\end{tabular}

As a result of this exercise, it appears that, while the original spreadsheet quantification results tend to be somewhat more conservative in accounting for low frequency scenarios, the mean frequency of $\approx 5.8 \times 10^{-5}$ per year is consistent with the other methods.

"Merging: The RISKMAN merge operation is a Boolean OR operation that creates a new event $Q$, where $Q=X+Y+Z$. Note that this new event $Q$ is not equal to the union, $U$, of $X, Y$, and $Z$. Thus, $Q$ will always slightly overstate the $\mathrm{OR}$ results in some manner (e.g, due to possible double counting of overlapping tails) and will be strongly affected by the event with the largest probability values (L2 in this case). 

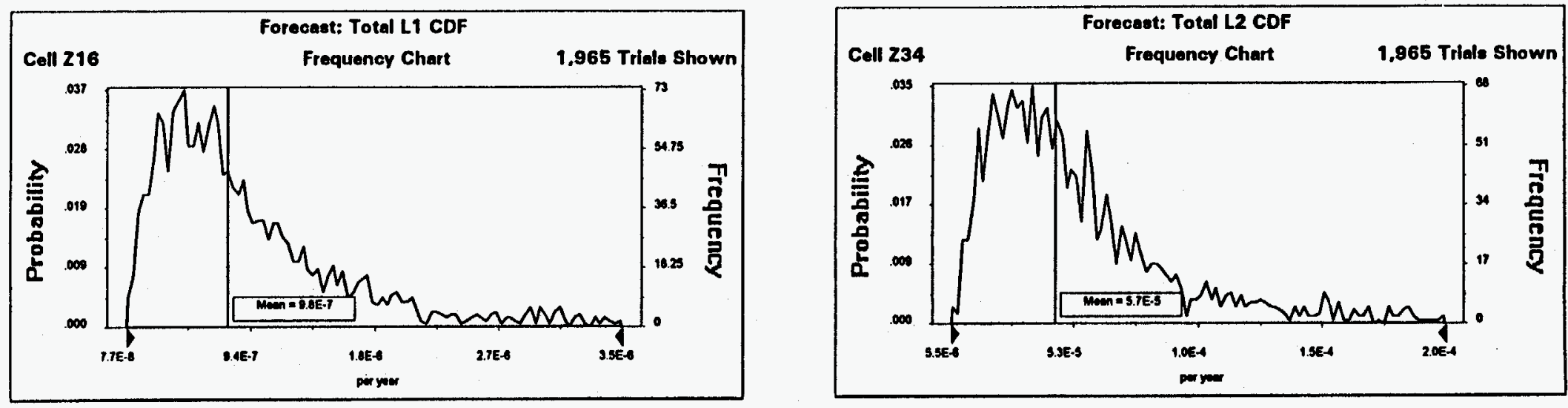

$\underset{1}{\infty}$
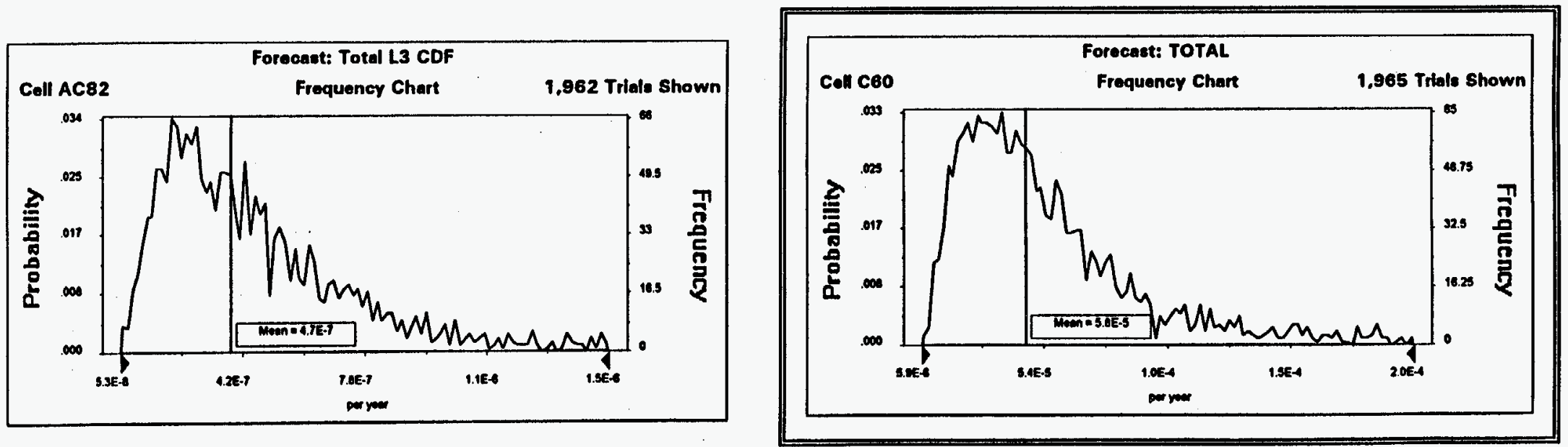

Fig. B.1. Final Crystal Ball quantification results. 


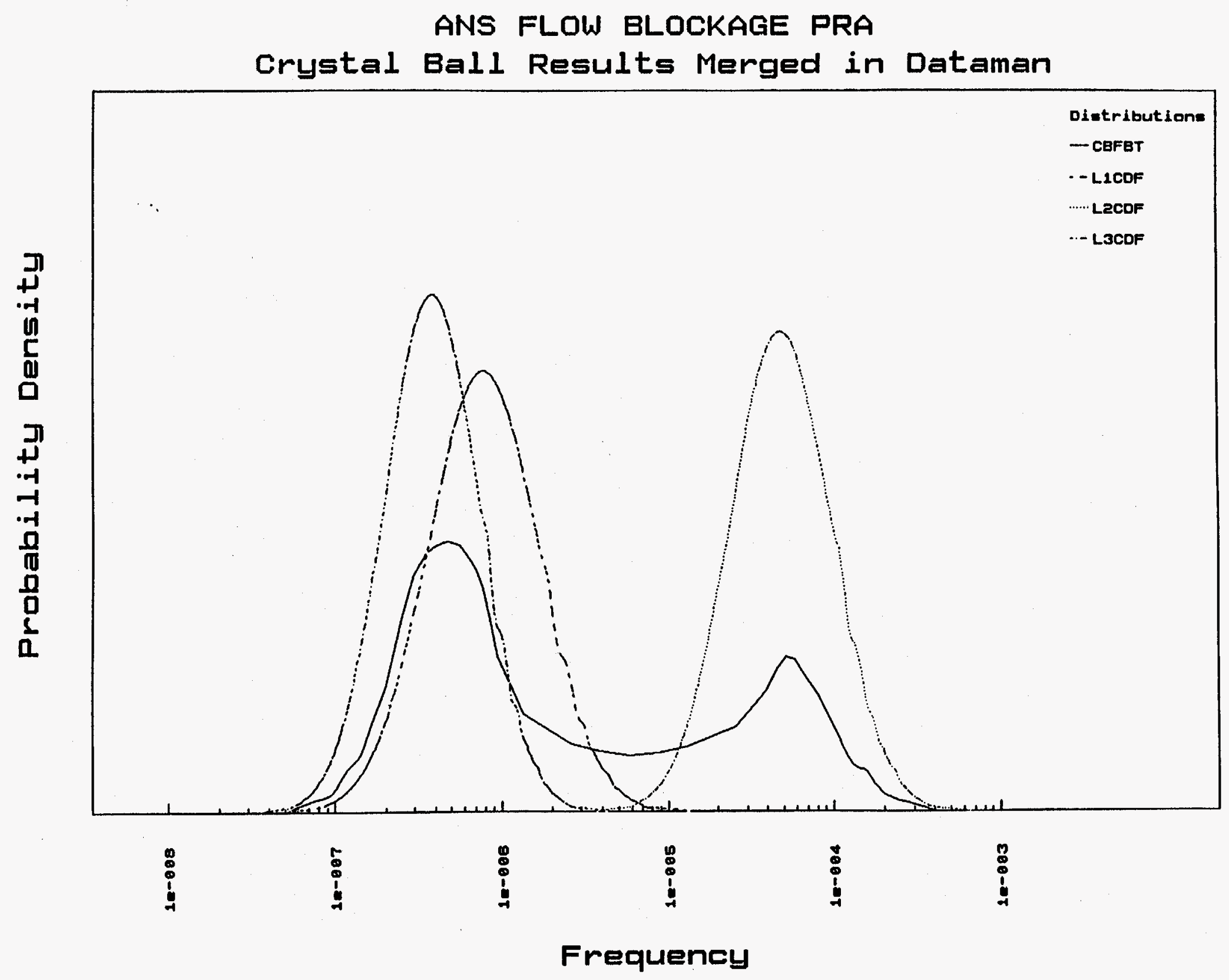

Fig. B.2. Crystal Ball results merged in DATAMAN. 


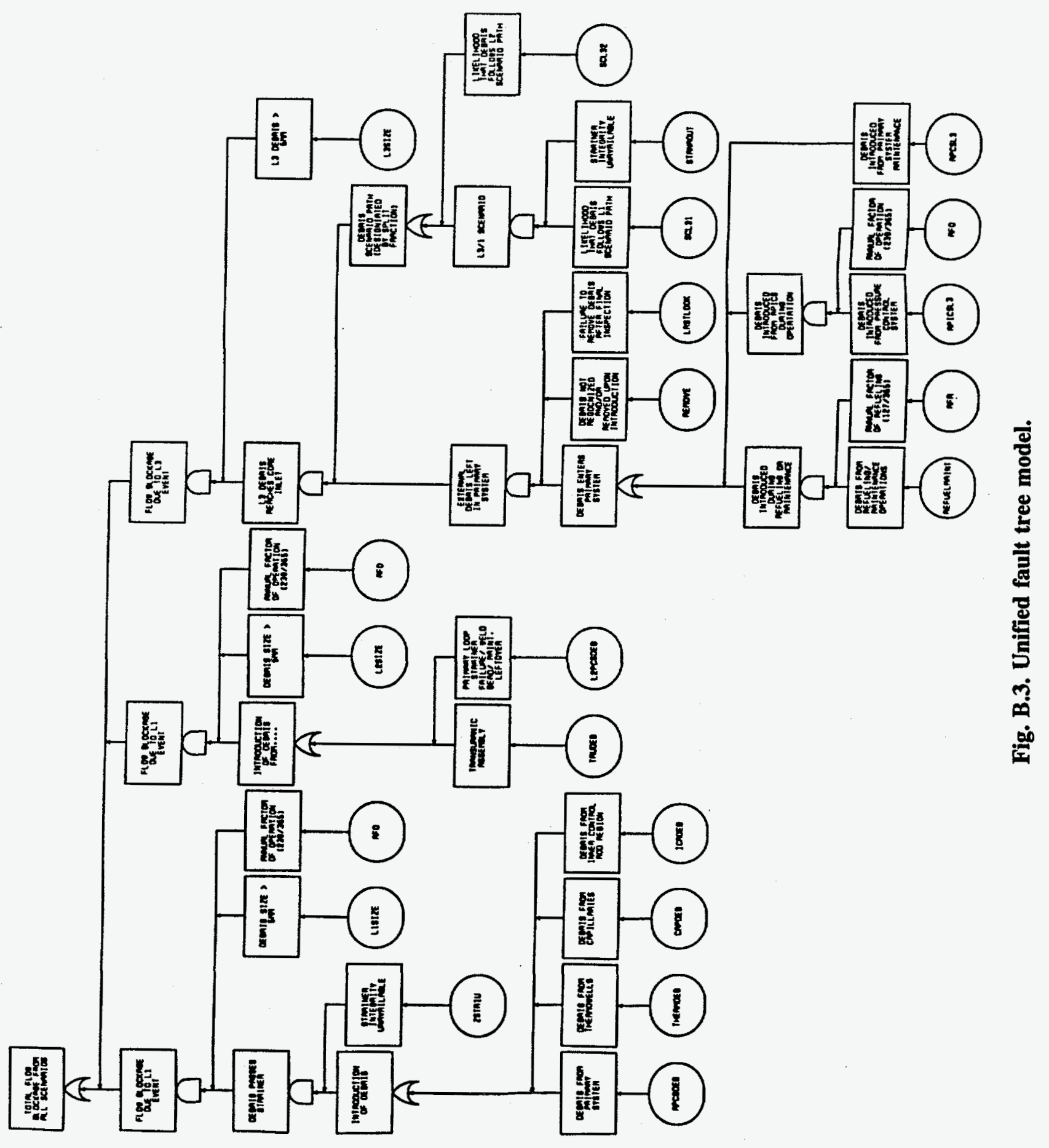


B-7

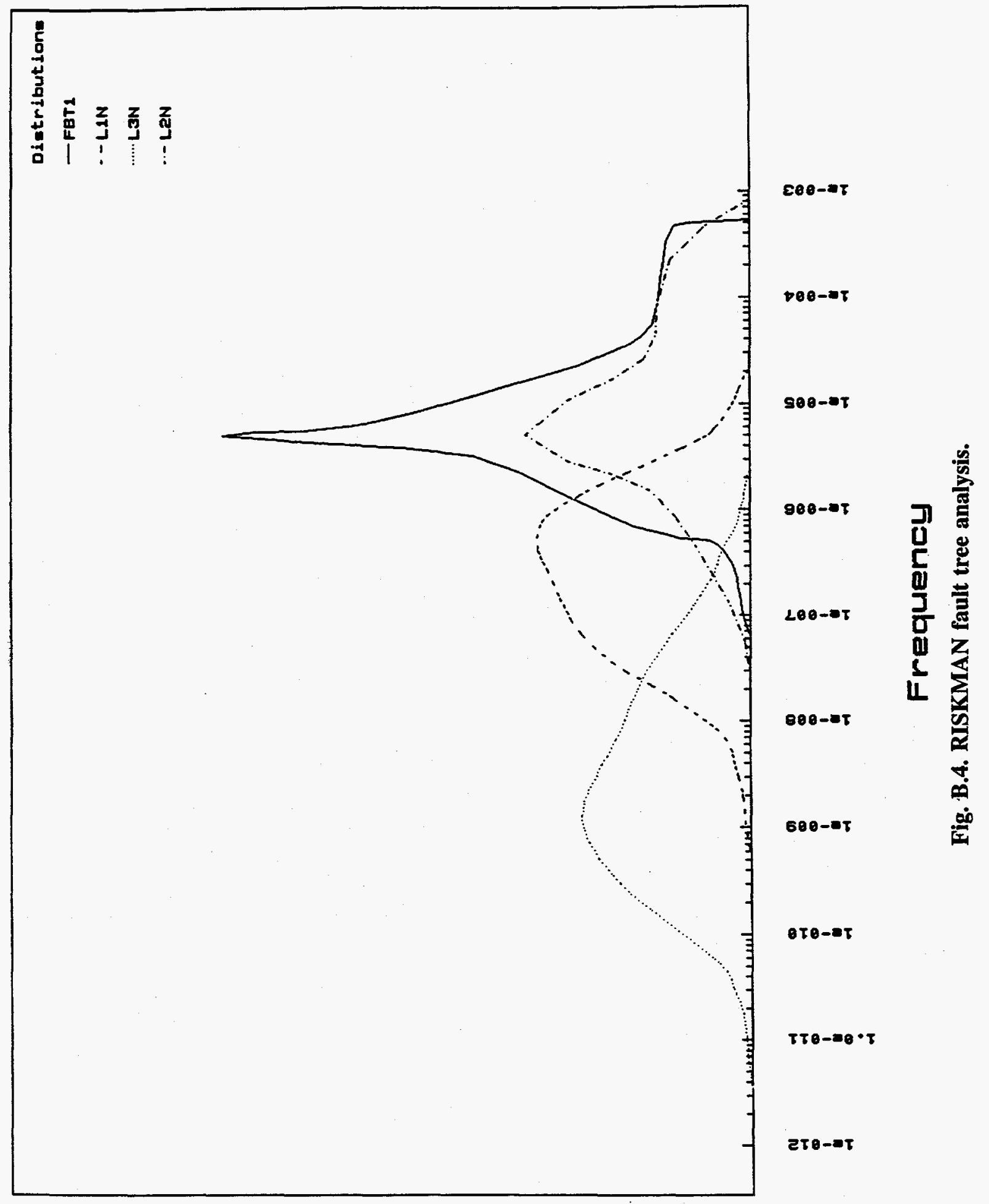

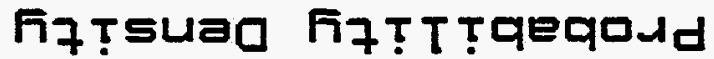


B-8

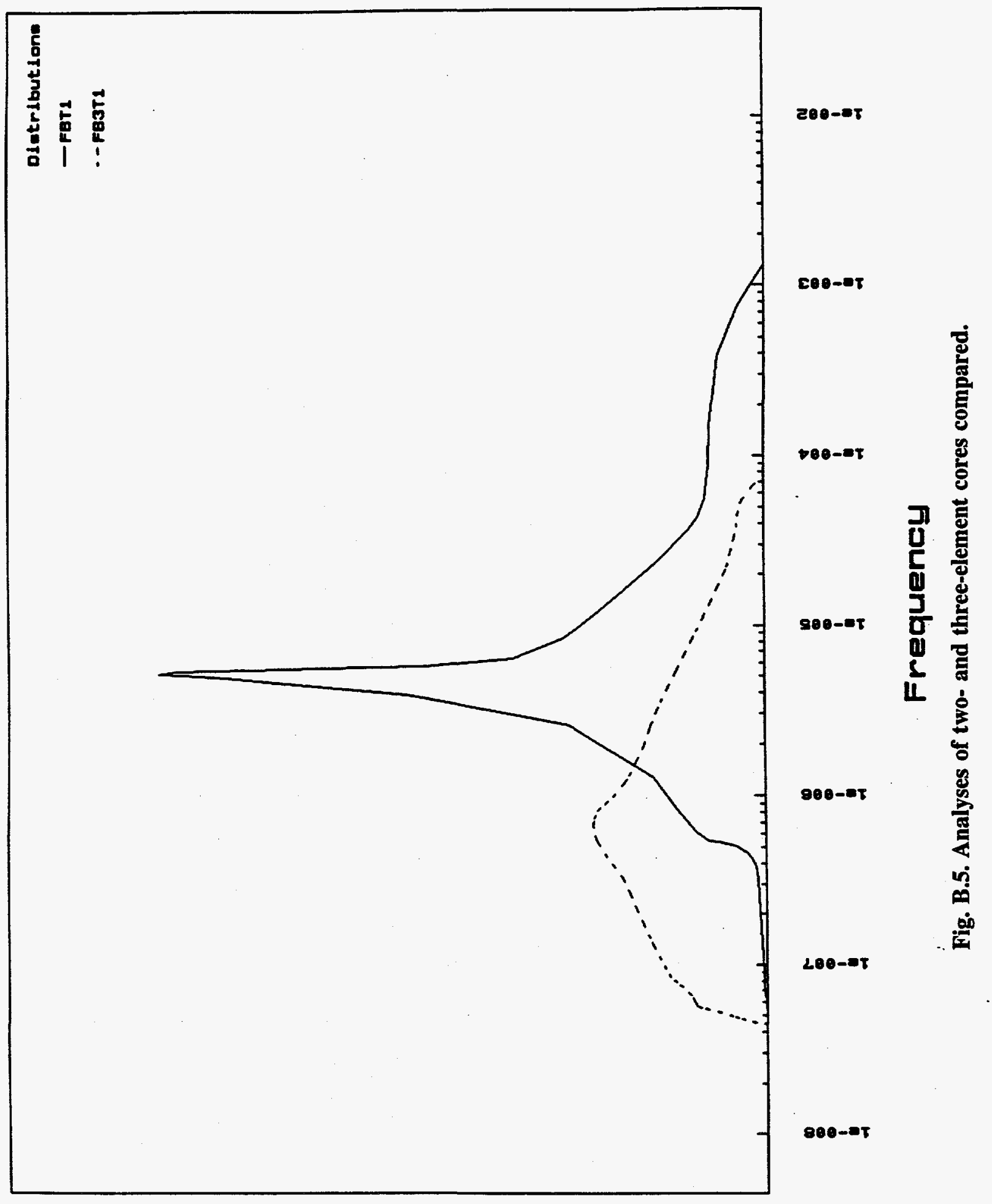

ศิ7тsuag 
APPENDIX C

BOOLEAN OPERATOR PROBABILITY CALCULATION AND RISKMAN SOFTWARE 



\section{Appendix C. BOOLEAN AND OPERATOR PROBABILITY CALCULATION AND RISKMAN SOFTWARE}

The Boolean AND (also referred to as AND) results in an event occurring only if every one of the inputs to the AND occurs. For example, if there are three inputs (say, A, B, and C) to the AND but only two inputs occur (say, A and C), then the AND does not occur; all three must occur for the AND to result in an occurrence. Statistically, this means that it must be possible for all three to occur at once; that is, a Venn diagram of $\mathrm{A}, \mathrm{B}$, and $\mathrm{C}$ would show that all three circles intersect with one another. Then, the probability that the AND occurs is the probability that all three inputs to the AND occur. Considering the Venn diagram again, this is the probability of the intersection of the three event circles. This intersection probability can be calculated as:

$\operatorname{Prob}(A$ and $B$ and $C)=\operatorname{Prob}(A) \operatorname{Prob}(B) \operatorname{Prob}(C)$, IF:

the three inputs are statistically independent.

"Statistically independent" means that the events can occur at the same time and have the following mathematical relationship:

$\operatorname{Prob}(A$ occurs given that $B$ occurs $)=\operatorname{Prob}(A)$.

The Prob(A occurs given that B occurs) is the conditional probability that A occurs if $\mathrm{B}$ occurs. The independence relationship means that the probability of $\mathrm{A}$ is not affected by the occurrence of $\mathrm{B}$.

Two events that are mutually exclusive (that is, if A occurs then B cannot occur) cannot be independent. In fact, they are dependent.

The note on statistical independence is important because it provides a calculational "shortcut" when it is true.

The Riskman software assumes that the statistical independence relationship is true when calculating the Boolean AND results for the fault tree. Depending on the actual conditional relationships of the events, this assumption may overstate or understate the probability of the Boolean AND result.

\section{BOOLEAN OR OPERATOR PROBABILITY GALCULATION AND RISKMAN SOFTWARE}

The Boolean OR (also referred to as OR) results in an event occurring if any input events occur. For example, if the OR has three input events, then only one of the input events has to occur in order for the Boolean OR to occur. For example, if there are three input events (say, $X, Y$, and $Z$ ) to the $O R$ but only one event (say, $X$ ) occurs, then the OR occurs. At least one input event must occur before the OR can occur. Statistically, this means that the inputs do not have to be able to occur at once; that is, a Venn diagram of $\mathrm{X}, \mathrm{Y}$, and $\mathrm{Z}$ could show that the three circles do not intersect at all, that they all intersect, that only some intersect, or all possible combinations. If, however, there are two inputs that must occur together (that is, that are highly dependent), the analyst should consider including them as a single entry to the OR rather than two separate inputs (the single entry might be represented as an AND input to the OR). There are related analysis considerations that will not be discussed here. 


\section{C-4}

Regardless of how the Venn diagram of the OR input looks, the probability that the OR occurs is the probability that any of the events occurs. Mathematically, this is the probability of the union of the events in the Venn diagram. Depending on (1) the number of input events for the OR and (2) the complexity of the interrelationships of the event inputs, the calculation of the probability of the OR (that is, the union) can get messy. A shortcut calculation is:

$$
\begin{aligned}
& \operatorname{Prob}(X \text { or } Y \text { or } Z)=\operatorname{Prob}(X)+\operatorname{Prob}(Y)+\operatorname{Prob}(Z) \text {, } \\
& \text { IF: }
\end{aligned}
$$

the three input events are statistically independent.

If they are not statistically independent, then it is necessary to (1) identify and evaluate the probabilities of all the intersections of the input events and (2) adjust (that is, reduce) the sum above for these intersection probabilities. So, if the event inputs are not independent, the shortcut calculation will generally overstate the probability of the OR operation. Whether or not the independence assumption may understate the OR operation results in some cases is a research issue.

The Riskman software assumes that the statistical independence relationship is true when calculating the Boolean OR results for the fault tree. Riskman does prevent the sum of any OR probabilities from exceeding 1. The Riskman seismic calculation component does make the proper adjustment for nonindependent OR inputs, but that software component is not used in this study.

Additionally, the Riskman software calculates the OR operator "merge" by creating a new event $Q$, where $\mathrm{Q}=\mathrm{X}+\mathrm{Y}+\mathrm{Z}$. Note that the union of $\mathrm{X}, \mathrm{Y}$, and $\mathrm{Z}$ is not equal to this new event $\mathrm{Q} ; \mathrm{Q}$ will always overstate the $O R$ results in some manner and will be strongly effected by the event with the largest probability values. Additionally, the possible range of values for $\mathrm{X}, \mathrm{Y}$, and $\mathrm{Z}$ will be reduced; the minimum value of the $\mathrm{OR}$ operator will be restricted to the minimum value of the input event with the largest probability. This is why the OR operator result for the L1, L2, and L3 inputs looks most like L3 and has none of the smaller values from the $\mathrm{L} 1$ and $\mathrm{L} 2$ graphs. The reason for using the $\mathrm{Q}$ event in Riskman is to provide an upper bound on the OR operator probability.

\section{RISKMAN SOFTWARE APPLICATIONS}

The Riskman software calculations for the Boolean AND and OR operations have already been discussed. While these Riskman calculations are not exact, they were not intended to provide sophisticated results. Per the PLG, Inc. experts, these calculations represent the state of the art with respect to rare event analysis for PRAs and personal computing capabilities of the late 1970s and early 1980 s.

\section{CONCLUSIONS AND SUGGESTIONS}

1. In discussions with PLG, Inc., they commented that with new levels of sophistication in PRA analysis and the current capabilities in computing power, it is possible to incorporate more exact calculational methods in software. This will likely be the subject of future research.

2. It is likely that the Crystal Ball software package that was also used for this study performs calculations in the same manner as Riskman. This conclusion is based on the graphs of the L1, L2, L3, and "merged" plots that are consistent between the two packages. 
3. Without a complete reanalysis with more sophisticated software, it is not possible to determine the exact magnitude of the impacts of any of these assumptions. Past assumptions for this rare event analysis have estimated that any calculated probability estimate would overstate-if not provide an upper bound on-the real probability value. 
APPENDIX D

LETTER TO DOMAIN EXPERTS, JUNE 8, 1994 

To: $\quad$ J. L. Anderson, K. K. Chipley, J. R. DeVore, P. S. Litherland, T. J. McManamy, G. R. McNutt, H. R. Payne, C. C. Queen

cc: G. F. Flanagan, R. M. Harrington, M. A. Linn, C. D. West

From:

C. T. Ramsey

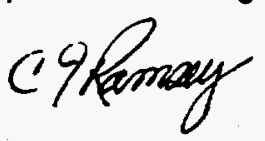

Date: $\quad$ June 8, 1994

Subject: Request and Guidance for Providing Discrete Probability Distribution Estimates of Equipment Failure Frequencies by Domain Experts

\section{Introduction}

On Thursday, May 26, 1992, many of you attended the safety seminar regarding core flow blockage in the ANS reactor. In this meeting, the groundwork was laid out for establishing a group of "domain experts" who, with their respective expertise, will aid in supplying the frequency basis for the ANS flow blockage analysis to be used in the next revision of the probabilistic risk analysis (PRA). This will be an exercise in what is called "Expert Judgement", not an expression of your emotion or feeling on the situation. Emotions and feelings would say that the events of concern will never occur, as would common sense. Expert judgement or expert opinion, on the other hand, uses the expert's state of knowledge about the systems/component(s) involved to logically assess all possible scenarios that could result in the event(s) of concern. Lest you should question the actual worth of such information, expert judgement has been widely used in risk and hazard analyses (References 1-5) and, when compared to empirical data, $93 \%$ of the elicited expert data taken in a correlation study between expert opinion and actual data was shown to lie within a factor of 4 of the observed values, $63 \%$ within a factor of 2 (Reference 6 ). So, you can see the value of your knowledge when it is applied to analyzing scenarios which would cause flow blockage, where little or no prior information exists.

\section{Designated Experts}

Reference 7 defines an expert as a person who has a background in the subject matter at the desired level of detail and who is recognized by his peers or those conducting the study as being qualified to answer questions. A domain expert applies the above definition to a certain area or field. The domain experts who have been asked to contribute to this study are as follows: 
J. L. Anderson, et al.

Page 2

June 8, 1994

\begin{tabular}{|l|l|c|}
\hline \multicolumn{1}{|c|}{ System } & \multicolumn{1}{|c|}{ Domain Expert } & Data File \\
\hline $\begin{array}{l}\text { Inner Control } \\
\text { Rods }\end{array}$ & $\begin{array}{l}\text { Ray Payne, } \\
\text { Steve Litherland }\end{array}$ & PAYNE.XLS \\
\hline $\begin{array}{l}\text { I \& C } \\
\text { Detrit. \& Upgrade }\end{array}$ & John Anderson & ANDERSON.XLS \\
\hline $\begin{array}{l}\text { Experiments \& } \\
\text { Transuranic } \\
\text { Assembly }\end{array}$ & Tom McManamy & $\begin{array}{l}\text { TM_EXP.XLS } \\
\text { TM_TRU.XLS }\end{array}$ \\
\hline $\begin{array}{l}\text { Refueling \& } \\
\text { Maintenance }\end{array}$ & Ken Chipley & CHIPLEY.XLS \\
\hline $\begin{array}{l}\text { Reactor Water } \\
\text { Systems }\end{array}$ & George MCNutt & $\begin{array}{l}\text { MCNUTTPC.XLS } \\
\text { MCNUTTMU.XLS }\end{array}$ \\
\hline
\end{tabular}

Some of these areas are very broad in their task breakdowns such as I \& $C$ and Reactor Assembly. Therefore, you may be required to contact some of your staff to assemble the information necessary to judge the probability of frequency as discussed below.

My part is that of a facilitator in eliciting this information from you and providing guidance and information if necessary in the area of my expertise (very loose definition) which is risk analysis. The data you provide will be aggregated to arrive at a single initiating event frequency distribution for each debris scenario. I will also be documenting the outcome for use in the PRA and other publications.

\section{The Objective}

The goal of this exercise is to quantitatively define, through a collective effort, the probability of frequency of failures which introduce debris of sufficient size into the primary coolant system such that, if it became entrapped on the core inlet of a fuel element, fuel damage due to the blockage would occur. By probability of frequency, 1 mean the most likely frequency of occurrence of debris-producing failures in your system(s). The outcome will be a probability distribution for potential flow blockage initiating events. 
J. L. Anderson, et al.

Page 3

June 8, 1994

\section{The Method}

The probability of frequency will be defined using discrete probability distributions, or DPDs. Most of you took part in providing information to the Flow Blockage Database to identify the potential debris that could be introduced into the primary coolant system. Since no experimental or experiential data exists as to the likelihood of failures producing this debris, your knowledge about your systems/ components/assemblies (SCA) must be relied on to determine what the failure frequency might actually be. In order to do this, you must first imagine a large number (e.g., 100,000) of your SCA's in continuous operation side-by-side for one year. (This is called a Poisson model.) Then, based on your knowledge of system design, available sources of debris, operating conditions, frequency of inspection and maintenance, similar occurrences in other facilities, etc., express your confidence that one failure would occur during the year if that many S/C/A's operated as described above.

Next, given that debris or foreign matter has been produced by a failure and the knowledge of potential types of debris from your system in the flow blockage database, an estimate of the size of the debris is necessary to evaluate the likelihood of fuel damage. For instance, what percentage of debris will be larger than $5 \mathrm{~mm}$ in effective diameter? Of that larger than $5 \mathrm{~mm}$, what percentage is greater than $10 \mathrm{~mm}$ ? And so on. It is currently estimated that any blockage larger than $10 \mathrm{~mm}$ in effective diameter is sufficient to bring about the onset of fuel damage in one or more fuel plates. However, as the core design changes, the threshold of fuel damage may also change. For this reason, specific ranges of debris sizes are called out.

\section{Data Input Sheets}

Provide your input using Microsoft Excel data input sheets on the ANS network. These network files are named as listed in Table 1 above and stored in the directory U:IITEAMIRAMSEYIFB_DATA. For those of you using Mac's, I will be more than happy to print out a copy for you if there is a problem with translating the file.

\section{Schedule}

Your completed input is needed by Monday, June 20,1994. The schedule for completing a draft report of the results of the entire internal debris flow blockage assessment is July 1, 1994. While you are formulating your DPD's, I will be modeling different blockage scenarios and searching for appropriate failure data for other components.

Know that by participating in this analysis, you are providing validation for the results, documented basis for the data used, and helping to address the potentially highest risk to the ANS. Please contact me if there is any doubt on your part as to what you have been asked to do. I am currently checking on the possibility of gathering ANS domain experts together with remaining HFIR personnel who participated in the expert 
J. L. Anderson, et al.

Page 4

June 8,1994

judgement analysis for flow blockage there to aid you in understanding what you are to do, and will keep you posted.

\section{Training}

You should have been contacted already about a brief training session on probability of frequency evaluations. This meeting is scheduled for Friday, June 10, 1994, at 3:00 p.m. in the Blue Room at FEDC. Topics to be covered are further explanation of what probability of frequency is, the mind-set and reasoning that must accompany an evaluation of this type, examples of the use of expert judgement analysis, individual exercises, and discussion. The session should last no longer than 1.5 hours. If you will be unable to attend, please contact either myself (6-5427) or Mark Linn (4-4617), and we can work out other arrangements for you.

\section{CTR:kkd}

\section{References:}

1 WASH-1400

2 EPRI Seismic Hazard Study

3 HFIR PRA

4 Seabrook PRA

5 NUREG 1150 Studies

6 Snaith, E. R., "The Correlation Between the Predicted and Observed Reliabilities of Components, Equipment, and Systems," National Center f Systems Reliability, U. K. Atomic Energy Authority, NCSR R18, 1981.

7 Mosleh, A., Bier, V., and Apostolakis, G., Methods for the Elicitation and Use of Expert Opinion in Risk Assessment, NUREG/CR-4962 (PLG-0533), August, 1987.

8 Meyer, M. A., and Booker, J. M., Eliciting and Analyzing Expert Judgement, NUREG/CR-5424 (LA-11667), January 1990.

9 Bonano, E. J., Hora, S. C., Keeney, R. L., and von Winterfeldt, D., Elicitation and Use of Expert Judgement in Performance Assessment for High-Level Radioactive Waste Repositories, NUREG/CR-5411 (SAND89-1821), May 1990. 
APPENDIX E

DOMAIN EXPERT QUERY RESPONSES 



\section{(Blow Blockage (Frequency Distribution Data OHeet}

\begin{tabular}{|c|c|c|c|c|c|c|c|}
\hline system & Source & Ireinis & Matering & Matringl & (culmm) & Est Mass. & Timo: of Eitry \\
\hline Refueling & Tool head & $\begin{array}{l}\text { Machine } \\
\text { screws, } \\
\text { retaining } \\
\text { rings, } \\
\text { fasteners, } \\
\text { etc. } \\
\end{array}$ & SST & M & $10 \mathrm{cu} \mathrm{mm}$ & $10 \mathrm{~g}$ & $\begin{array}{l}\text { Refueling or } \\
\text { maintenance }\end{array}$ \\
\hline Refueling & $\begin{array}{l}\text { Irradiation } \\
\text { Capsule }\end{array}$ & $\begin{array}{l}\text { Small seal } \\
\text { fragment }\end{array}$ & Nickel & M & $5 \mathrm{cu} \mathrm{mm}$ & $5 \mathrm{~g}$ & $\begin{array}{l}\text { Refueling or } \\
\text { maintenance }\end{array}$ \\
\hline Refueling & Absorber & $\begin{array}{l}\text { Absorber } \\
\text { piece }\end{array}$ & Hafnium & $\mathbf{M}$ & 3 cu mm & $5 g$ & $\begin{array}{l}\text { Refueling or } \\
\text { maintenance }\end{array}$ \\
\hline
\end{tabular}

\section{Guidance:}

In the following scenario, a theoretical number of your system, component, or assembly (S/C/A) operate side-by-side for one year.

You are asked to express your knowledge as to the most likely number of S/C/A's that will incurr one debris creating failure.

\section{Establish Failure Rate (FR) Likelihood Distribution}

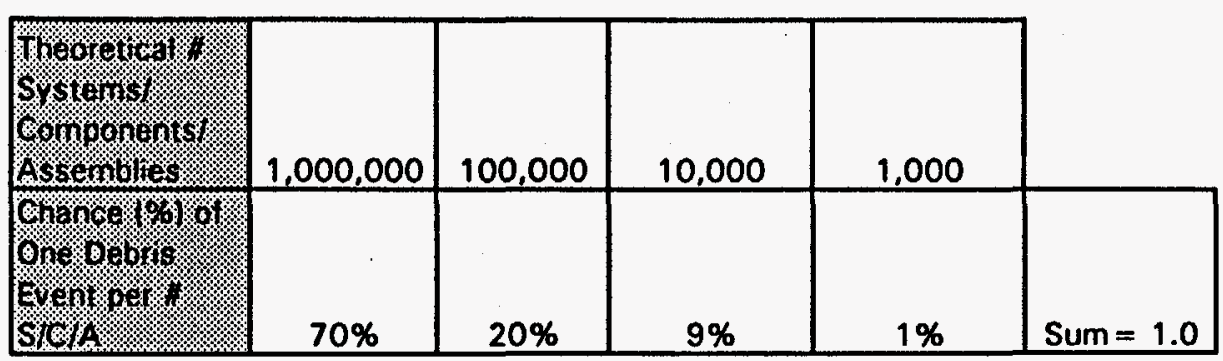

\section{Establish Debris Size Likelihood Distribution}

\begin{tabular}{|c|c|c|c|c|}
\hline Banger. & $\begin{array}{c}x<5 \mathrm{~mm} \\
\text { width or } \\
\text { dia. }\end{array}$ & $\begin{array}{l}5<x<10 \mathrm{~mm} \\
\text { width or dia. }\end{array}$ & $\begin{array}{c}x> \\
10 \mathrm{~mm} \\
\text { width or } \\
\text { dia. }\end{array}$ & \\
\hline \%orverits. & $60 \%$ & $30 \%$ & $10 \%$ & Sum $=1.0$ \\
\hline
\end{tabular}

IMPORTANT: Document your evaluation process; i.e., how you decomposed what was and was not important and why. 
Additional information pertaining to the above estimates (e.g, maint. frequency, inspection, monitoring instrumentation):

The size of the debris is directly related to the sizes of the detachable components. Most of the delachable components such as springs, seals, etc., will be smaller than $5 \mathrm{~mm}$. Also,
components inclined to break unexpectedly will generally be small in crossection. Larger components (greater than $5 \mathrm{~mm}$ ) will be welded or forged, and are less likely to break
with the low forces involved. Certainly, those components as large as $10 \mathrm{~mm}$ will require considerable force to break and form debris.
Frequent replacement of tools prior to wear and fracture damage will reduce the likelihood of failure. The non-replaceable parts of the system are likely to be very large, bulky,
robust structures.


Blow Blockage (Frequency Distribution Data Oreet

\begin{tabular}{|c|c|c|c|c|c|c|c|}
\hline System & Source & Them: & Material & Martiria! & Sizo: & Sest Muiss & Timo or entr. \\
\hline $\begin{array}{l}\text { Primary } \\
\text { Coolant } \\
\end{array}$ & $\begin{array}{l}\text { Pump suction } \\
\text { and } \\
\text { discharge } \\
\end{array}$ & $\begin{array}{l}\text { Gate valve (2 } \\
\text { per loop) } \\
\text { internals } \\
\end{array}$ & metal & $\mathbf{M}$ & Unknown & Unknown & $\begin{array}{l}\text { Startup and } \\
\text { operation }\end{array}$ \\
\hline $\begin{array}{l}\text { Primary } \\
\text { Coolant } \\
\end{array}$ & $\begin{array}{l}\text { RPCS pump } \\
\text { discharge }\end{array}$ & $\begin{array}{l}\text { Check Valve } \\
\text { disk }\end{array}$ & metal & $\mathbf{M}$ & Unknown & Unknown & $\begin{array}{l}\text { Startup and } \\
\text { operation }\end{array}$ \\
\hline $\begin{array}{l}\text { Primary } \\
\text { Coolant } \\
\end{array}$ & \begin{tabular}{|l|} 
RPICS from \\
discharge of \\
makeup \\
pumps
\end{tabular} & $\begin{array}{l}\text { Check valve } \\
\text { internals }\end{array}$ & metal & $\mathbf{M}$ & Unknown & Unknown & $\begin{array}{l}\text { Startup and } \\
\text { operation }\end{array}$ \\
\hline $\begin{array}{l}\text { Primary } \\
\text { Coolant }\end{array}$ & \begin{tabular}{|l} 
RPCS \\
Combined \\
hot leg
\end{tabular} & Flow Element & metal & $\mathbf{M}$ & Unknown & Unknown & $\begin{array}{l}\text { Startup and } \\
\text { operation }\end{array}$ \\
\hline $\begin{array}{l}\text { Primary } \\
\text { Coolant }\end{array}$ & Each loop & $\begin{array}{l}\text { Loop Strainer } \\
\text { Baskets }\end{array}$ & metal & $\mathbf{M}$ & Unknown & Unknown & $\begin{array}{l}\text { Startup and } \\
\text { operation }\end{array}$ \\
\hline
\end{tabular}

\section{Guidance:}

In the following scenario, a theoretical number of your system, component, or assembly (S/C/A) operate side-by-side for one year. You are asked to express your knowledge as to the most likely number of $S / C / A$ 's that will incurr one debris creating failure.

\section{Establish Failure Rate (FR) Likelihood Distribution}

Establish Debris Size Likelihood Distribution

IMPORTANT: Document your evaluation process; i.e., how you decomposed what was and was not important and why.

\begin{tabular}{|c|c|c|c|c|}
\hline 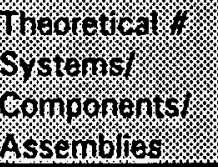 & $1,000,000$ & 100,000 & 10,000 & 1,000 \\
\hline 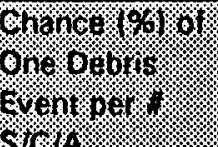 & & $25 \%$ & $10 \%$ & $5 \%$ \\
\hline
\end{tabular}

\begin{tabular}{|c|c|c|c|}
\hline Rebris & $\begin{array}{c}x<5 \mathrm{~mm} \\
\text { width or } \\
\text { dia. }\end{array}$ & $\begin{array}{c}5<x<10 \mathrm{~mm} \\
\text { width or dia. }\end{array}$ & $\begin{array}{c}x> \\
10 \mathrm{~mm} \\
\text { width or } \\
\text { dia. }\end{array}$ \\
\hline 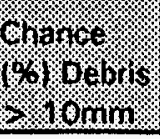 & $20 \%$ & $30 \%$ & $50 \%$ \\
\hline
\end{tabular}


Additional information pertaining to the above estimates (e.g, maint. frequency, inspection, monitoring instrumentation):

For failed material to get into the core, one of two things must happen. The failure must occur down stream of the strainer or the strainer must also fail.
Within the primary piping system there is only one item located between the strainers and the core (1 gate valve). The wedge would have to break apart
to generate loose parts that would block the core. Probable cause would be vibration damaging the seat and gate to failure where pieces might break off.
Monitoring should identify the potential for a problem long before it happens.
The strainer is designed to remove all parts litems) larger than $0.5 \mathrm{~mm}$. For the strainer to fail, multiple impacts would be required. Monitoring the
strainer for loose parts should alert the operator of potential for releasing loose parts (itemslto the core.


Bhour Brockage (trequency Distribution Data Oheet

\begin{tabular}{|c|c|c|c|c|c|c|c|}
\hline Syytems. & souros & Attern: & Material & Morerilin! & 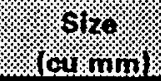 & Est & King of Enitri. \\
\hline $\begin{array}{l}\text { Pressure \& } \\
\text { Inventory } \\
\text { Control } \\
\end{array}$ & $\begin{array}{l}\text { Refuelling } \\
\text { system }\end{array}$ & Loose parts & metal & M & Unknown & Unknown & $\begin{array}{l}\text { Refueling/startu } \\
\text { p }\end{array}$ \\
\hline $\begin{array}{l}\text { Pressure \& } \\
\text { Inventory } \\
\text { Control } \\
\end{array}$ & $\begin{array}{l}\text { RPICS and/or } \\
\text { RVCS }\end{array}$ & $\begin{array}{l}\text { Resins from } \\
\text { cleanup } \\
\text { system }\end{array}$ & Liquidous & $\mathbf{R}$ & Unknown & Unknown & All modes \\
\hline $\begin{array}{l}\text { Pressure \& } \\
\text { Inventory } \\
\text { Control } \\
\end{array}$ & RVCS & Loose parts & metal & $M$ & Unknown & Unknown & $\begin{array}{l}\text { Normal ops or } \\
\text { CPBT change } \\
\text { out } \\
\end{array}$ \\
\hline $\begin{array}{l}\text { Pressure \& } \\
\text { Inventory } \\
\text { Control }\end{array}$ & $\begin{array}{l}\text { Hot leg and } \\
\text { cold leg }\end{array}$ & $\begin{array}{l}\text { Thermocouple } \\
\text { (16) weilds }\end{array}$ & Imetal beads & M & Unknown & Unknown & $\begin{array}{l}\text { Startup and } \\
\text { operation }\end{array}$ \\
\hline $\begin{array}{l}\text { Pressure \& } \\
\text { Inventory } \\
\text { Control } \\
\end{array}$ & RPICS & $\begin{array}{l}\text { Makeup Line } \\
\text { Gate valve (4) } \\
\text { internals }\end{array}$ & metal & $M$ & Unknown & Unknown & $\begin{array}{l}\text { Startup and } \\
\text { operation }\end{array}$ \\
\hline \begin{tabular}{|l|} 
Pressure \& \\
Inventory \\
Control \\
\end{tabular} & RPICS & $\begin{array}{l}\text { Makeup pump } \\
\text { impellers (2) }\end{array}$ & metal & $\mathbf{M}$ & Unknown & Unknown & $\begin{array}{l}\text { Startup and } \\
\text { operation }\end{array}$ \\
\hline $\begin{array}{l}\text { Pressure \& } \\
\text { Inventory } \\
\text { Control } \\
\end{array}$ & RPICS & $\begin{array}{l}\text { Makeup line } \\
\text { flow olement } \\
\text { frengent }\end{array}$ & metal & M & Unknown & Unknown & $\begin{array}{l}\text { Startup and } \\
\text { operation }\end{array}$ \\
\hline $\begin{array}{l}\text { Pressure \& } \\
\text { Inventory } \\
\text { Control }\end{array}$ & |RPICS & $\begin{array}{l}\text { recirc. line } \\
3 / 4^{*} \text { valve (3) } \\
\text { internals }\end{array}$ & Imetal & $\mathrm{M}$ & Unknown & Unknown & $\begin{array}{l}\text { Startup and } \\
\text { operation }\end{array}$ \\
\hline
\end{tabular}

\section{Guidance:}

In the following scenario, a theoretical number of your system, component, or assembly (S/C/A) operate side-by-side for one year.

You are esked to express your knowledge as to the most likely number of S/C/A's that will incurr one debris creating failure. 


\section{Establish Failure Rate (FR) Likelihood Distribution}

\begin{tabular}{|c|c|c|c|c|}
\hline $\begin{array}{l}\text { Theoretical f } \\
\text { Systems/ } \\
\text { Components } \\
\text { Assemblies }\end{array}$ & $1,000,000$ & 100,000 & 10,000 & 1,000 \\
\hline $\begin{array}{l}\text { Chance (\%) of } \\
\text { One Debris } \\
\text { Event per } \\
\text { S/C/A }\end{array}$ & $40 \%$ & $30 \%$ & $20 \%$ & $10 \%$ \\
\hline
\end{tabular}

\section{Establish Debris Size Likelihood Distribution}

\begin{tabular}{|c|c|c|c|c|}
\hline $\begin{array}{l}\text { Range of } \\
\text { Debris } \\
\text { Sizes }\end{array}$ & $\begin{array}{c}x<5 \mathrm{~mm} \\
\text { width or } \\
\text { dia. }\end{array}$ & $\begin{array}{c}5<x<10 \mathrm{~mm} \\
\text { width or dia. }\end{array}$ & $\begin{array}{c}x> \\
10 \mathrm{~mm} \\
\text { width or } \\
\text { dia. }\end{array}$ & \\
\hline $\begin{array}{l}\text { Chance } \\
\text { (\%) Debris } \\
\text { > } 10 \mathrm{~mm}\end{array}$ & $40 \%$ & $20 \%$ & $40 \%$ & Sum $=1.0$ \\
\hline
\end{tabular}

IMPORTANT: Document your evaluetion process: i.e.. how you decomposed what was and was not important and why.

Additional information pertaining to the above estimates (e.g, maint. frequency, inspection, monitoring instrumentation):

For any of these items to get to the core, the strainers in the primary cooling system cold leg would also have to fail. 
Blow Blockage (Frequency Distribution Data $\mathcal{O}^{2}$ heet

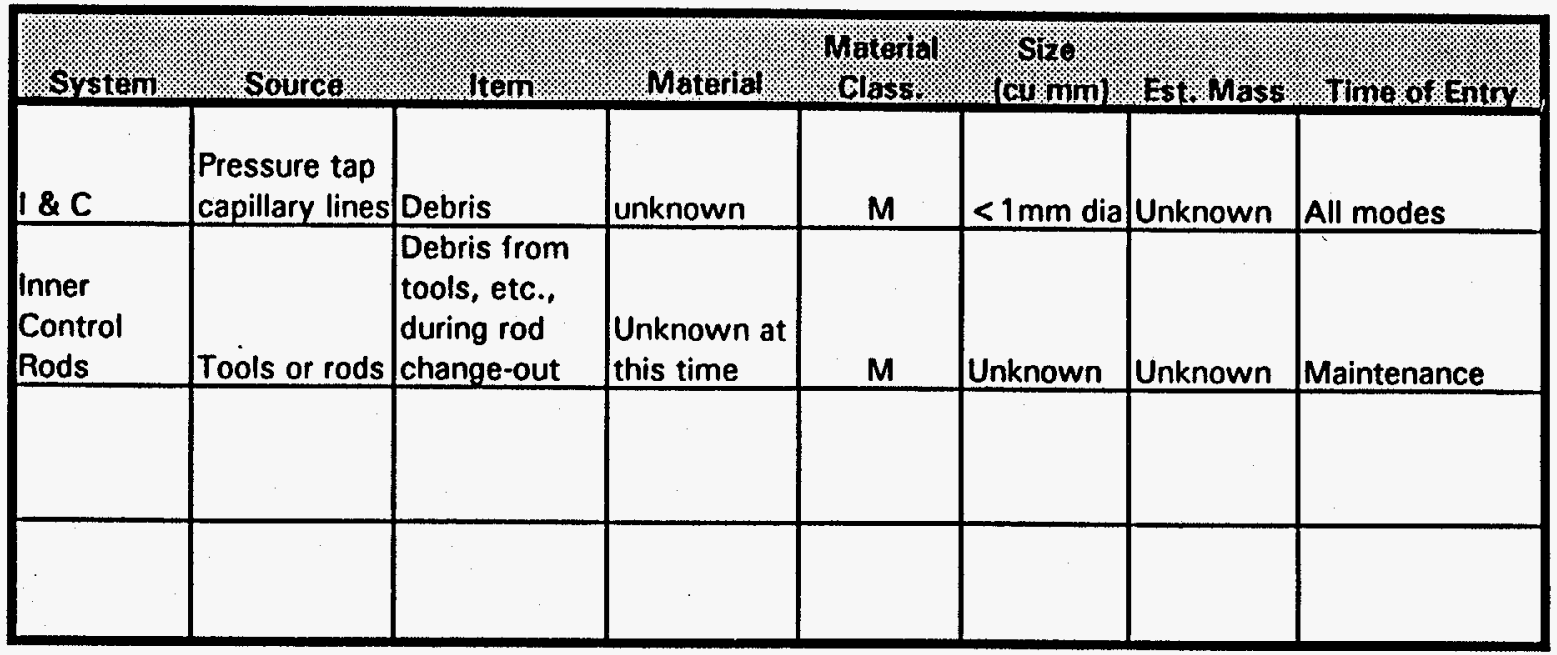

Guidance:

In the following scenario, a theoretical number of your system, component, or assembly (S/C/A) operate side-by-side for one year.

You are asked to express your knowledge as to the most likely number of $S / C / A$ 's that will incurr one debris creating failure.

\section{Establish Failure Rate (FR) Likelihood Distribution}

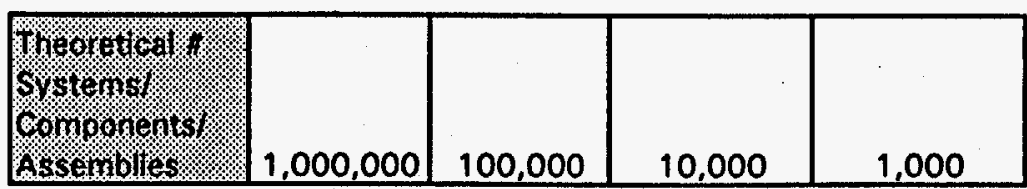

Thermowells

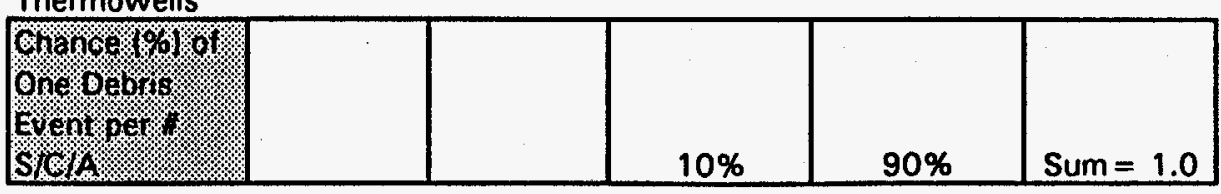

Pressure Taps \%1000\% $\%$ \%onotor $601 \%$ Sto 2 .

\section{Establish Debris Size Likelihood Distribution}

\begin{tabular}{|c|c|c|c|}
\hline 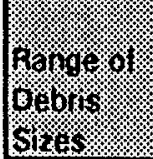 & $\begin{array}{c}x<5 \mathrm{~mm} \\
\text { width or } \\
\text { dia. }\end{array}$ & $\mid \begin{array}{c}5<x<10 \mathrm{~mm} \\
\text { width or dia. }\end{array}$ & $\begin{array}{c}x> \\
10 \mathrm{~mm} \\
\text { width or } \\
\text { dia. }\end{array}$ \\
\hline
\end{tabular}
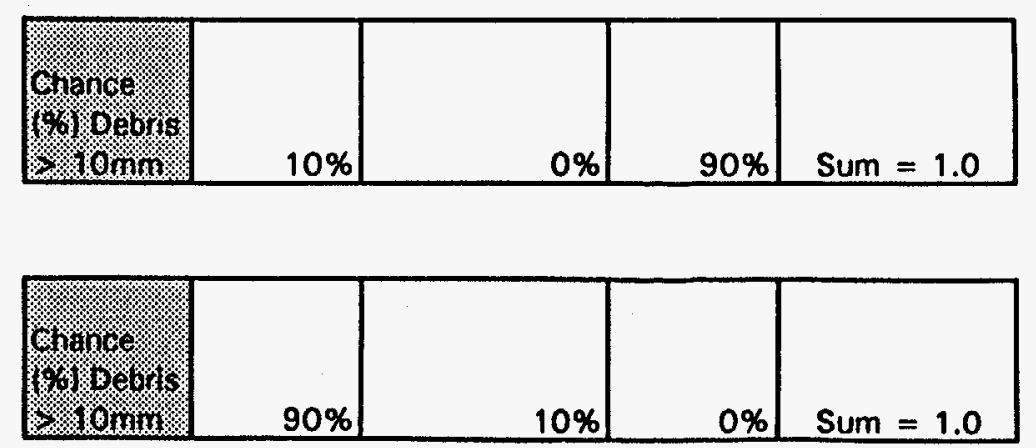
IMPORTANT: Document your evaluation process; i.e., how you decomposed what was and was not Important and why.

Additional information pertaining to the above estimates (e.g, maint. frequency, inspection, monitoring instrumentation):

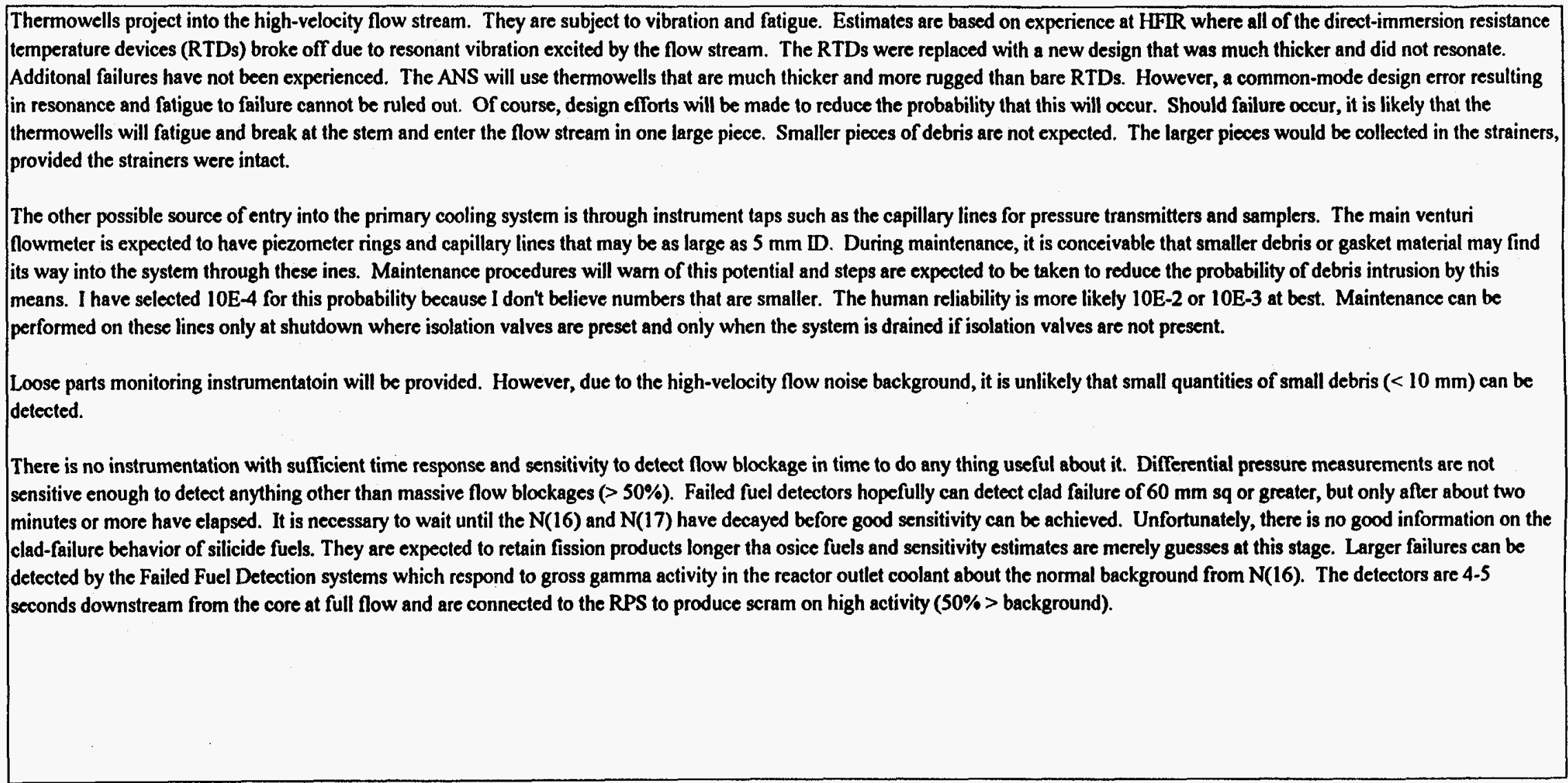


Crous Brockage (Frequency Distribution Data OHeet

\begin{tabular}{|c|c|c|c|c|c|c|c|}
\hline Systams & Sourcos & Item & Matertals & Motoris & . & $8 \mathrm{Et}_{\mathrm{St}}$ & পু \\
\hline $\begin{array}{l}\text { Inner } \\
\text { Control } \\
\text { Rods }\end{array}$ & $\begin{array}{l}\text { Inner Control } \\
\text { Rod }\end{array}$ & $\begin{array}{l}\text { Upper sppt } \\
\text { springs, rollis, \& } \\
\text { roller axles }\end{array}$ & Inconel & $M$ & $\begin{array}{l}1.6 \times 1.6 \times \\
9 \mathrm{~cm}\end{array}$ & $150 \mathrm{gm}$ & $\begin{array}{l}\text { Anytime. Most } \\
\text { likely at rod } \\
\text { change-out. }\end{array}$ \\
\hline $\begin{array}{l}\text { Inner } \\
\text { Control } \\
\text { Rods } \\
\end{array}$ & $\begin{array}{l}\text { Inner Control } \\
\text { Rod }\end{array}$ & $\begin{array}{l}\text { Upper suppt spring } \\
\text { attach- mnt bolts } \\
\text { \& nuts }\end{array}$ & Inconel & $M$ & $1 \times 1 \times 3 \mathrm{~cm}$ & $25 \mathrm{gm}$ & $\begin{array}{l}\text { Anytime. Most } \\
\text { likely at rod } \\
\text { change-out. }\end{array}$ \\
\hline $\begin{array}{l}\text { Inner } \\
\text { Control } \\
\text { Rods } \\
\end{array}$ & $\begin{array}{l}\text { Inner Control } \\
\text { Rod }\end{array}$ & $\begin{array}{l}\text { Thread locking } \\
\text { pins }\end{array}$ & Inconel & $M$ & $0.5 \times 2 \mathrm{~cm}$ & $5 \mathrm{gm}$ & Operation \\
\hline $\begin{array}{l}\text { Inner } \\
\text { Control } \\
\text { Rods }\end{array}$ & $\begin{array}{l}\text { Inner Control } \\
\text { Rod }\end{array}$ & \begin{tabular}{|l|} 
Guide tube upper \\
bearing fragments
\end{tabular} & Graphite & $M$ & $10 \times 4 \mathrm{~cm}$ & $500 \mathrm{gm}$ & Operation \\
\hline $\begin{array}{l}\text { Inner } \\
\text { Control } \\
\text { Rods } \\
\end{array}$ & $\begin{array}{l}\text { Inner Control } \\
\text { Rod }\end{array}$ & \begin{tabular}{|l|} 
Upper support \\
spring spider frame \\
fragments
\end{tabular} & Inconel & $M$ & $\begin{array}{l}2.5 \times 2.5 \times 16 \\
\mathrm{~cm}\end{array}$ & $750 \mathrm{gm}$ & All modes \\
\hline $\begin{array}{l}\text { Inner } \\
\text { Control } \\
\text { Rods } \\
\end{array}$ & $\begin{array}{l}\text { Inner Control } \\
\text { Rod }\end{array}$ & $\begin{array}{l}\text { ICR drive shaft } \\
\text { disconnect bolts \& } \\
\text { springs }\end{array}$ & $\begin{array}{l}\text { Inconel \& } \\
\text { steel }\end{array}$ & $M$ & $\begin{array}{l}2 \mathrm{~cm} \text { dia } x \\
20 \mathrm{~cm} \text { long }\end{array}$ & $500 \mathrm{gm}$ & $\begin{array}{l}\text { Anytime. Most } \\
\text { ilkely at rod } \\
\text { change-out. }\end{array}$ \\
\hline $\begin{array}{l}\text { Inner } \\
\text { Controf } \\
\text { Rods } \\
\end{array}$ & $\begin{array}{l}\text { Inner Control } \\
\text { Rod }\end{array}$ & \begin{tabular}{|l|} 
Acceleration/ \\
deceleration spring \\
fragments
\end{tabular} & Steel & $M$ & $\begin{array}{l}1 \mathrm{~cm} \text { dia } x \\
10 \mathrm{~cm} \text { long } \\
\end{array}$ & $50 \mathrm{gm}$ & All modes \\
\hline $\begin{array}{l}\text { Inner } \\
\text { Control } \\
\text { Rods } \\
\end{array}$ & $\begin{array}{l}\text { Inner Control } \\
\text { Rod }\end{array}$ & $\begin{array}{l}\text { Latch disks or disk } \\
\text { fragments }\end{array}$ & $\begin{array}{l}\text { Stellite or } \\
\text { ceramic }\end{array}$ & $\mathbf{M}$ & $\begin{array}{l}1.4 \mathrm{~cm} \text { dia } x \\
0.6 \mathrm{~cm} \mathrm{t}\end{array}$ & $5 \mathrm{gm}$ & $\begin{array}{l}\text { Post scram rod } \\
\text { changeout. }\end{array}$ \\
\hline $\begin{array}{l}\text { Pressure \& } \\
\text { Inventory } \\
\text { Control }\end{array}$ & $\begin{array}{l}\text { Refuelling } \\
\text { system }\end{array}$ & Loose parts & metal & $\mathbf{M}$ & Unknown & Unknown & Refueling/startup \\
\hline
\end{tabular}

Guidance:

In the following scenario, a theoretical number of your system, component, or assembly (S/C/A) operate side-by-side for one year.

You are asked to express your knowledge as to the most likely number of $S / C / A$ 's that will incurr one debris creating failure. 


\section{Establish Failure Rate (FR) Likelihood Distribution}

\begin{tabular}{|c|c|c|c|c|c|}
\hline $\begin{array}{l}\text { Theoretich } 7 \\
\text { Systems } \\
\text { Componfont } \\
\text { Assemblios }\end{array}$ & $1,000,000$ & 100,000 & 10,000 & 1,000 & \\
\hline $\begin{array}{l}\text { Chance }(\%) \text { of } \\
\text { One Debris } \\
\text { Event per }) \\
\text { SICIA. }\end{array}$ & $83 \%$ & $10 \%$ & $6 \%$ & $2 \%$ & Sum $=1.0$ \\
\hline
\end{tabular}

\section{Establish Debris Size Likelihood Distribution}

\begin{tabular}{|c|c|c|c|c|}
\hline 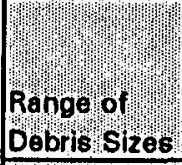 & $\begin{array}{c}x<5 \mathrm{~mm} \\
\text { width or } \\
\text { dia. }\end{array}$ & $\begin{array}{c}5<x<10 \mathrm{~mm} \\
\text { width or dia. }\end{array}$ & $\begin{array}{c}x> \\
10 \mathrm{~mm} \\
\text { width or } \\
\text { dia. }\end{array}$ & \\
\hline 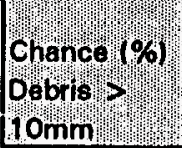 & $30 \%$ & $10 \%$ & $60 \%$ & Sum $=1.0$ \\
\hline
\end{tabular}

IMPORTANT: Document your evaluation process: l.e., how you decomposed what was and was not important and why.

Additional information pertaining to the above estimates (e.g, maint. frequency, inspection, monitoring instrumentation):

The only logical source of debris from the inner control rod drive system component failure is the rod guides above the core (screws, rollers, pins, lest springs) or fragments of the guide bushings located at the upper end of the guide tube. Fragments of the guide bushings would be $<=1$ mm in one dimension, and, in my opinion, $<=5 \mathrm{~mm}$ in the other two dimensions. Any debris from the rod guides above the core could vary in size from < $5 \mathrm{~mm}$ to $>10 \mathrm{~mm}$. If this debris were produced during core replacement or control rod replacement, the debris would be removed with the core or fall into a region where it could not be carried into the core inlet. If it is produced during operation, this debris would have to be carried through the entire primary system. including the strainer, before reaching the core.

If any debris $>10 \mathrm{~mm}$ in size is produced during operetion, it will be in the central region above the core and must be carried out through openings in the inner cylinder. This cylinder has not been fully designed at this time, but it is quite possible to make the openings $<=10 \mathrm{~mm}$. 
Blow Blockage Frequency Distribution Data $O$ \%eet

\begin{tabular}{|c|c|c|c|c|c|c|c|}
\hline System & Source & items & Materifil & Maroial & 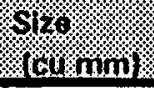 & Estin.Muss. & trino: \\
\hline TRU & $\begin{array}{l}\text { Transuranium } \\
\text { rod housing }\end{array}$ & Weld Beads & Metal & $M$ & Unknown & $1 \mathrm{~g}$ & $\begin{array}{l}\text { Power } \\
\text { Operation }\end{array}$ \\
\hline TRU & $\begin{array}{l}\text { Transuranium } \\
\text { rod housing } \\
\end{array}$ & $\begin{array}{l}\text { Compression } \\
\text { spring } \\
\text { fragments }\end{array}$ & Metal & $M$ & Unknown & $.5 \mathrm{~g}$ & $\begin{array}{l}\text { Power } \\
\text { Operation }\end{array}$ \\
\hline TRU & $\begin{array}{l}\text { Transuranium } \\
\text { rod housing }\end{array}$ & $\begin{array}{l}\text { Upper retaining } \\
\text { ring. }\end{array}$ & Metal & $M$ & Unknown & Unknown & \begin{tabular}{|l} 
Power \\
Operation
\end{tabular} \\
\hline TRU & $\begin{array}{l}\text { Transuranium } \\
\text { rod housing }\end{array}$ & $\begin{array}{l}\text { Single } \\
\text { transuranic rod. }\end{array}$ & IMetal & $M$ & Unknown & Unknown & $\begin{array}{l}\text { Power } \\
\text { Operation }\end{array}$ \\
\hline
\end{tabular}

\section{Guidance:}

In the following scenario, a theoretical number of your system, component, or assembly (S/C/A) operate side-by-side for one year.

You are asked to express your knowledge as to the most likely number of S/C/A's that will incurr one debris creating failure.

\section{Establish Failure Rate (FR) Likelihood Distribution}

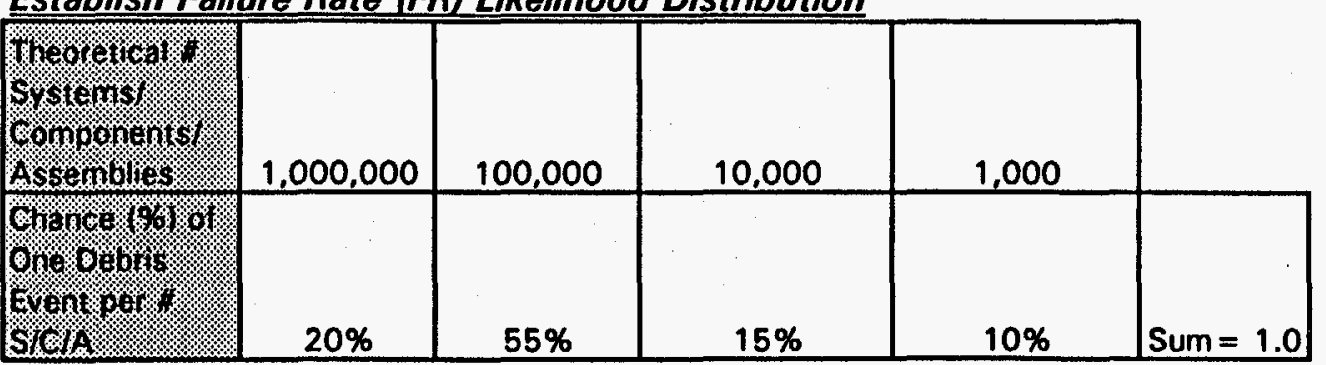

Establish Debris Size Likelihood Distribution

\begin{tabular}{|c|c|c|c|c|}
\hline 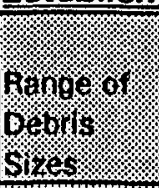 & $\begin{array}{c}x<5 \mathrm{~mm} \\
\text { width or } \\
\text { dia. }\end{array}$ & $\begin{array}{c}5<x< \\
10 \mathrm{~mm} \text { width } \\
\text { or dia. }\end{array}$ & $\begin{array}{c}x> \\
10 \mathrm{~mm} \\
\text { width or } \\
\text { dia. }\end{array}$ & \\
\hline 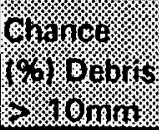 & $40 \%$ & $50 \%$ & $10 \%$ & Sum $=1.0$ \\
\hline
\end{tabular}


Additional information pertaining to the likelihood of introduction of the above debris (e.g, maint. frequency, inspection, monitoring instrumentation):

In the absence of expert input, I conversed with Andy Rittenhouse, current transuranic assembly designer, Tom McManamy, ANS experiments, and David Cook, Safety at Research Reactors Division. Mr. Rittenhouse identified the above debris concerns in his design. Mr. Cook, in his many years of experience with the High Flux Isotope Reactor (HFIR), expressed concern with the potential for sudden failure of one of the transuranic rods during operation. There was an incident with iridium targets at HFIR recently which, though the iridium targets are different than the transuranic rods, prompted his concern. My estimates are based on the information supplied by Mssrs. Rittenhouse and Cook and reflections on the location and environment in which these components are to be placed. 
APPENDIX F

EXCEL SPREADSHEET MODEL CONTAINING EXPERT INPUT, EVENT TREES, AND RESULTS 



\section{Appendix F. EXCEL SPREADSHEET MODEL CONTAINING EXPERT INPUT, EVENT TREES, AND RESULTS}

The expert data were compiled in the Excel spreadsheet shown in the following pages. It is separated into the three flow blockage scenarios $(\mathrm{L} 1, \mathrm{~L} 2, \mathrm{~L} 3)$ described in the main body of this report. Within the same spreadsheet file, simple event trees were constructed to represent the possible sequences of events that could occur following the particular scenario initiating event. The expected initiating frequency distribution for each scenario is linked to its respective event tree as the initiating event. The top events that follow the initiator are designated appropriate assumed distributions in Crystal Ball (discussed below). The formula cells were used to quantify each sequence as forecasts in Crystal Ball. In this manner, when a quantification run is made, Monte Carlo sampling is performed for all values at the same time, both in the input data and in the event tree sequence analysis. The point estimate results are shown in the cells themselves; the Monte Carlo results are reflected in the sample graphs shown in the spreadsheet. Bin frequencies may not appear exactly as $1 \times 10^{-5}$ etc. because of the random sampling that has taken place during quantification. The actual Crystal Ball quantification results are located in the output reports of Appendixes $\mathrm{G}$ and $\mathrm{H}$.

Recall that the experts were asked to consider a large number of identical systems (their own systems) in continuous operation for one year. The confidence levels provided under each bin by the domain experts represent their level of certainty that the true annual mean frequency is that particular frequency. For instance, the inner control rod system expert is $83 \%$ confident that the mean frequency of debris producing failures from his domain is $1 \times 10^{-6} /$ year (or less), $10 \%$ at $1 \times 10^{-5} /$ year, $5 \%$ at $1 \times 10^{-4} /$ year, and $2 \%$ at $1 \times 10^{-3} /$ year (or more). Each probability bin is multiplied by the corresponding confidence level and summed to determine the point estimate mean (expected) frequency for each contributing system in a given scenario. In the previous example, the expected mean is $\left(0.83 \times 1 \times 10^{-6}\right)+\left(0.1 \times 1 \times 10^{-5}\right)+\left(0.05 \times 1 \times 10^{-4}\right)+\left(0.02 \times 1 \times 10^{-3}\right)=2.68 \times 10^{-5}$ per year. Formulas are designated as "forecasts" in Crystal Ball. They perform the same arithmetic operations as before, but they will perform them hundreds of times during a run, each time using a different sample of the assumed distribution assigned to the probability bins.

In analyzing all scenarios, some modeling parameters were set regarding the type of distribution . used to represent each variable. When using Crystal Ball, input data is called an "assumption" because it is assumed to conform to a probability distribution (normal, lognormal, beta, gamma, etc.). All failure event bin frequencies $(1 \mathrm{E}-6,1 \mathrm{E}-05,1 \mathrm{E}-04,1 \mathrm{E}-03)$ were thus assumed in Crystal Ball to follow a lognormal distribution. (One of the reasons that the lognormal distribution is frequently used for describing failures in reliability and risk analysis is that data for rarely occurring events may not be extensive, and component failure rates can possibly vary by factors or orders of magnitude, as in the estimates here.) When this is done, the software arbitrarily assigns a $10 \%$ standard deviation to represent the uncertainty in the input (i.e., how much does the confidence vary?). Were we using actual experience data, this standard deviation might be acceptable. However, this study is based on expert estimates of the event frequencies, which, though based in sound knowledge, are inherently less uncertain. Therefore, in order to reflect less uncertainty, the standard deviation was increased to $100 \%$ of the expected mean value. The effect is to spread, or flatten, the probability distribution over a wider range of frequencies, an action that reduces the interior of the distribution and increases the width of the tails. The effect of this flattening was not evaluated at this time, but may be in the future when more actual data exist. 


\section{L1 Scenario Event Input Data}

Establish Failure Rate (FR) Likelihood Distribution

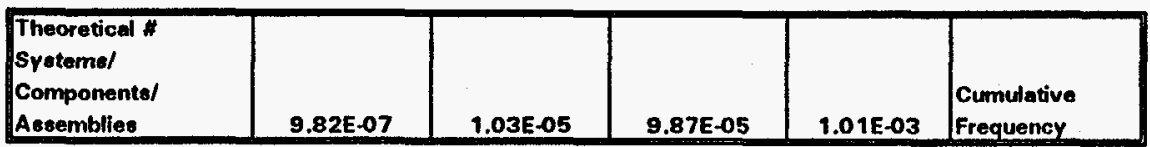

\begin{tabular}{|c|c|c|c|c|c|}
\hline MeNutt - RPCS LI & \multicolumn{3}{|c|}{ See Noto 1 Below } & & \multirow{2}{*}{$\begin{array}{r}5.74 E-05 \\
9.24 E-04 \\
\end{array}$} \\
\hline $\begin{array}{l}\text { Anderson- } \\
\text { Thermowells }\end{array}$ & 0.00 & 0.00 & 0.10 & 0.90 & \\
\hline $\begin{array}{l}\text { Andorson - cepillary } \\
\text { debris }\end{array}$ & 0.00 & 0.00 & 0.90 & 0.10 & $1.91 \mathrm{E}-04$ \\
\hline Payno. ot. al. & 0.83 & 0.10 & 0.05 & 0.02 & 2.71E-05 \\
\hline
\end{tabular}

Size Likelihood Distribution

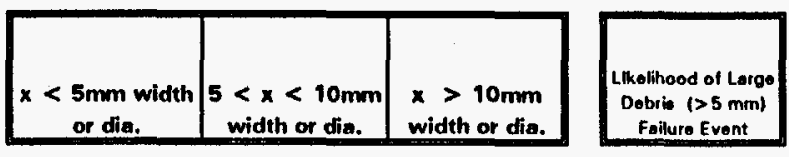

\begin{tabular}{|c|c|c|c|}
\hline 0.2 & 0.3 & 0.5 & $4.59 E-05$ \\
\hline 0.1 & 0 & 0.9 & 8.31E-04 \\
\hline 0.9 & 0.1 & 0 & $1.91 E-05$ \\
\hline 0.3 & 0.1 & 0.6 & $1.90 E-05$ \\
\hline 0.375 & 0.125 & 0.5 & $9.15 E-04$ \\
\hline
\end{tabular}

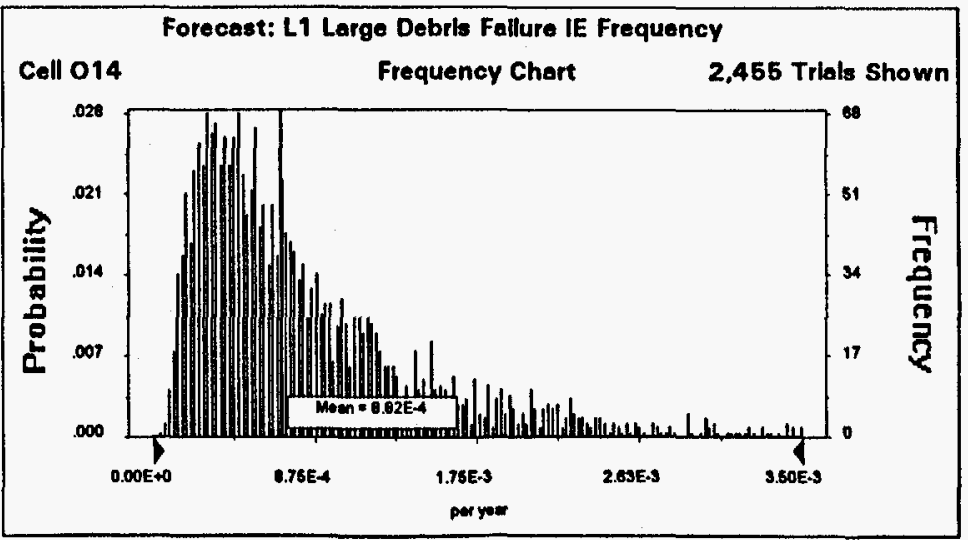


F-6

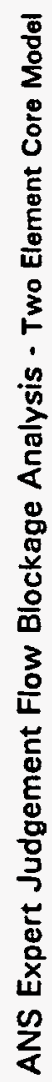

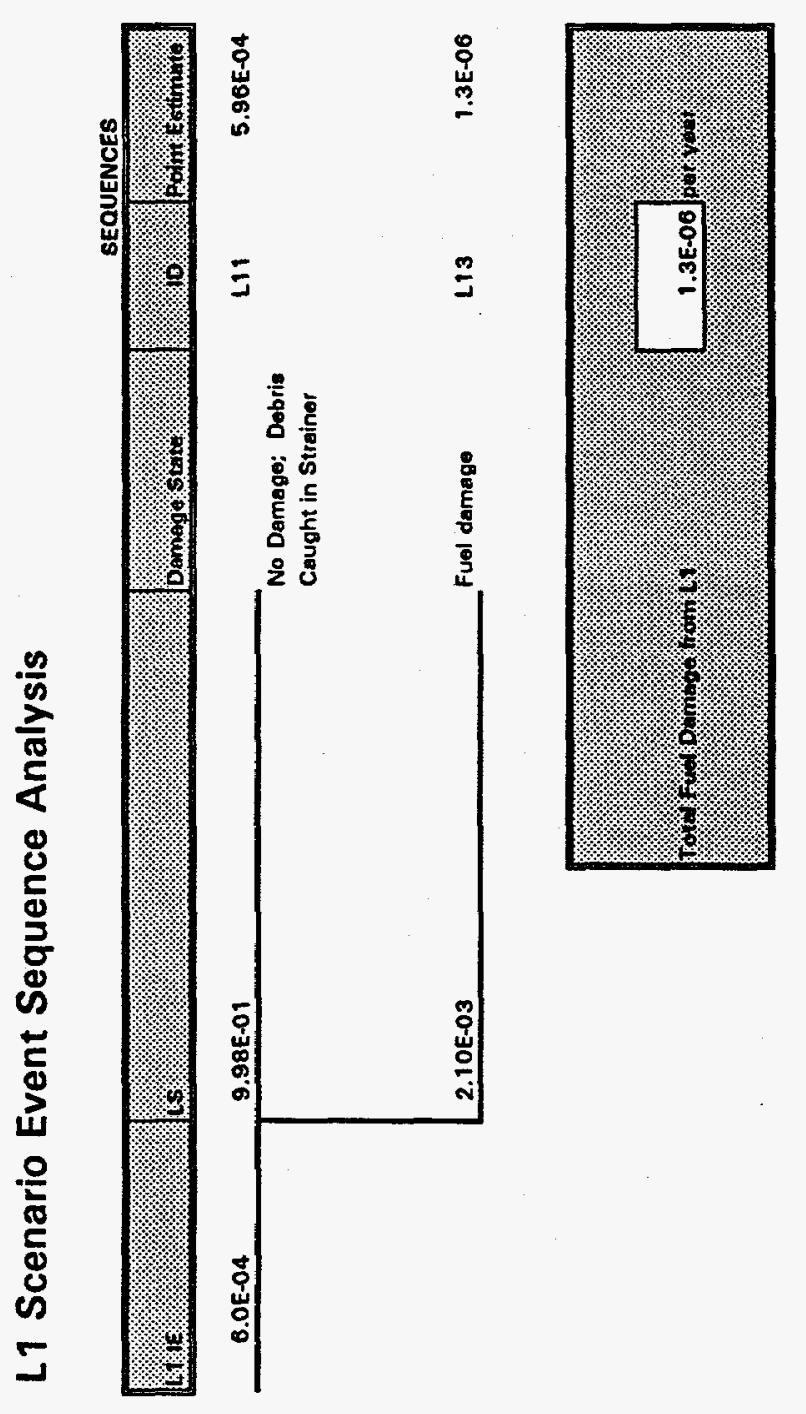

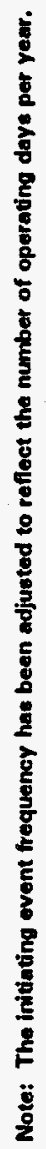

8 
F-7

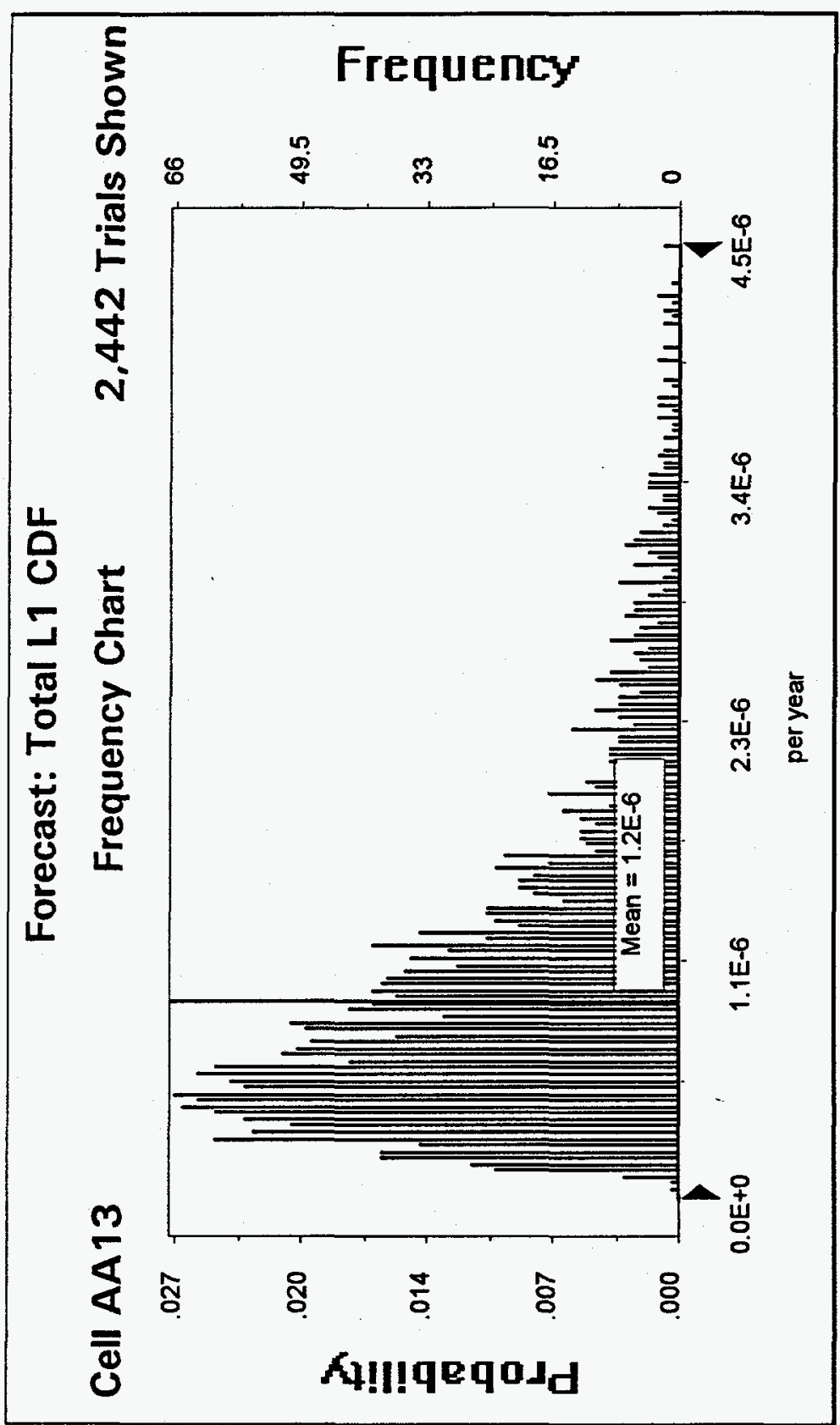


F-8

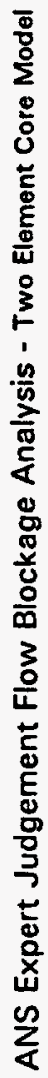
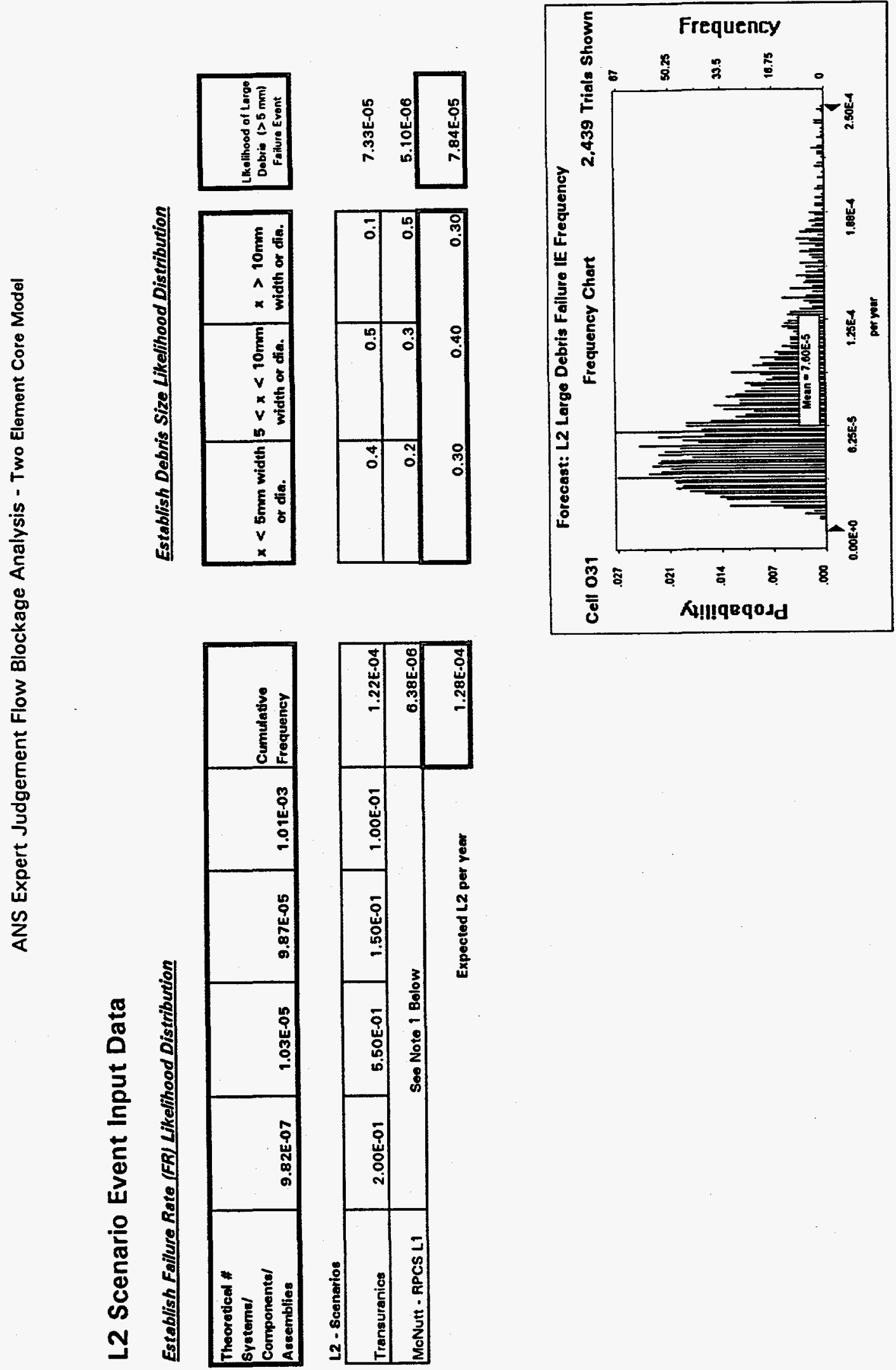

ำ

$\stackrel{8}{8}$ 
F-9

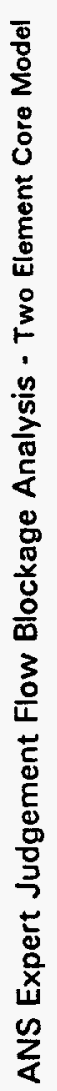

$\frac{5}{5}$
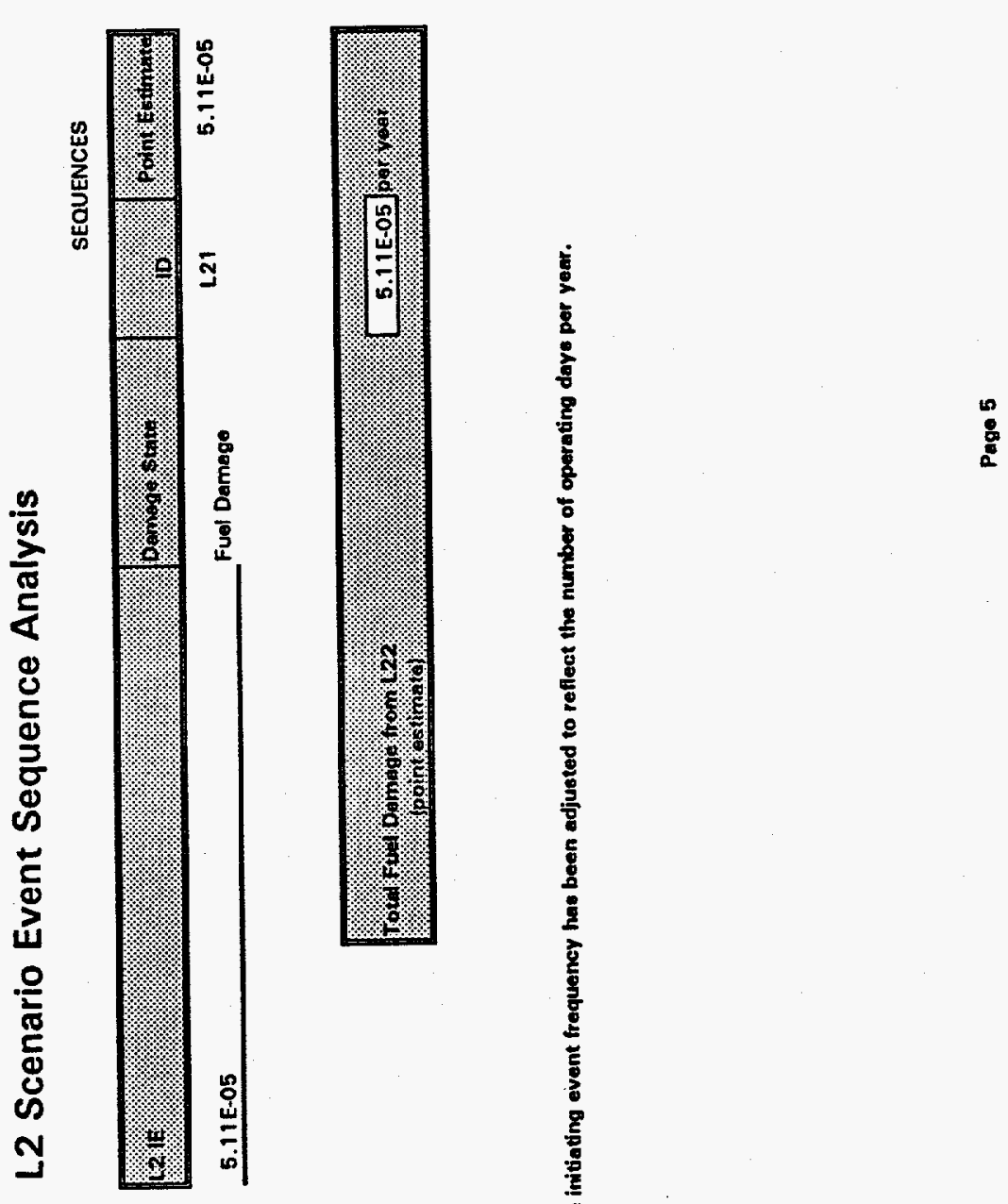

8

$\bar{\sigma}$
물
啇 


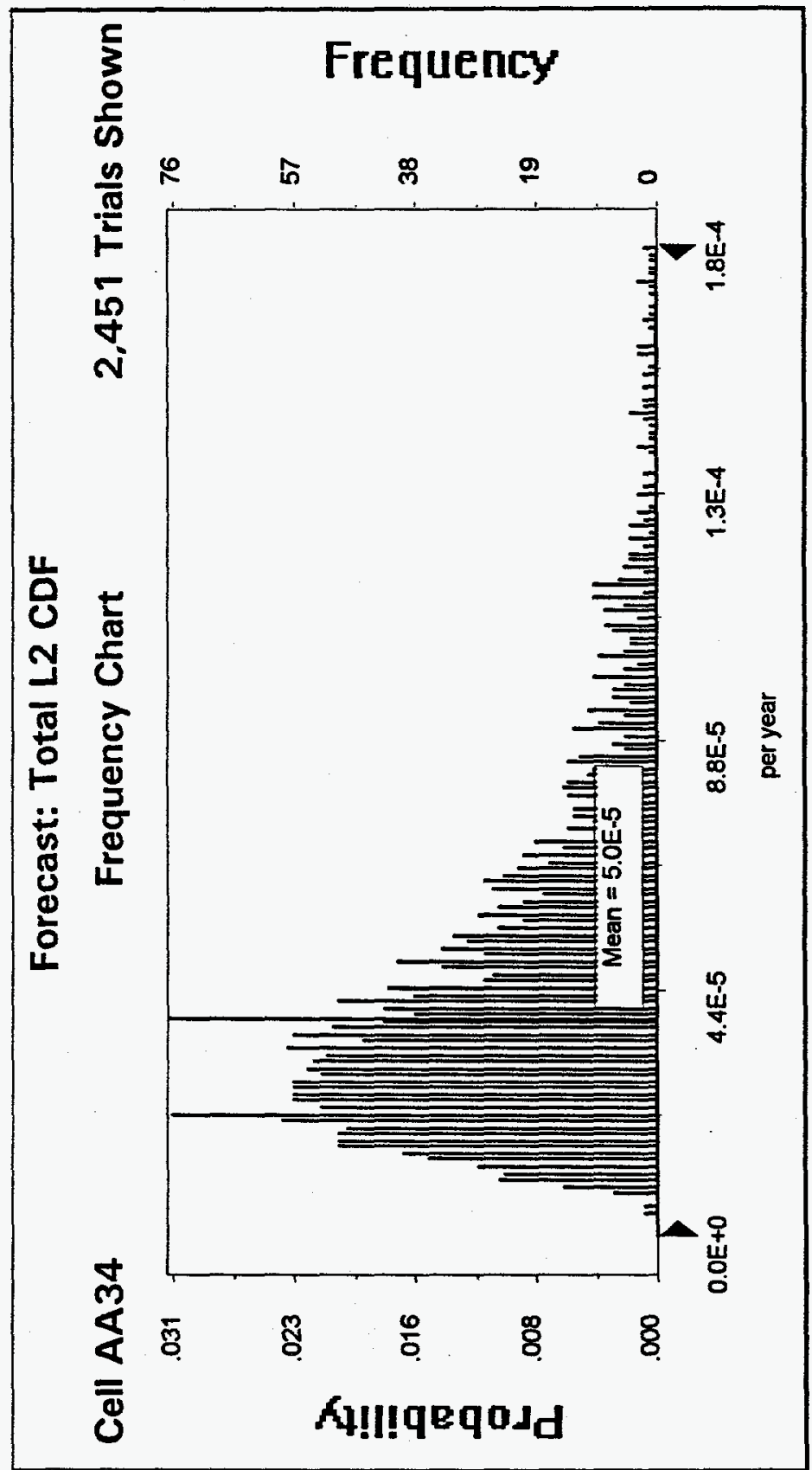


Establish Failure Rate (FR) Likelihood Distribution

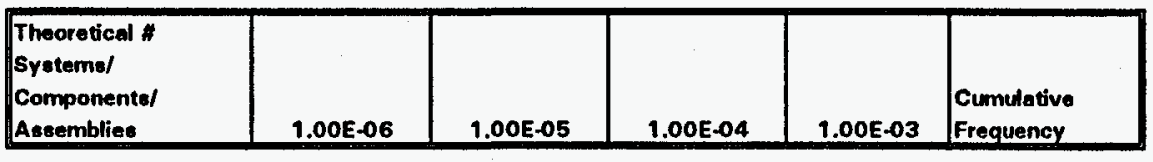

\begin{tabular}{|c|c|c|c|c|c|}
\hline Chipley - Rofuoling & 0.70 & 0.20 & 0.09 & 0.01 & $2.18 E-05$ \\
\hline MoNutt - RPICS & 0.40 & 0.30 & 0.20 & 0.10 & $1.25 \mathrm{E}-04$ \\
\hline Menutt - RPCS L3 & \multicolumn{3}{|c|}{ See Note 1 Below } & & 6.38E-05 \\
\hline
\end{tabular}

\section{Note 1: Primary Coolant System Eatimates}

The Reector Primary Coolent System (RPCS) can be involved in all three scenarios. The export's ostimated frequency was divided by scenario based on the location of equipment identified by the expert and the anticipatod maintenance activities associated with this equipment. This operation le displayed below.

\begin{tabular}{|c|c|c|c|c|c|}
\hline Total RPCS & 0.60 & 0.25 & 0.10 & 0.05 & 6.38E-05 \\
\hline \multicolumn{5}{|c|}{ LI estimate assumes $80 \%$ of total frequency } & $5.74 E-05$ \\
\hline \multicolumn{5}{|c|}{ L2 estimato assumes $10 \%$ of totel frequeney } & $6.38 \mathrm{E}-06$ \\
\hline \multicolumn{5}{|c|}{ L3 ostimate assumes froq. from maint. octivities = Pldebri } & 6.38E-05 \\
\hline
\end{tabular}

\section{Size Likelihood Distribution}

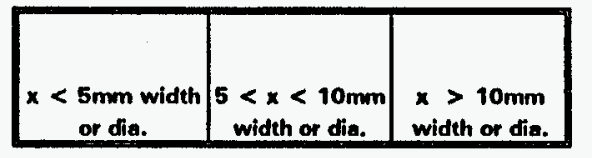

Likelihood of Large
Debrie (>5 mm) Dobrie $(>5 \mathrm{~mm})$
Failure Event

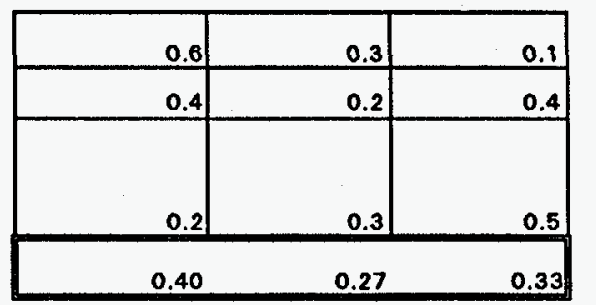

8.71E-06

$7.48 E-05$

$5.10 E-05$

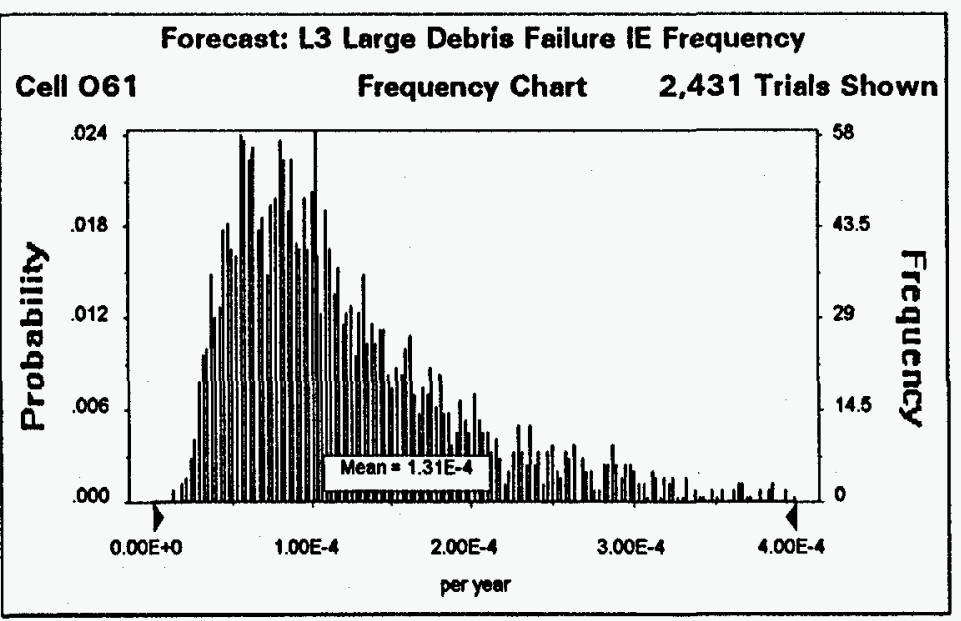


ANS Expert Judgement Flow Blockage Analysis - Two Element Core Model

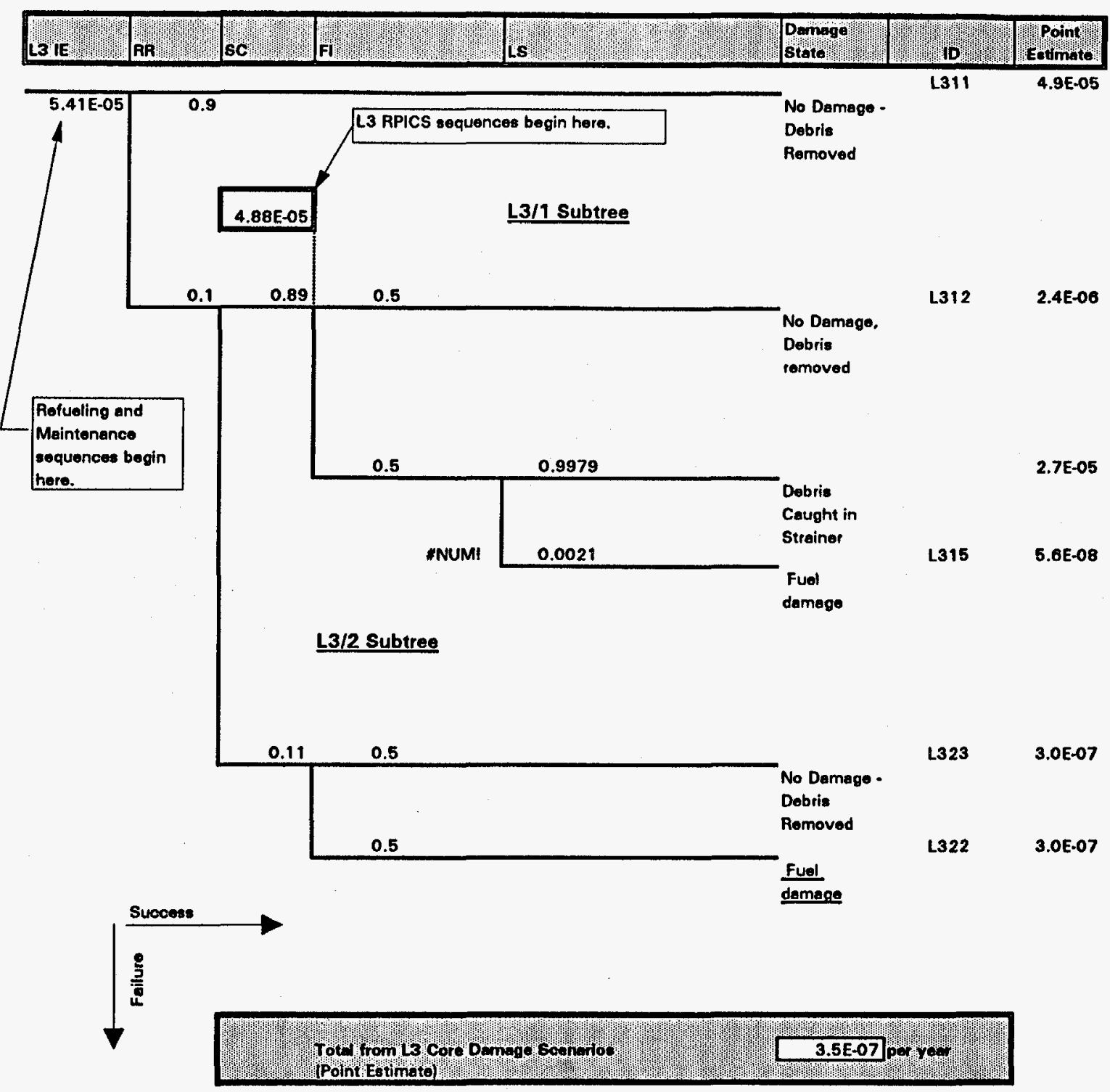


F-13

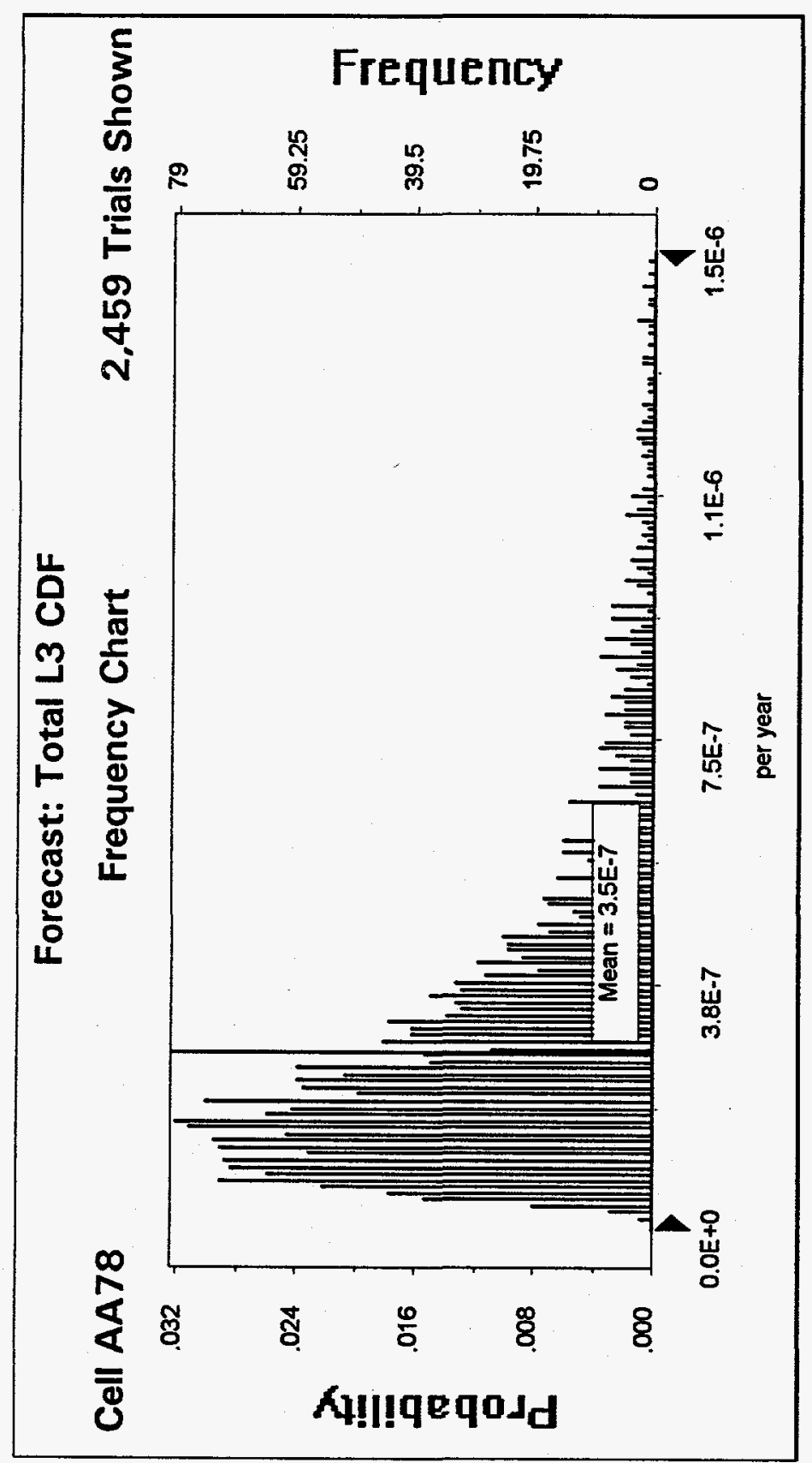

$:$ 
F-14

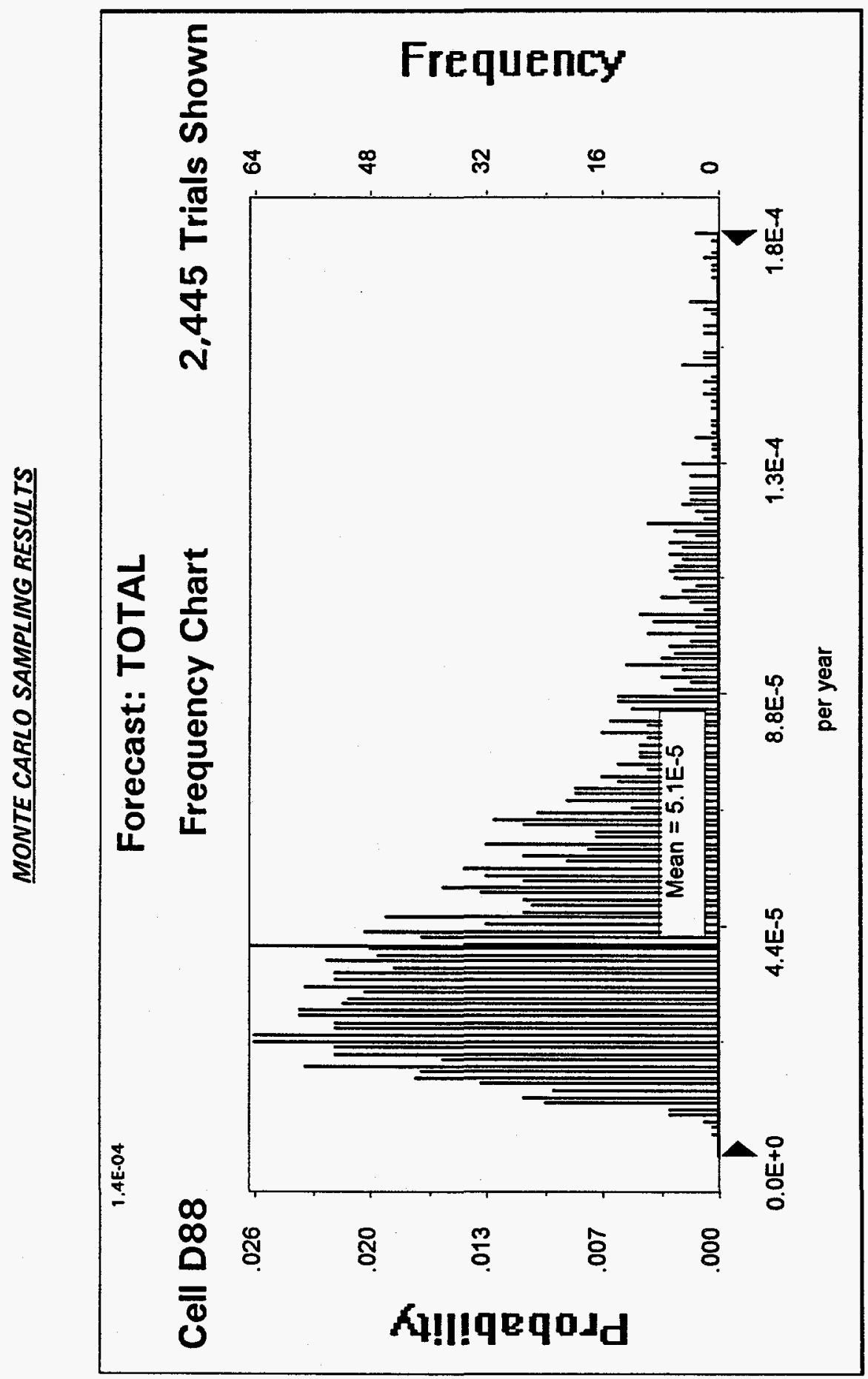


APPENDIX G

CRYSTAL BALL SIMULATION OUTPUT REPORT-TWO-ELEMENT CORE 

The simulation reports in Appendixes $\mathrm{G}$ and $\mathrm{H}$ include charts and statistical information for the calculated forecast (sequence end state) distributions and all the assumptions (initiating-event and topevent frequencies) used in their quantification. There are two sections to each appendix. The first section presents the forecast results, in other words, those probabilities or likelihoods to be calculated. Accompanying each forecast is applicable statistical information, a graphical representation of the forecast based on the sampling quantification, and the percentiles that represent the distribution.

The other section of each appendix contains all the input assumptions, so called because an assumed distribution type is associated with the input variable. The initiating-event frequencies in the flow blockage analysis were assumed to be lognormally distributed. One reason that lognormal distributions are often suitable for describing failures in reliability and risk analysis is that data for rare events may not be extensive; thus, component failure rates may vary by factors or orders of magnitude. It is then appropriate to view the lognormal distribution as applicable to situations where there is considerable uncertainty in the failure parameters (Ref. 7, p. 40). The degree of uncertainty in the assumptions is expressed by the standard deviation quantity. The three conditions underlying lognormal distributions are as follows:

1. The unknown variable can increase without bound but is confined to a finite value at the lower limit (zero in this case).

2. The unknown variable exhibits a positively skewed distribution.

3. The natural logarithm of the unknown variable yields a normal curve.

Crystal Ball runs a Monte Carlo simulation for a specified number of trials. During each trial, Crystal Ball samples from the different assumption distributions and uses the defined Excel formulas to calculate the forecast distribution and associated properties. As a result of the sampling, the value of the assumption changes slightly with each iteration. For example, the designated bins for the initiator frequency originally read as $1 \times 10^{-6}, 1 \times 10^{-5}, 1 \times 10^{-4}$, and $1 \times 10^{-3}$. However, they do not appear as those values in the first row of data in the following spreadsheet because of the sampling. Each simulation involved approximately 2000 sampling trials. 


$$
\text { G-4 }
$$

\section{Crystal Ball Report}

Simulation started on $3 / 7 / 95$ at 13:33:58

Simulation stopped on $3 / 7 / 95$ at 13:38:19

Forecast: TOTAL

Cell: D88

Summary:

Display Range is from $0.0 \mathrm{E}+0$ to $1.8 \mathrm{E}-4$ per year

Entire Range is from $4.6 \mathrm{E}-6$ to $4.9 \mathrm{E}-4$ per year

After 2,500 Trials, the Std. Error of the Mean is 8.3E-7

$\begin{array}{lr}\text { Statistics: } & \text { Value } \\ \text { Trials } & 2500 \\ \text { Mean } & 5.1 \mathrm{E}-05 \\ \text { Median (approx.) } & 3.9 \mathrm{E}-05 \\ \text { Mode (approx.) } & 2.3 \mathrm{E}-05 \\ \text { Standard Deviation } & 4.1 \mathrm{E}-05 \\ \text { Variance } & 1.7 \mathrm{E}-09 \\ \text { Skewness } & 3.02 \mathrm{E}+00 \\ \text { Kurtosis } & 1.85 \mathrm{E}+01 \\ \text { Coeff. of Variability } & 8.12 \mathrm{E}-01 \\ \text { Range Minimum } & 4.6 \mathrm{E}-06 \\ \text { Range Maximum } & 4.9 \mathrm{E}-04 \\ \text { Range Width } & 4.9 \mathrm{E}-04 \\ \text { Mean Std. Error } & 8.30 \mathrm{E}-07\end{array}$

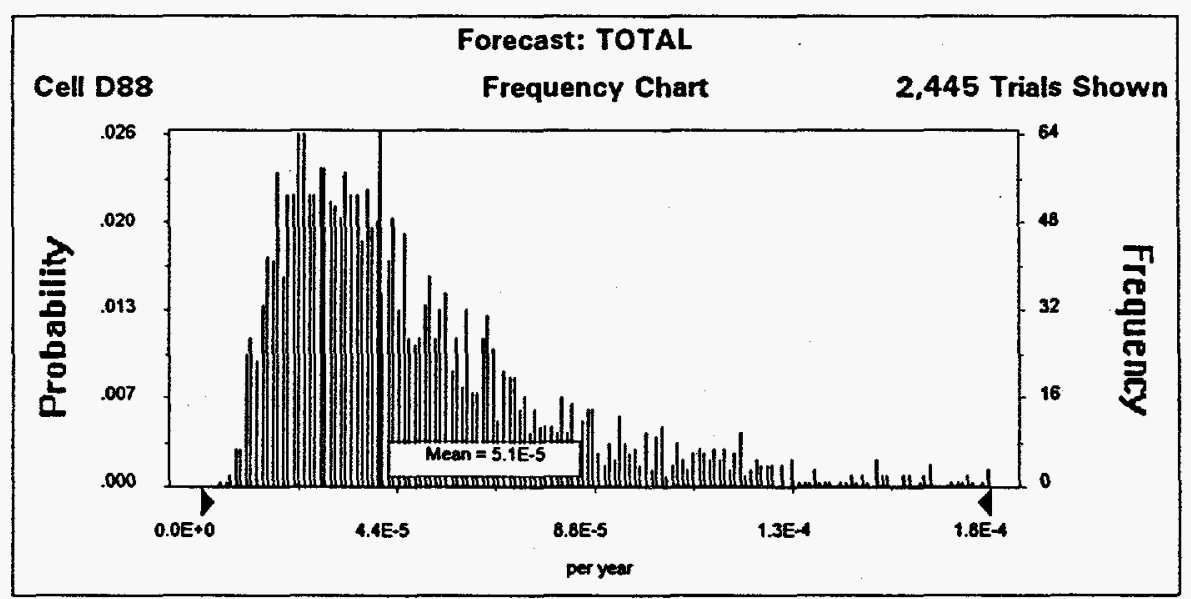


Forecast: TOTAL (cont'd)

Cell: D88

Percentiles:

\begin{tabular}{r} 
Percentile \\
\hline $0 \%$ \\
$5 \%$ \\
$25 \%$ \\
$50 \%$ \\
$75 \%$ \\
$95 \%$ \\
$100 \%$
\end{tabular}

\begin{tabular}{r} 
per vear (approx.) \\
\hline $4.6 \mathrm{E}-06$ \\
$1.4 \mathrm{E}-05$ \\
$2.5 \mathrm{E}-05$ \\
$3.9 \mathrm{E}-05$ \\
$6.3 \mathrm{E}-05$ \\
$1.2 \mathrm{E}-04$ \\
$4.9 \mathrm{E}-04$
\end{tabular}

End of Forecast 
Summary:

Display Range is from $0.0 \mathrm{E}+0$ to $4.5 \mathrm{E}-6$ per year

Entire Range is from 4.5E-8 to 1.2E-5 per year

After 2,500 Trials, the Std. Error of the Mean is 2.2E-8

Statistics:

Value

Trials

2500

Mean

1.2E-06

Median (approx.)

8.6E-07

Mode (approx.)

4.9E-07

Standard Deviation

1.1E-06

Variance

1.3E-12

Skewness

$3.10 E+00$

Kurtosis

$1.88 \mathrm{E}+01$

Coeff. of Variability

9.43E-01

Range Minimum

4.5E-08

Range Maximum

1.2E-05

Range Width

1.2E-05

Mean Std. Error

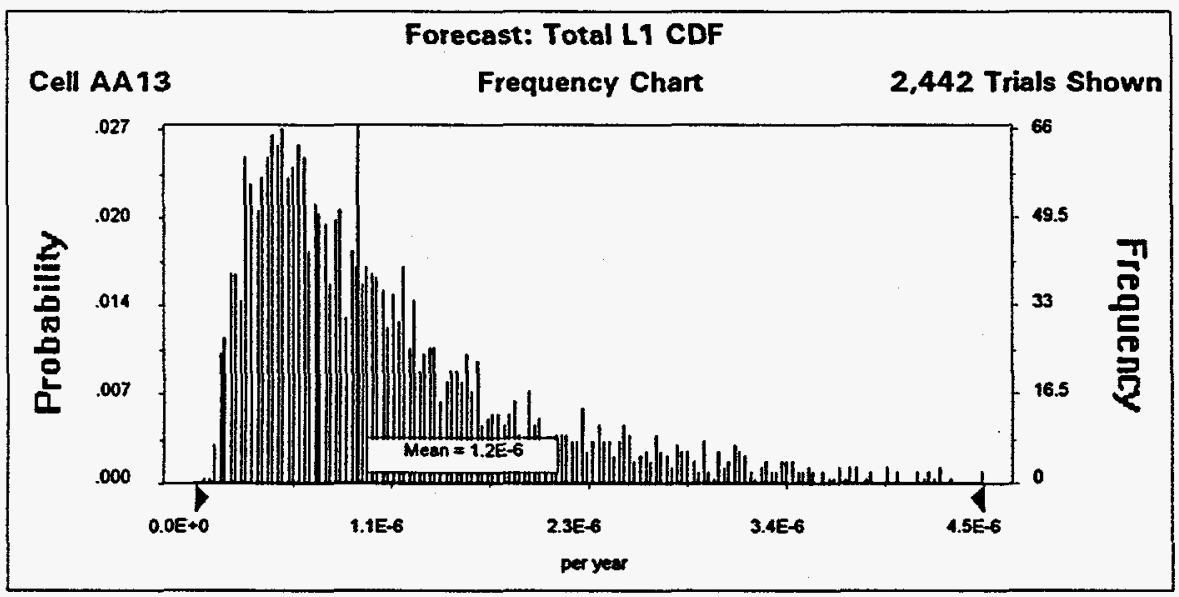


Forecast: Total L1 CDF (cont'd)

Percentiles:

\begin{tabular}{r} 
Percentile \\
\hline $0 \%$ \\
$5 \%$ \\
$25 \%$ \\
$50 \%$ \\
$75 \%$ \\
$95 \%$ \\
$100 \%$
\end{tabular}

per year (approx.)
$4.5 \mathrm{E}-08$
$2.3 \mathrm{E}-07$
$5.0 \mathrm{E}-07$
$8.6 \mathrm{E}-07$
$1.5 \mathrm{E}-06$
$3.2 \mathrm{E}-06$
$1.2 \mathrm{E}-05$

End of Forecast 
Summary:

Display Range is from $0.0 \mathrm{E}+0$ to $1.8 \mathrm{E}-4$ per year

Entire Range is from $4.5 \mathrm{E}-6$ to $4.8 \mathrm{E}-4$ per year

After 2,500 Trials, the Std. Error of the Mean is 8.0E-7

$\begin{array}{lr}\text { Statistics: } & \frac{\text { Value }}{2500} \\ \text { Trials } & 2.0 \mathrm{E}-05 \\ \text { Mean } & 3.8 \mathrm{E}-05 \\ \text { Median (approx.) } & 2.2 \mathrm{E}-05 \\ \text { Mode (approx.) } & 4.0 \mathrm{E}-05 \\ \text { Standard Deviation } & 1.6 \mathrm{E}-09 \\ \text { Variance } & 3.00 \mathrm{E}+00 \\ \text { Skewness } & 1.84 \mathrm{E}+01 \\ \text { Kurtosis } & 8.09 \mathrm{E}-01 \\ \text { Coeff. of Variability } & 4.5 \mathrm{E}-06 \\ \text { Range Minimum } & 4.8 \mathrm{E}-04 \\ \text { Range Maximum } & 4.7 \mathrm{E}-04 \\ \text { Range Width } & 8.02 \mathrm{E}-07 \\ \text { Mean Std. Error } & \end{array}$

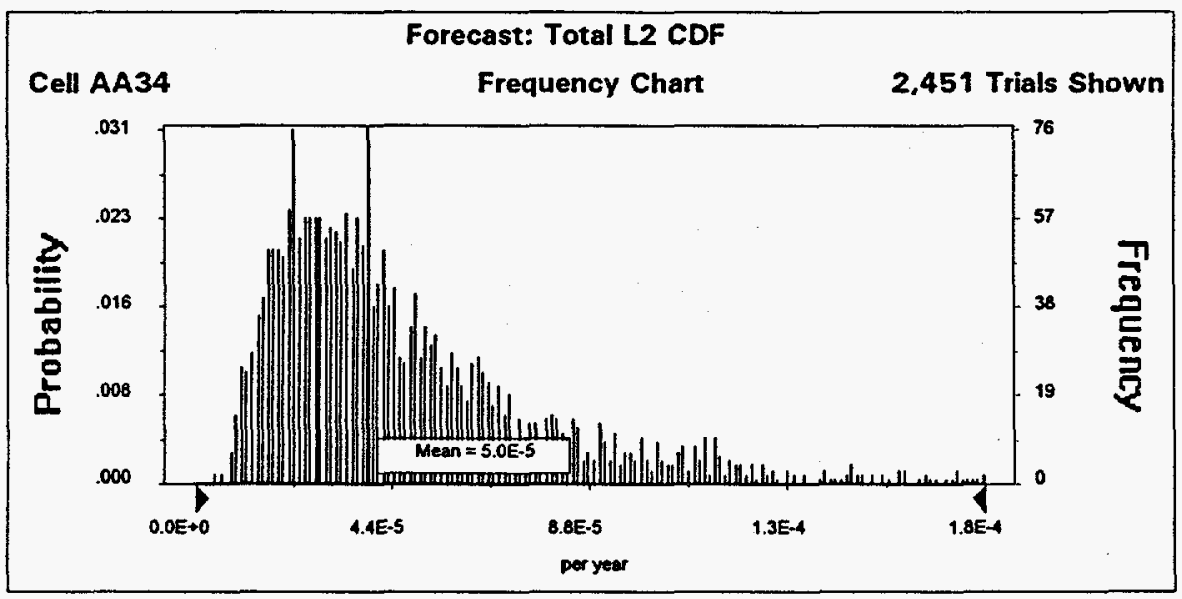


Forecast: Total L2 CDF (cont'd)

Percentiles:

\begin{tabular}{r} 
Percentile \\
\hline $0 \%$ \\
$5 \%$ \\
$25 \%$ \\
$50 \%$ \\
$75 \%$ \\
$95 \%$ \\
$100 \%$
\end{tabular}

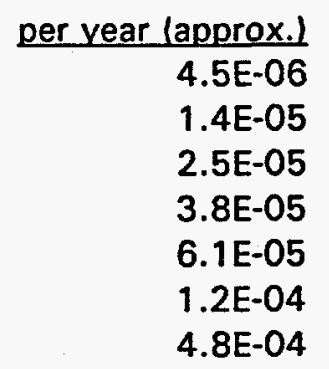

End of Forecast 
Summary:

Display Range is from $0.0 E+0$ to $1.5 E-6$ per year

Entire Range is from 1.3E-8 to $7.8 \mathrm{E}-6$ per year

After 2,500 Trials, the Std. Error of the Mean is 8.2E-9

$\begin{array}{lr}\text { Statistics: } & \frac{\text { Value }}{2500} \\ \text { Trials } & 3.5 \mathrm{E}-07 \\ \text { Mean } & 2.4 \mathrm{E}-07 \\ \text { Median (approx.) } & 1.4 \mathrm{E}-07 \\ \text { Mode (approx.) } & 4.1 \mathrm{E}-07 \\ \text { Standard Deviation } & 1.7 \mathrm{E}-13 \\ \text { Variance } & 6.26 \mathrm{E}+00 \\ \text { Skewness } & 7.54 \mathrm{E}+01 \\ \text { Kurtosis } & 1.18 \mathrm{E}+00 \\ \text { Coeff. of Variability } & 1.3 \mathrm{E}-08 \\ \text { Range Minimum } & 7.8 \mathrm{E}-06 \\ \text { Range Maximum } & 7.8 \mathrm{E}-06 \\ \text { Range Width } & 8.16 \mathrm{E}-09 \\ \text { Mean Std. Error } & \end{array}$

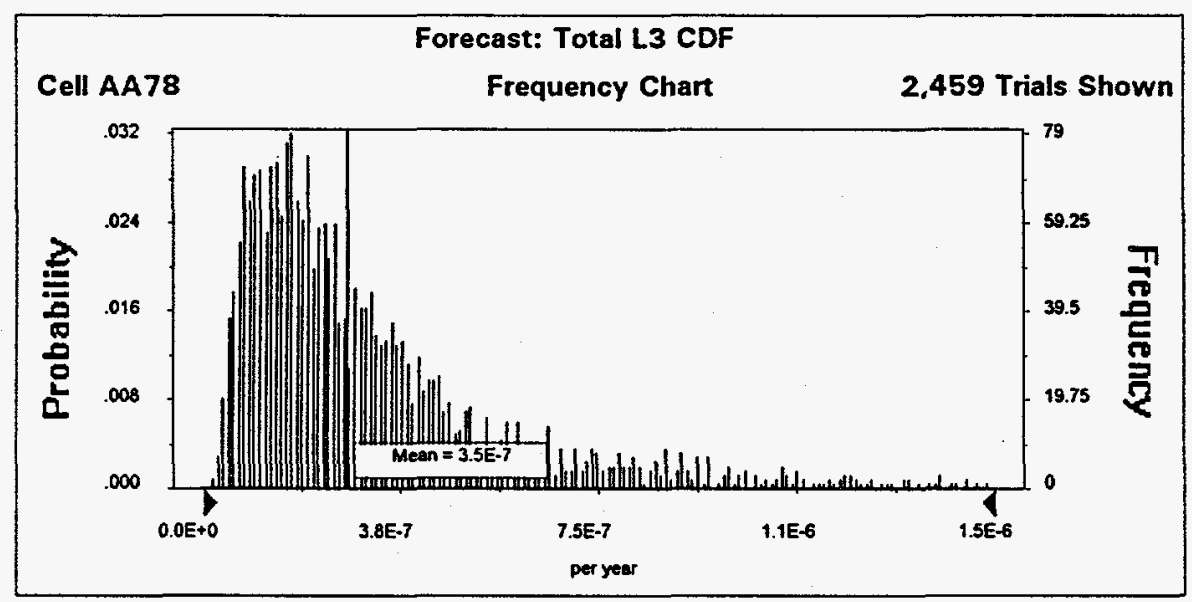


Forecast: Total L3 CDF (cont'd)

Percentiles:

\begin{tabular}{r} 
Percentile \\
\hline $0 \%$ \\
$5 \%$ \\
$25 \%$ \\
$50 \%$ \\
$75 \%$ \\
$95 \%$ \\
$100 \%$
\end{tabular}

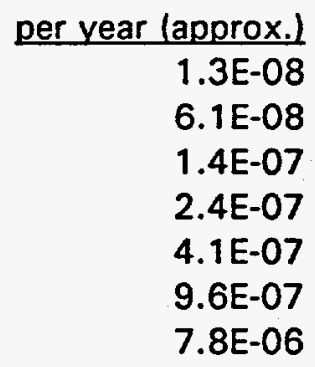

End of Forecast 
Summary:

Display Range is from $0.00 \mathrm{E}+0$ to $3.50 \mathrm{E}-3$ per year

Entire Range is from $4.13 \mathrm{E}-5$ to $9.88 \mathrm{E}-3$ per year

After 2,500 Trials, the Std. Error of the Mean is 1.64E-5

$\begin{array}{lr}\text { Statistics: } & \frac{\text { Value }}{2500} \\ \text { Trials } & 8.82 \mathrm{E}-04 \\ \text { Mean } & 6.42 \mathrm{E}-04 \\ \text { Median (approx.) } & 4.02 \mathrm{E}-04 \\ \text { Mode (approx.) } & 8.22 \mathrm{E}-04 \\ \text { Standard Deviation } & 6.76 \mathrm{E}-07 \\ \text { Variance } & 3.11 \\ \text { Skewness } & 19.40 \\ \text { Kurtosis } & 0.93 \\ \text { Coeff. of Variability } & 4.13 \mathrm{E}-05 \\ \text { Range Minimum } & 9.88 \mathrm{E}-03 \\ \text { Range Maximum } & 9.84 \mathrm{E}-03 \\ \text { Range Width } & 1.64 \mathrm{E}-05 \\ \text { Mean Std. Error } & \end{array}$

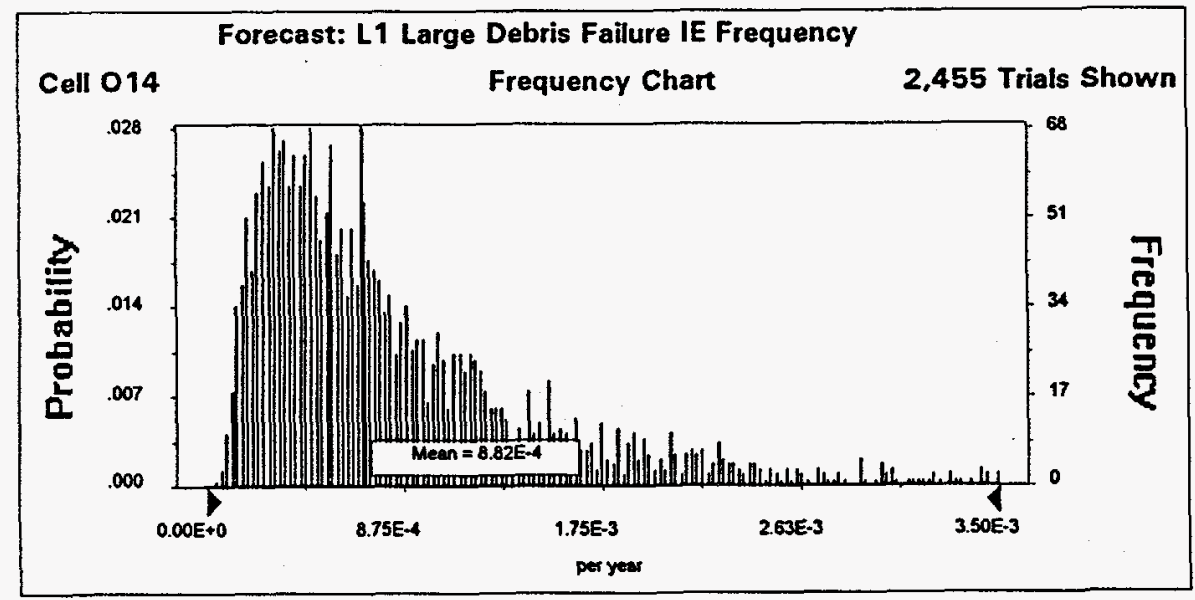


Forecast: L1 Large Debris Failure IE Frequency (cont'd)

Percentiles:

\begin{tabular}{r} 
Percentile \\
\hline $0 \%$ \\
$5 \%$ \\
$25 \%$ \\
$50 \%$ \\
$75 \%$ \\
$95 \%$ \\
$100 \%$
\end{tabular}

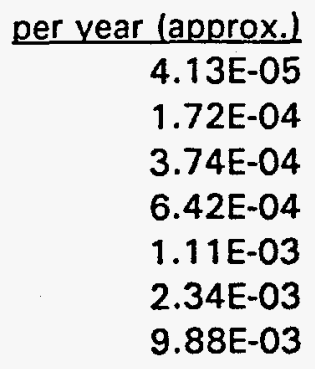

End of Forecast 
Summary:

Display Range is from $0.00 E+0$ to $2.50 E-4$ per year

Entire Range is from 6.86E-6 to 7.33E-4 per year

After 2,500 Trials, the Std. Error of the Mean is $1.23 \mathrm{E}-6$

Statistics:

Value

Trials

2500

Mean

$7.60 \mathrm{E}-05$

Median (approx.)

5.86E-05

Mode (approx.)

3.35E-05

Standard Deviation

$6.15 \mathrm{E}-05$

Variance

3.78E-09

Skewness

3.00

Kurtosis

18.36

Coeff. of Variability

0.81

Range Minimum

6.86E-06

Range Maximum

7.33E-04

Range Width

7.26E-04

Mean Std. Error

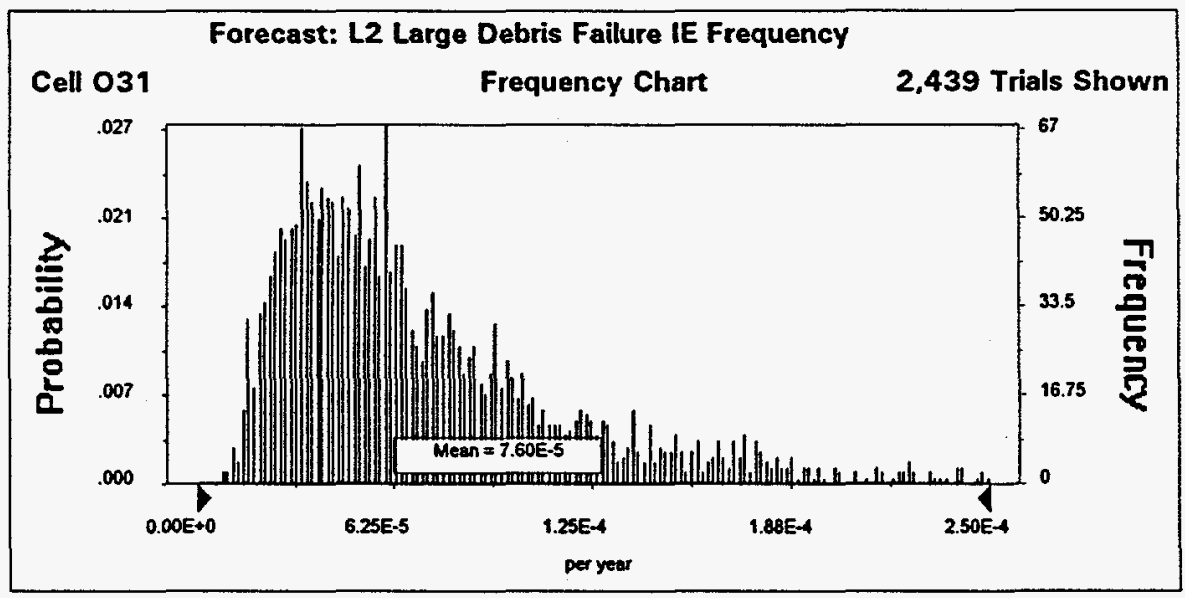


Forecast: L2 Large Debris Failure IE Frequency (cont'd)

Percentiles:

\begin{tabular}{r} 
Percentile \\
\hline $0 \%$ \\
$5 \%$ \\
$25 \%$ \\
$50 \%$ \\
$75 \%$ \\
$95 \%$ \\
$100 \%$
\end{tabular}

\begin{tabular}{r} 
per vear (approx.) \\
\hline $6.86 \mathrm{E}-06$ \\
$2.08 \mathrm{E}-05$ \\
$3.77 \mathrm{E}-05$ \\
$5.86 \mathrm{E}-05$ \\
$9.37 \mathrm{E}-05$ \\
$1.83 \mathrm{E}-04$ \\
$7.33 \mathrm{E}-04$
\end{tabular}

End of Forecast 
Summary:

Display Range is from $0.00 E+0$ to $4.00 E-4$ per year

Entire Range is from 1.22E-5 to $1.20 \mathrm{E}-3$ per year

After 2,500 Trials, the Std. Error of the Mean is 2.03E-6

$\begin{array}{lr}\text { Statistics: } & \text { Value } \\ \text { Trials } & 2500 \\ \text { Mean } & 1.31 \mathrm{E}-04 \\ \text { Median (approx.) } & 1.03 \mathrm{E}-04 \\ \text { Mode (approx.) } & 5.57 \mathrm{E}-05 \\ \text { Standard Deviation } & 1.02 \mathrm{E}-04 \\ \text { Variance } & 1.03 \mathrm{E}-08 \\ \text { Skewness } & 2.91 \\ \text { Kurtosis } & 17.50 \\ \text { Coeff. of Variability } & 0.78 \\ \text { Range Minimum } & 1.22 \mathrm{E}-05 \\ \text { Range Maximum } & 1.20 \mathrm{E}-03 \\ \text { Range Width } & 1.19 \mathrm{E}-03 \\ \text { Mean Std. Error } & 2.03 \mathrm{E}-06\end{array}$

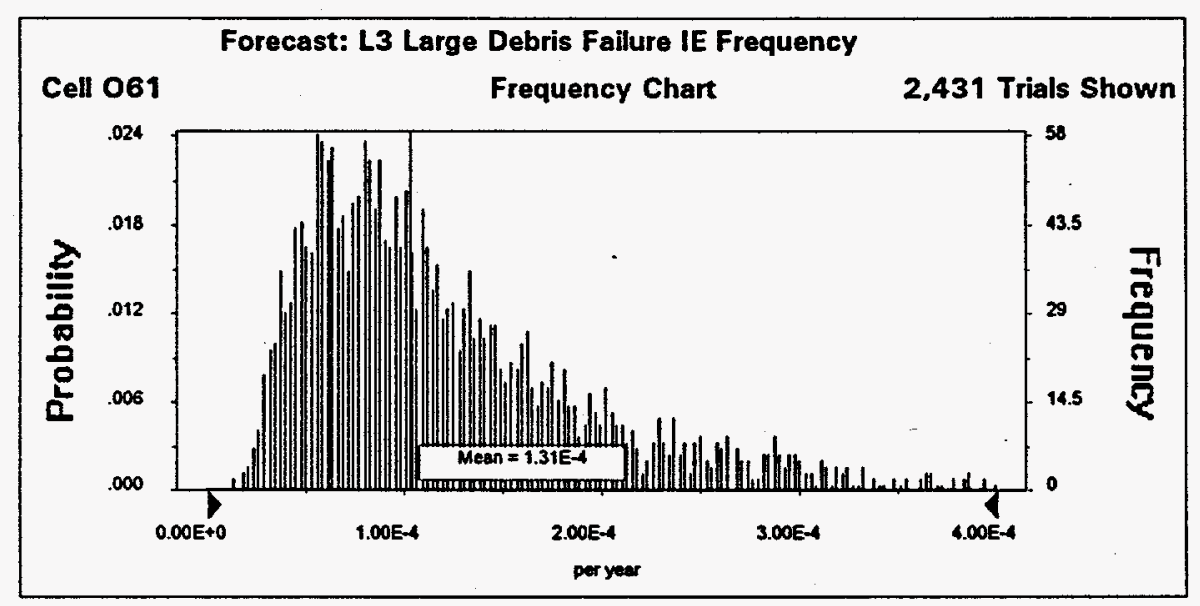




\section{G-17}

Forecast: L3 Large Debris Failure IE Frequency (cont'd)

Cell: 061

Percentiles:

\begin{tabular}{r} 
Percentile \\
\hline $0 \%$ \\
$5 \%$ \\
$25 \%$ \\
$50 \%$ \\
$75 \%$ \\
$95 \%$ \\
$100 \%$
\end{tabular}

\begin{tabular}{r} 
per year (approx.) \\
\hline $1.22 \mathrm{E}-05$ \\
$3.73 \mathrm{E}-05$ \\
$6.70 \mathrm{E}-05$ \\
$1.03 \mathrm{E}-04$ \\
$1.61 \mathrm{E}-04$ \\
$3.09 \mathrm{E}-04$ \\
$1.20 \mathrm{E}-03$
\end{tabular}

End of Forecast 
Assumptions

Assumption: Once in a million years

Céll: D8

Lognormal distribution with parameters:

Mean

Standard Dev.
1.00E-06

1.00E-06

Selected range is from $0.00 E+0$ to + Infinity Mean value in simulation was $9.90 \mathrm{E}-7$

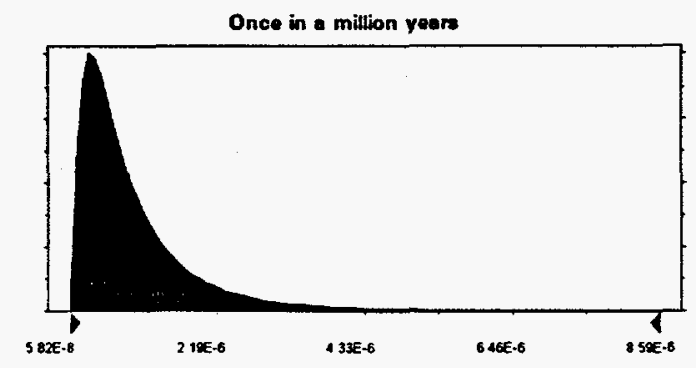

Assumption: one in 100,000

Cell: E8

Lognormal distribution with parameters:

Mean

Standard Dev.

Selected range is from $0.00 E+0$ to + Infinity Mean value in simulation was $9.85 \mathrm{E}-6$

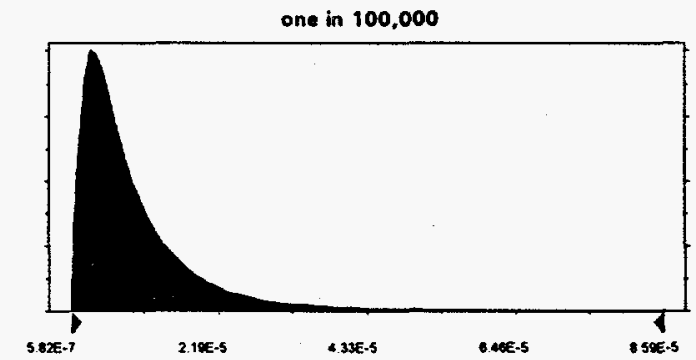


Lognormal distribution with parameters:
Mean
$1.00 E-04$
Standard Dev.
$1.00 \mathrm{E}-04$

Selected range is from $0.00 E+0$ to + Infinity Mean value in simulation was $1.02 \mathrm{E}-4$

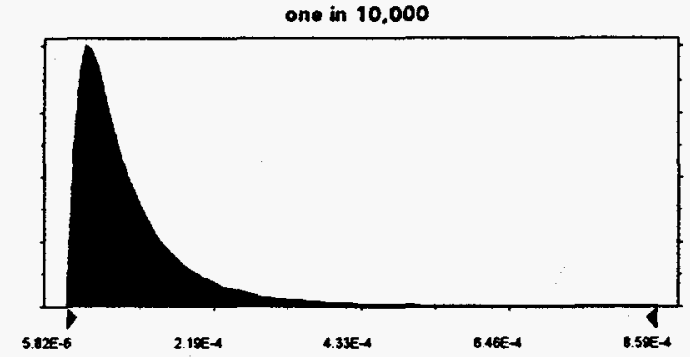

Assumption: Once every 1.000 years

Lognormal distribution with parameters:
Mean
$1.00 E-03$
Standard Dev.
$1.00 E-03$

Selected range is from $0.00 E+0$ to + Infinity Mean value in simulation was $9.75 \mathrm{E}-4$

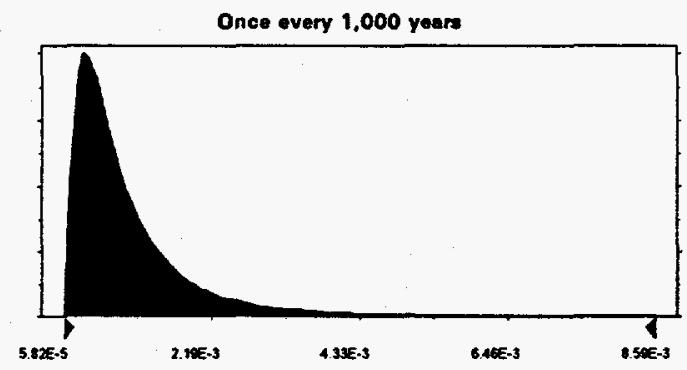


Lognormal distribution with parameters:
Mean
2.1E-03
Standard Dev.
2.1E-04

Selected range is from $0.0 E+0$ to + Infinity Mean value in simulation was $2.1 \mathrm{E}-3$

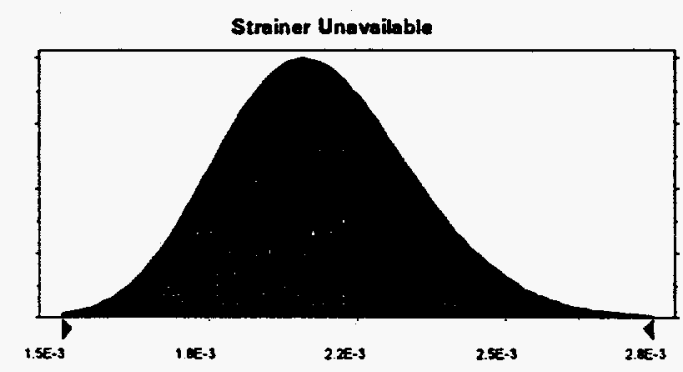

Assumption: Debris is Recognized and Removed

Lognormal distribution with parameters:
Mean
0.10
Standard Dev.
0.05

Selected range is from 0.00 to + Infinity Mean value in simulation was 0.10

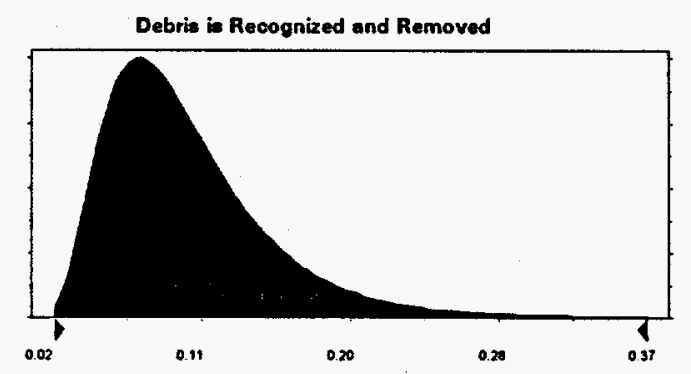


Lognormal distribution with parameters:
Mean
0.50
Standard Dev.
0.09

Selected range is from 0.00 to + Infinity Mean value in simulation was 0.50

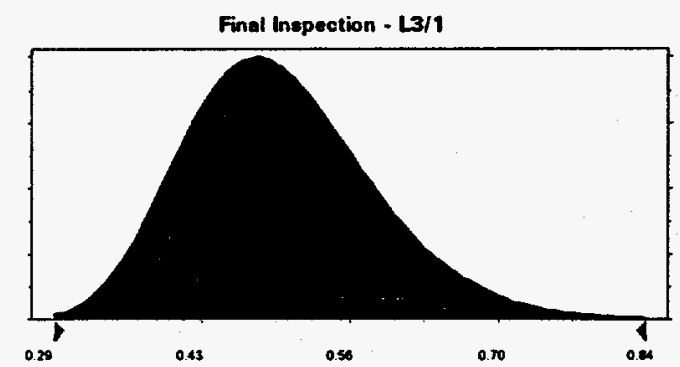

Assumption: Failure to Remove at Final Inspection

Lognormal distribution with parameters:
Mean
0.50
Standard Dev.
0.09

Selected range is from 0.00 to + Infinity

Mean value in simulation was 0.50

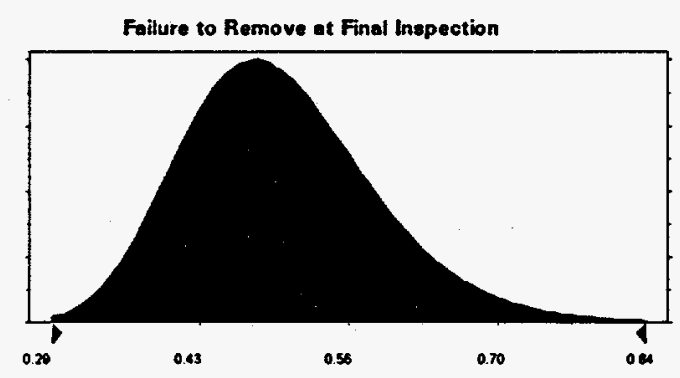


Lognormal distribution with parameters:

$\begin{array}{ll}\text { Mean } & 0.89 \\ \text { Standard Dev. } & 0.09\end{array}$

Selected range is from 0.00 to 1.00

Mean value in simulation was 0.87

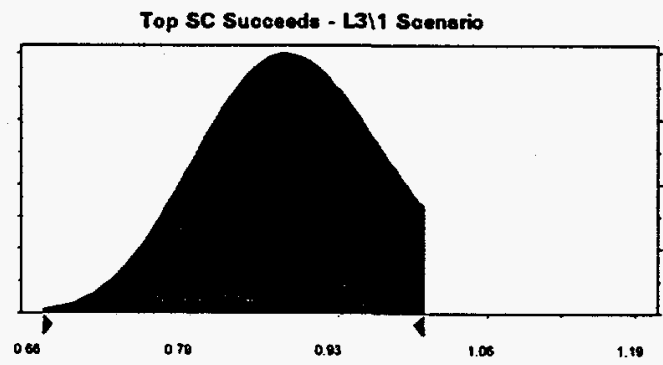

Assumption: Top SC Fails - L3/2 Scenario

Lognormal distribution with parameters:
Mean
0.11
Standard Dev.
0.05

Selected range is from 0.00 to + Infinity

Mean value in simulation was 0.11

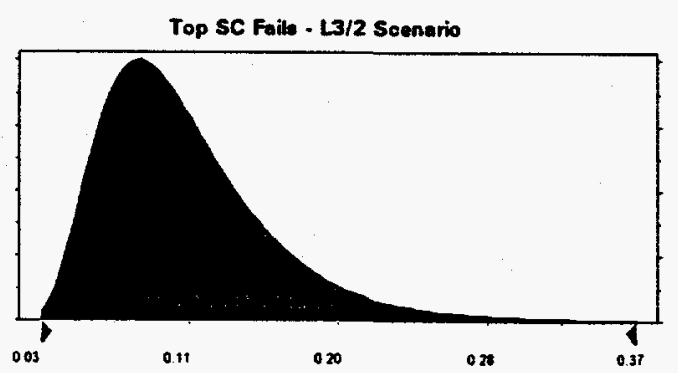

End of Assumptions 
APPENDIX H

CRYSTAL BALL SIMULATION OUTPUT REPORT-THREE ELEMENT CORE 



\section{Crystal Ball Report}

Simulation started on $3 / 3 / 95$ at $8: 42: 58$

Simulation stopped on $3 / 3 / 95$ at $8: 46: 07$

Forecast: TOTAL

Summary:

Display Range is from 9.31E-7 to $1.69 \mathrm{E}-5$ per year

Entire Range is from 3.98E-7 to $5.48 \mathrm{E}-5$ per year

After 2,500 Trials, the Std. Error of the Mean is 8.49E-8

Statistics:

Trials

Value

Mean

2500

Median (approx.)

4.98E-06

Mode (approx.)

3.88E-06

Standard Deviation

2.85E-06

Variance

4.24E-06

Skewness

$1.80 \mathrm{E}-11$

Kurtosis

$4.05 E+00$

Coeff. of Variability

$3.31 E+01$

Range Minimum

8.51E-01

Range Maximum

3.98E-07

Range Width

5.48E-05

Mean Std. Error

5.44E-05

8.49E-08

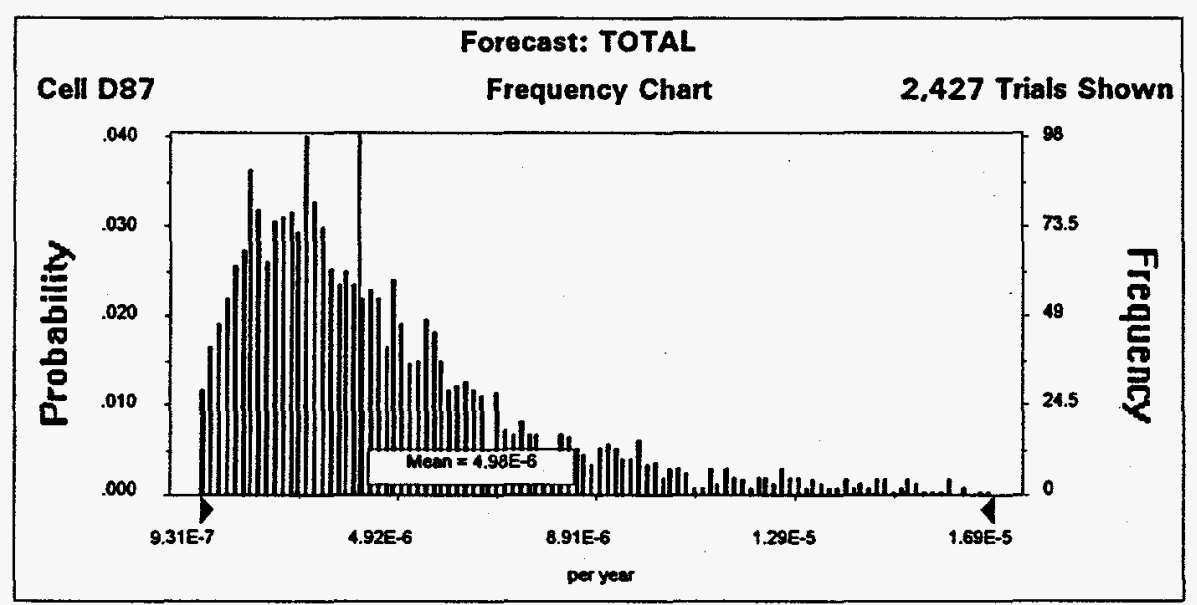


$\mathrm{H}-4$

Forecast: TOTAL (cont'd)

Cell: D87

Percentiles:

\begin{tabular}{rr} 
Percentile & per vear (approx.) \\
\hline $0 \%$ & $3.98 \mathrm{E}-07$ \\
$5 \%$ & $1.36 \mathrm{E}-06$ \\
$25 \%$ & $2.53 \mathrm{E}-06$ \\
$50 \%$ & $3.88 \mathrm{E}-06$ \\
$75 \%$ & $5.97 \mathrm{E}-06$ \\
$95 \%$ & $1.23 \mathrm{E}-05$ \\
$100 \%$ & $5.48 \mathrm{E}-05$
\end{tabular}

End of Forecast 
Summary:

Display Range is from 1.85E-7 to $4.98 \mathrm{E}-6$ per year

Entire Range is from $8.57 \mathrm{E}-8$ to $1.74 \mathrm{E}-5$ per year

After 2,500 Trials, the Std. Error of the Mean is 2.61E-8

Statistics:

Value

Trials

2500

Mean

$1.33 E-06$

Median (approx.)

9.69E-07

Mode (approx.)

6.93E-07

Standard Deviation

1.30E-06

Variance

$1.70 \mathrm{E}-12$

Skewness

$4.29 E+00$

Kurtosis

$3.64 \mathrm{E}+01$

Coeff. of Variability

9.81E-01

Range Minimum

8.57E-08

Range Maximum

1.74E-05

Range Width

$1.74 \mathrm{E}-05$

Mean Std. Error

2.61E-08

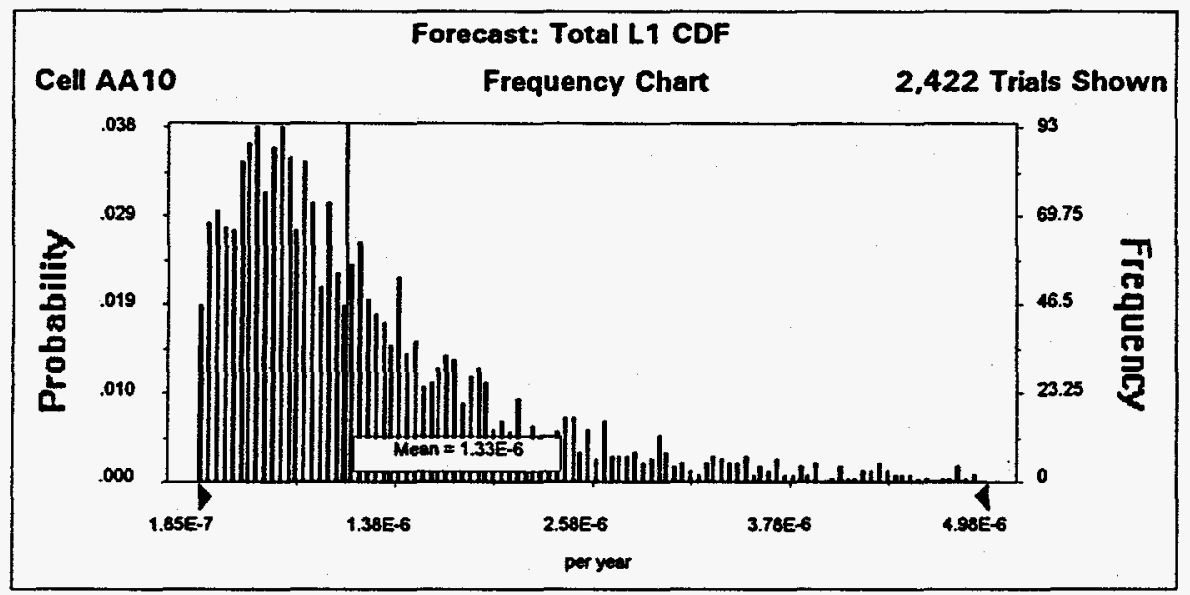


Forecast: Total L1 CDF (cont'd)

Percentiles:

\begin{tabular}{rr} 
Percentile & per vear (approx.l \\
\hline $0 \%$ & $8.57 \mathrm{E}-08$ \\
$5 \%$ & $2.75 \mathrm{E}-07$ \\
$25 \%$ & $5.82 \mathrm{E}-07$ \\
$50 \%$ & $9.69 \mathrm{E}-07$ \\
$75 \%$ & $1.64 \mathrm{E}-06$ \\
$95 \%$ & $3.52 \mathrm{E}-06$ \\
$100 \%$ & $1.74 \mathrm{E}-05$
\end{tabular}

End of Forecast 
Summary:

Display Range is from 6.50E-7 to $1.09 E-5$ per year

Entire Range is from 2.83E-7 to $3.58 \mathrm{E}-5$ per year

After 2,500 Trials, the Std. Error of the Mean is 5.35E-8

$\begin{array}{lr}\text { Statistics: } & \frac{\text { Value }}{2500} \\ \text { Trials } & 3.31 \mathrm{E}-06 \\ \text { Mean } & 2.61 \mathrm{E}-06 \\ \text { Median (approx.) } & 1.88 \mathrm{E}-06 \\ \text { Mode (approx.) } & 2.68 \mathrm{E}-06 \\ \text { Standard Deviation } & 7.17 \mathrm{E}-12 \\ \text { Variance } & 3.87 \mathrm{E}+00 \\ \text { Skewness } & 3.10 \mathrm{E}+01 \\ \text { Kurtosis } & 8.09 \mathrm{E}-01 \\ \text { Coeff. of Variability } & 2.83 \mathrm{E}-07 \\ \text { Range Minimum } & 3.58 \mathrm{E}-05 \\ \text { Range Maximum } & 3.55 \mathrm{E}-05 \\ \text { Range Width } & 5.35 \mathrm{E}-08 \\ \text { Mean Std. Error } & \end{array}$

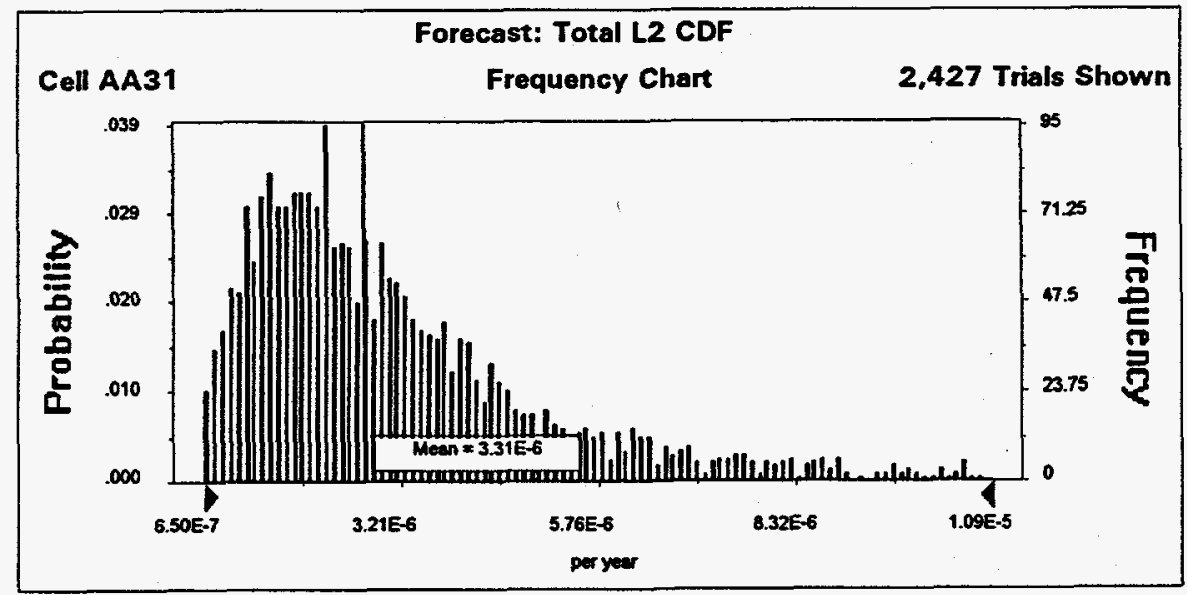


Forecast: Total L2 CDF (cont'd)

Percentiles:

\begin{tabular}{r} 
Percentile \\
\hline $0 \%$ \\
$5 \%$ \\
$25 \%$ \\
$50 \%$ \\
$75 \%$ \\
$95 \%$ \\
$100 \%$
\end{tabular}

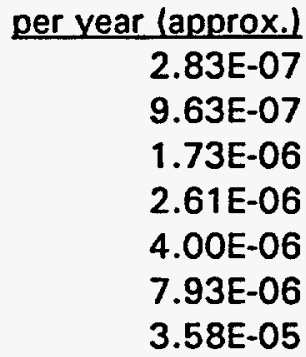

End of Forecast 
Summary:

Display Range is from $1.75 \mathrm{E}-8$ to $1.46 \mathrm{E}-6$ per year

Entire Range is from $1.75 \mathrm{E}-8$ to $1.21 \mathrm{E}-5$ per year

After 2,500 Trials, the Std. Error of the Mean is 8.30E-9

Statistics:

Trials

Value

Mean

2500

Median (approx.)

3.48E-07

Mode (approx.)

2.43E-07

Standard Deviation

1.99E-07

Variance

4.15E-07

Skewness

1.72E-13

Kurtosis

$1.11 E+01$

Coeff. of Variability

$2.70 E+02$

Range Minimum

$1.19 E+00$

Range Maximum

1.75E-08

Range Width

1.21E-05

Mean Std. Error

1.21E-05

8.30E-09

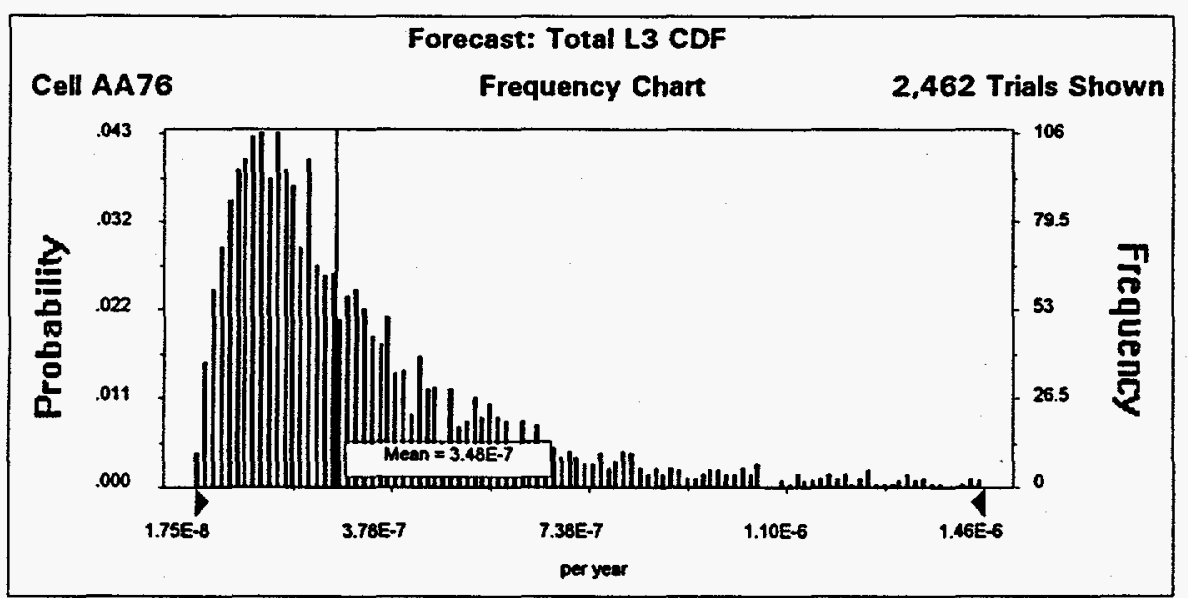


Forecast: Total L3 CDF (cont'd)

Percentiles:

\begin{tabular}{r} 
Percentile \\
\hline $0 \%$ \\
$5 \%$ \\
$25 \%$ \\
$50 \%$ \\
$75 \%$ \\
$95 \%$ \\
$100 \%$
\end{tabular}

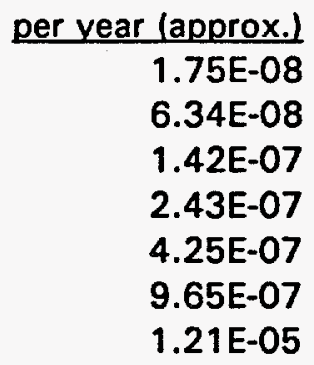

End of Forecast 
Summary:

Display Range is from 1.55E-4 to $3.66 \mathrm{E}-3$ per year

Entire Range is from $6.10 \mathrm{E}-5$ to $1.26 \mathrm{E}-2$ per year

After 2,500 Trials, the Std. Error of the Mean is $1.88 \mathrm{E}-5$

Statistics

Trials

Value

Trials

2500

Median (approx.)

Mode (approx.)

Standard Deviation

9.78E-04

7.14E-04

5.00E-04

Variance

9.40E-04

Skewness

8.83E-07

Kurtosis

$4.08 \mathrm{E}+00$

Coeff. of Variability

$3.32 E+01$

Range Minimum

9.61E-01

Range Maximum

6.10E-05

Range Width

1.26E-02

1.26E-02

Mean Std. Error

$1.88 E-05$

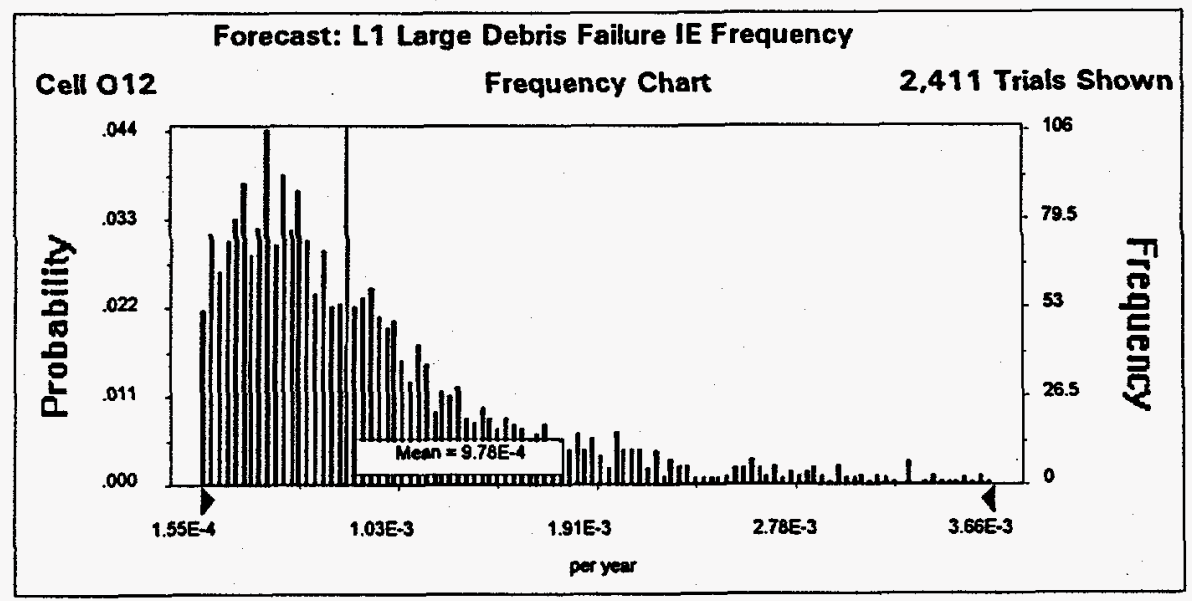


Forecast: LI Large Debris Failure IE Frequency (cont'd)

Percentiles:

\begin{tabular}{rr} 
Percentile & per vear (approx.) \\
\hline $0 \%$ & $6.10 \mathrm{E}-05$ \\
$5 \%$ & $2.04 \mathrm{E}-04$ \\
$25 \%$ & $4.36 \mathrm{E}-04$ \\
$50 \%$ & $7.14 \mathrm{E}-04$ \\
$75 \%$ & $1.19 \mathrm{E}-03$ \\
$95 \%$ & $2.61 \mathrm{E}-03$ \\
$100 \%$ & $1.26 \mathrm{E}-02$
\end{tabular}

End of Forecast 
Forecast: L2 Large Debris Failure IE Frequency

Cell: 029

Summary:

Display Range is from 9.97E-7 to $1.67 \mathrm{E}-5$ per year

Entire Range is from $4.34 \mathrm{E}-7$ to $5.49 \mathrm{E}-5$ per year

After 2,500 Trials, the Std. Error of the Mean is 8.21E-8

Statistics:

Value

Trials

2500

Mean

5.07E-06

Median (approx.)

4.01E-06

Mode (approx.)

2.88E-06

Standard Deviation

4.11E-06

Variance

1.69E-11

Skewness

$3.87 E+00$

Kurtosis

3.10E + 01

Coeff, of Variability

8.09E-01

Range Minimum

4.34E-07

Range Maximum

5.49E-05

Range Width

5.45E-05

Mean Std. Error

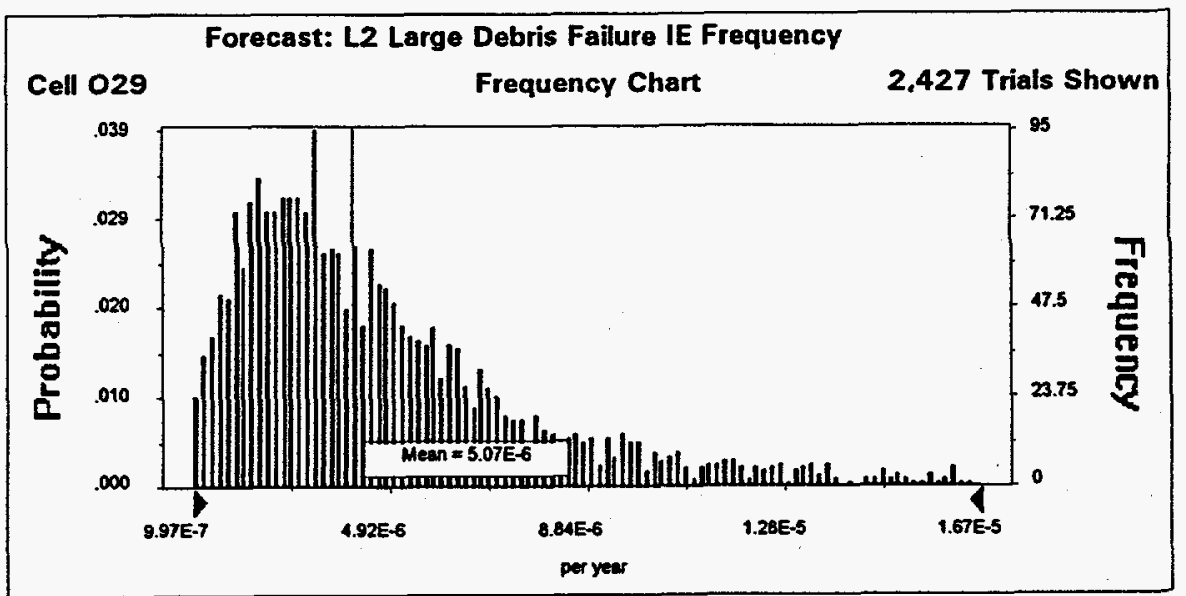


Forecast: L2 Large Debris Failure IE Frequency (cont'd)

Percentiles:

\begin{tabular}{r} 
Percentile \\
\hline $0 \%$ \\
$5 \%$ \\
$25 \%$ \\
$50 \%$ \\
$75 \%$ \\
$95 \%$ \\
$100 \%$
\end{tabular}

\begin{tabular}{r} 
per year (approx.) \\
\hline $4.34 \mathrm{E}-07$ \\
$1.48 \mathrm{E}-06$ \\
$2.66 \mathrm{E}-06$ \\
$4.01 \mathrm{E}-06$ \\
$6.13 \mathrm{E}-06$ \\
$1.22 \mathrm{E}-05$ \\
$5.49 \mathrm{E}-05$
\end{tabular}

End of Forecast 
Summary:

Display Range is from 2.61E-5 to $4.36 \mathrm{E}-4$ per year

Entire Range is from $1.13 E-5$ to $1.43 E-3$ per year

After 2,500 Trials, the Std. Error of the Mean is 2.14E-6

$\begin{array}{lr}\text { Statistics: } & \text { Value } \\ \text { Trials } & 2500 \\ \text { Mean } & 1.34 \mathrm{E}-04 \\ \text { Median (approx.) } & 1.06 \mathrm{E}-04 \\ \text { Mode (approx.) } & 8.92 \mathrm{E}-05 \\ \text { Standard Deviation } & 1.07 \mathrm{E}-04 \\ \text { Variance } & 1.15 \mathrm{E}-08 \\ \text { Skewness } & 3.82 \mathrm{E}+00 \\ \text { Kurtosis } & 3.04 \mathrm{E}+01 \\ \text { Coeff. of Variability } & 8.01 \mathrm{E}-01 \\ \text { Range Minimum } & 1.13 \mathrm{E}-05 \\ \text { Range Maximum } & 1.43 \mathrm{E}-03 \\ \text { Range Width } & 1.42 \mathrm{E}-03 \\ \text { Mean Std. Error } & 2.14 \mathrm{E}-06\end{array}$

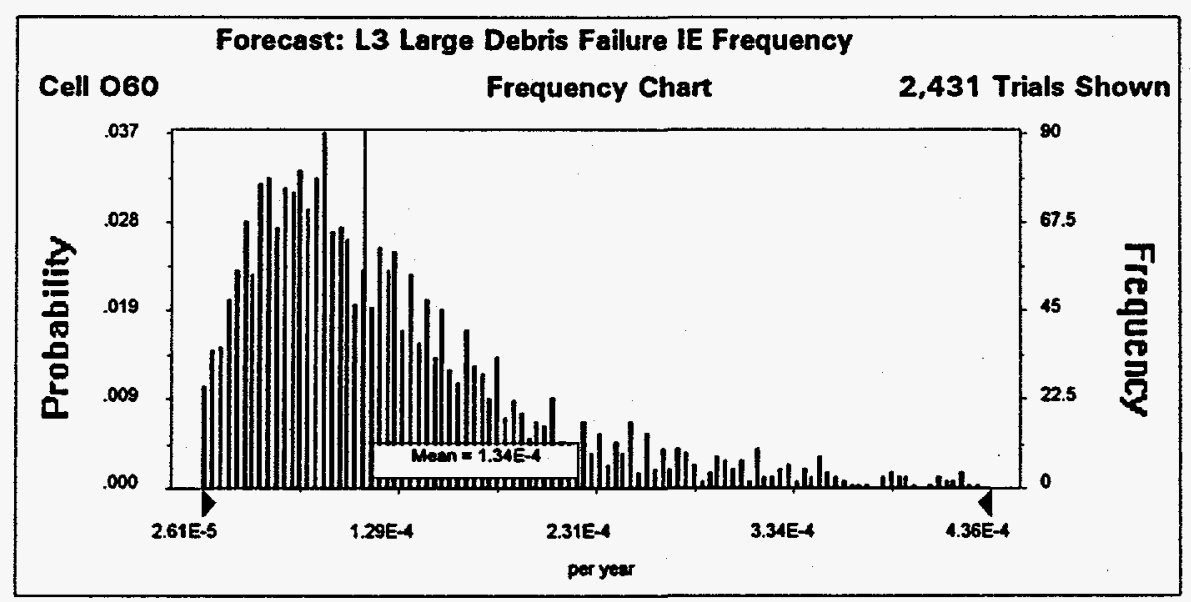


Forecast: L3 Large Debris Failure IE Frequency (cont'd)

Cell: 060

Percentiles:

\begin{tabular}{r} 
Percentile \\
\hline $0 \%$ \\
$5 \%$ \\
$25 \%$ \\
$50 \%$ \\
$75 \%$ \\
$95 \%$ \\
$100 \%$
\end{tabular}

\begin{tabular}{r} 
per year (approx.) \\
\hline $1.13 \mathrm{E}-05$ \\
$3.94 \mathrm{E}-05$ \\
$7.05 \mathrm{E}-05$ \\
$1.06 \mathrm{E}-04$ \\
$1.63 \mathrm{E}-04$ \\
$3.18 \mathrm{E}-04$ \\
$1.43 \mathrm{E}-03$
\end{tabular}

End of Forecast 


\section{Assumptions}

Assumption: Once in a million years

Lognormal distribution with parameters:

$\begin{array}{ll}\text { Mean } & 1.00 E-06 \\ \text { Standard Dev. } & 1.00 E-06\end{array}$

Selected range is from $0.00 E+0$ to + Infinity

Mean value in simulation was $9.93 \mathrm{E}-7$

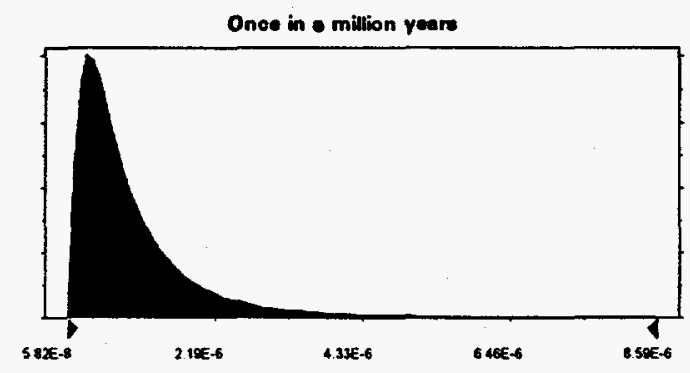

Assumption: one in 100,000

Cell: E5

Lognormal distribution with parameters:

Mean

Standard Dev.

Selected range is from $0.00 E+0$ to + Infinity

Mean value in simulation was 9.97E-6

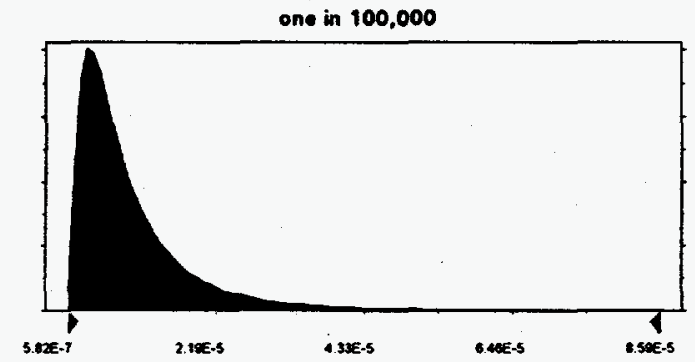


Assumption: one in 10.000

Lognormal distribution with parameters:
Mean
1.00E-04
Standard Dev.
1.00E-04

Selected range is from $0.00 E+0$ to + Infinity

Mean value in simulation was $1.02 \mathrm{E}-4$

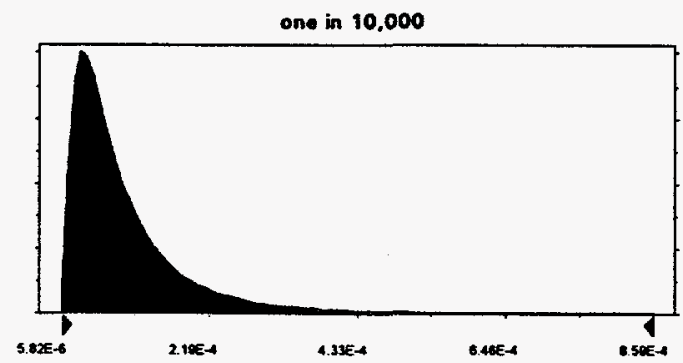

Assumption: Once every 1,000 years

Lognormal distribution with parameters:

Mean

$1.00 \mathrm{E}-03$

Standard Dev.

$1.00 \mathrm{E}-03$

Selected range is from $0.00 E+0$ to + Infinity

Mean value in simulation was $1.00 \mathrm{E}-3$

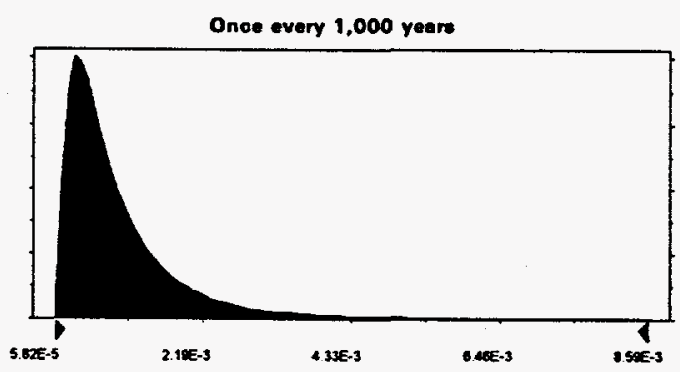


Assumption: Strainer Unavailable

Lognormal distribution with parameters:

Mean

Standard Dev.
2.1E-03

2.1E-04

Selected range is from $0.0 E+0$ to + Infinity

Mean value in simulation was $2.1 \mathrm{E}-3$

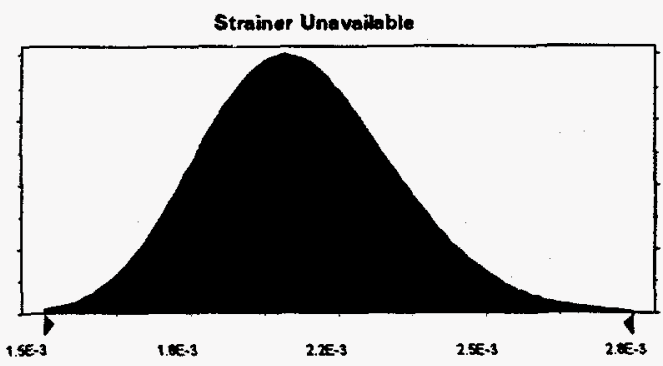

Assumption: Debris is Recognized and Removed

Lognormal distribution with parameters:

Mean

Standard Dev.

Selected range is from 0.00 to + Infinity Mean value in simulation was 0.10

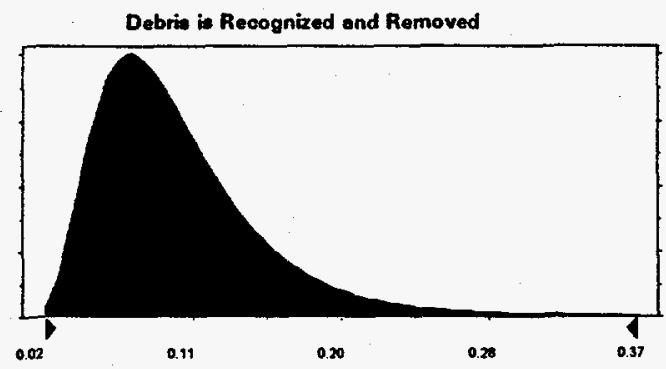


Assumption: Final Inspection - L3/1

Lognormal distribution with parameters:
Mean
0.50
Standard Dev.
0.09

Selected range is from 0.00 to + Infinity Mean value in simulation was 0.50

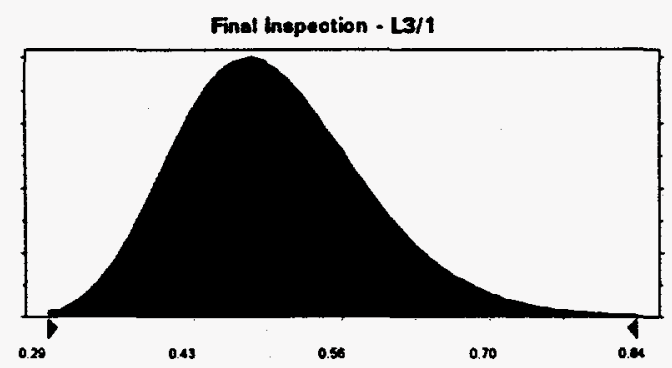

Assumption: Failure to Remove at Final Inspection

Lognormal distribution with parameters:
Mean
0.50
Standard Dev.
0.09

Selected range is from 0.00 to + Infinity

Mean value in simulation was 0.50

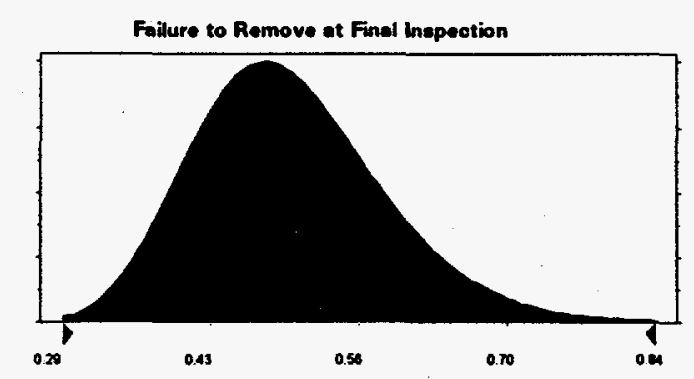

End of Assumptions 


\section{Internal Distribution}

1. B. R. Appleton

2. R. E. Battle

3. R. S. Booth

4-8. J. H. Campbell

9. K. K. Chipley

10. J. E. Cleaves

11. G. F. Flanagan

12. R. M. Harrington

13-16. R. L. Johnson

17. K. K. Jones

18. M. A. Linn

19. J. A. March-Leuba

20. G. R. McNutt

21. D. L. Moses
22. M. D. Muhlheim

23. F. J. Peretz

24. C. C. Queen

25. C. T. Ramsey

26. D. L. Selby

27. R. P. Taleyarkhan

28. C. D. West

29. G. L. Yoder

30. ORNL Patent Office

31. Central Research Library

Document Reference Section

32. Y-12 Technical Library

33-34. Laboratory Records Dept.

35. Laboratory Records, RC

\section{External Distribution}

36. K. K. Conway, Laboratory Facilities Branch, U.S. Department of Energy, Oak Ridge Operations Office, CE-523, P.O. Box 2001, Oak Ridge, TN 37831-2001

37. R. R. Fullwood, Brookhaven National Laboratory, Upton, NY 11973

38. J. C. Lin, PLG, Inc., 4590 MacArthur Blvd., Suite 400, Newport Beach, CA 92660-2027

39. U.S. Department of Energy, ANS Project Office, Oak Ridge Operations, FEDC, MS-8218, P.O. Box 2009, Oak Ridge, TN 37831-8218

40. Office of Scientific and Technical Information, P.O. Box 62, Oak Ridge, TN 37831 
- 

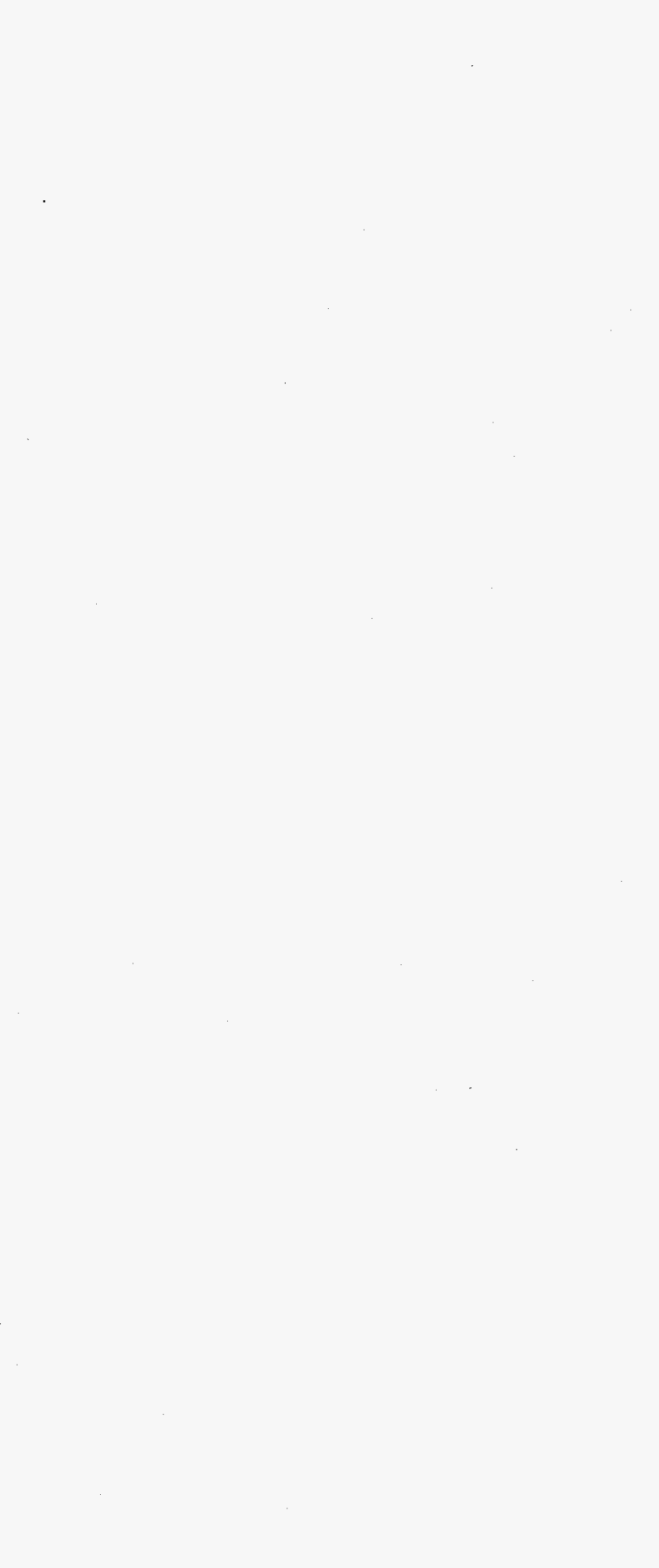
